San Jose State University

SJSU ScholarWorks

Master's Theses

Master's Theses and Graduate Research

Summer 2014

\title{
The Effects of Post-Operative Analgesics on Ovarian Surface Angiogenesis After Transplantation of Young Ovaries Into Aged Mice
}

Christine Petrovec

San Jose State University

Follow this and additional works at: https://scholarworks.sjsu.edu/etd_theses

\section{Recommended Citation}

Petrovec, Christine, "The Effects of Post-Operative Analgesics on Ovarian Surface Angiogenesis After Transplantation of Young Ovaries Into Aged Mice" (2014). Master's Theses. 4476.

DOI: https://doi.org/10.31979/etd.tqz4-v4wg

https://scholarworks.sjsu.edu/etd_theses/4476

This Thesis is brought to you for free and open access by the Master's Theses and Graduate Research at SJSU ScholarWorks. It has been accepted for inclusion in Master's Theses by an authorized administrator of SJSU ScholarWorks. For more information, please contact scholarworks@sjsu.edu. 


\title{
THE EFFECTS OF POST-OPERATIVE ANALGESICS ON OVARIAN SURFACE ANGIOGENESIS AFTER TRANSPLANTATION OF YOUNG OVARIES INTO AGED MICE
}

\author{
A Thesis \\ Presented to \\ The Faculty of the Department of Biological Sciences \\ San José State University \\ In Partial Fulfillment \\ of the Requirements for the Degree \\ Master of Science
}

by

Christine A. Petrovec

August 2014 
(C)2014

Christine A. Petrovec

ALL RIGHTS RESERVED 
The Designated Thesis Committee Approves the Thesis Titled

\section{THE EFFECTS OF POST-OPERATIVE ANALGESICS ON OVARIAN SURFACE ANGIOGENESIS AFTER TRANSPLANTATION OF YOUNG OVARIES INTO AGED MICE \\ by}

Christine A. Petrovec

APPROVED FOR THE DEPARTMENT OF BIOLOGICAL SCIENCES

SAN JOSÉ STATE UNIVERSITY

August 2014
Dr. Shelley Cargill
Department of Biological Sciences
Dr. Michael Sneary
Department of Biological Sciences
Dr. Daniel Holley
Department of Biological Sciences 


\section{ABSTRACT \\ THE EFFECTS OF POST-OPERATIVE ANALGESICS ON OVARIAN SURFACE ANGIOGENESIS AFTER TRANSPLANTATION OF YOUNG OVARIES INTO AGED MICE}

by Christine A. Petrovec

The formation of new blood vessels from pre-existing vasculature, termed angiogenesis, is essential for tissue viability and continuous organ function after murine ovary allotransplantation. Interference with the process of angiogenesis can result in cellular injury and tissue necrosis in the transplanted ovarian tissue. Although recommended, the use of analgesics for post-operative pain management has been shown to alter angiogenesis and could negatively affect transplanted ovarian tissue viability. The present study evaluated the effects of two analgesics, the opiate buprenorphine and the non-steroidal anti-inflammatory drug meloxicam, on superficial ovarian vessel formation after the transplantation of young ovaries into aged mice. One-Way ANOVA evaluation indicated a significant increase in total surface vessel number $(p=0.001)$ and total number of vessel branches $(p=0.027)$ in meloxicam-treated mice when compared to the saline control or buprenorphine-treated mice. Additionally, the meloxicam-treated mice showed a significantly greater concentration of vessels at an ovary surface depth of approximately $90 \mu \mathrm{m}(p<0.001)$ when compared to both saline control and buprenorphine-treated mice. These results suggest that meloxicam is a post-operative analgesic that could be used after ovary allotransplantation to limit disruptions in angiogenesis and to maximize vessel formation to establish successful ovary function. 


\section{ACKNOWLEDGEMENTS}

I would like to extend my deepest gratitude and sincerest thanks to my graduate advisor, Dr. Shelley Cargill. Her encouraging and patient demeanor successfully guided my graduate experience through the trials and tribulations that I now warmly refer to as research. Her advice and experience provided excellent tools with which I will use to continue my education in physiology. I would also like to thank Dr. Daniel Holley and Dr. Michael Sneary for their support and enthusiastic participation on my thesis committee. Both Dr. Sneary and Dr. Holley have continued to be positive influences in my college career from my first physiology class through my graduate education. All their efforts and instruction have been greatly appreciated. I would also like to thank Dr. Luis Bonachea for all of his help deciphering data and making sanity out of numerical chaos. His sage advice and constructive comments were exactly what I needed to move my analysis in the right direction.

In addition, I would like to thank all the members of the Cargill Lab for their assistance and support. Their help and teamwork was truly invaluable. A special, great big thank you to my husband Rob Petrovec for his endless encouragement and his programming expertise that made both our lives easier. He is awesome. Lastly, I wanted to thank my father, Charles Koehler, who never forgot to remind me that hard work has great rewards. I miss you. 


\section{TABLE OF CONTENTS}

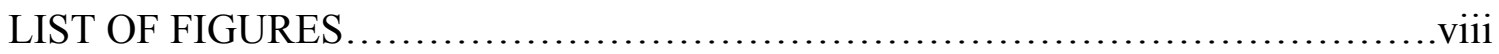

LIST OF TABLES....................................................... ix

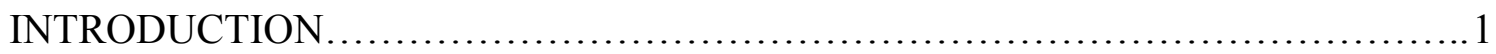

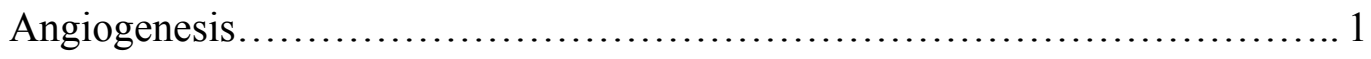

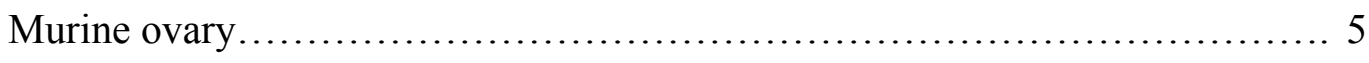

Vasculogenesis.................................................. 7

Post-operative analgesia.......................................... 9

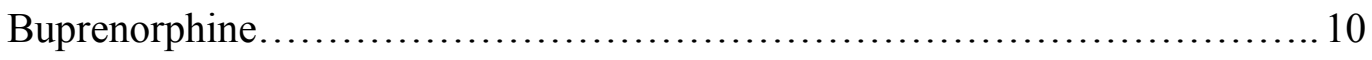

Meloxicam...................................................... 18

Vessel identification and quantitation................................ 25

MATERIALS AND METHODS ............................................. 28

Animals............................................................ 28

Ovarian transplantation and treatment administration.................... 28

Fixation and preservation of ovaries.................................. 30

CD31 Immunohistochemistry procedure ............................... 30

Ovarian tissue embedding and slide processing .......................... 32

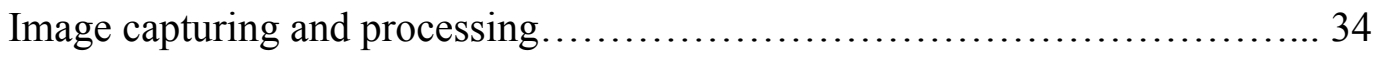

Statistical analysis.............................................. 36

RESULTS............................................................ 39

Superficial vessel analysis...................................... 39 
Individual section analysis....................................... 45

Vessel branch and junction analysis................................... 54

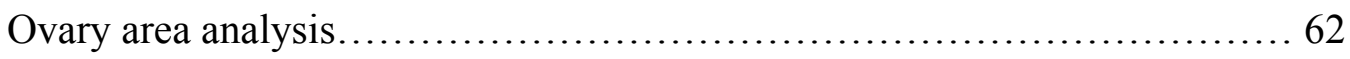

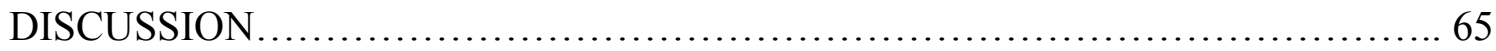

REFERENCES CITED..................................................... 78 


\section{LIST OF FIGURES}

Figure 1. Computer analyzed saline treatment group tissue section vessel structures... 35

Figure 2. Mean total number of vessels per ovary.............................. 40

Figure 3. Mean total number of vessel branches per ovary......................42

Figure 4. Mean total number of main vessel and vessel branch junctions per ovary ...43

Figure 5. Mean percent vessel density per ovary........................... 44

Figure 6. Third section mean total number of vessels......................... 46

Figure 7. Fifth section mean total number of vessels.........................47

Figure 8. Seventh section mean total number of vessels........................ 48

Figure 9. Fifth section mean total number of vessel branches....................50

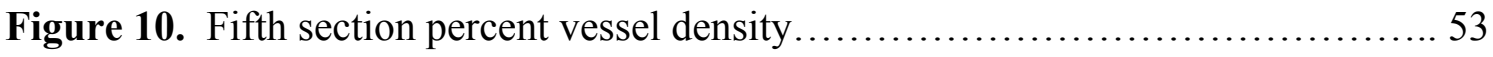

Figure 11. Mean average number of branches per vessel per ovary............... 55

Figure 12. Mean average number of main vessel and vessel branch junctions

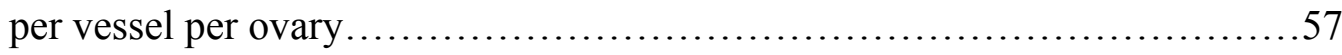

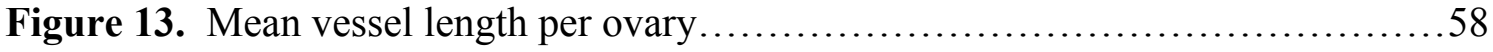

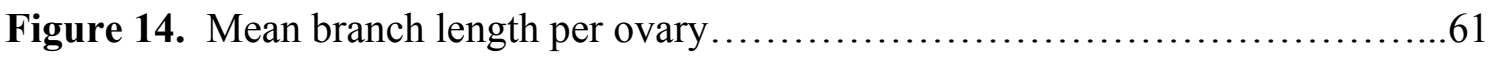

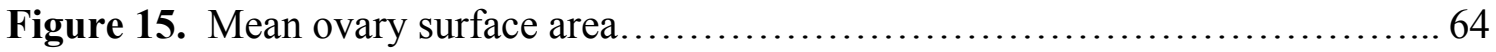




\section{LIST OF TABLES}

Table 1. Mean total number of vessels, total number of vessel branches, total number of main vessel and branch junctions and percent vessel density per ovary...... 40

Table 2. Mean total number of vessels per third, fifth and seventh sections...........45

Table 3. Mean total number of branches per third, fifth and seventh sections..........49

Table 4. Mean total number of main vessel and branch junctions per third, fifth and seventh sections ...................................................... 52

Table 5. Percent vessel density per third, fifth and seventh sections................ 54

Table 6. Mean average number of branches and average number of main vessel and branch junctions per vessel........................................55

Table 7. Mean average vessel lengths.................................... 58

Table 8. Mean average branch lengths..................................... 60

Table 9. Mean surface areas..............................................63 


\section{Introduction}

In order to immediately preserve tissue viability in modern organ transplantation the anastomosis of larger vessels is required for successful vascular perfusion leading to consistent gas and nutrient distribution and swift metabolic waste removal (Brodie, 1903; Starzi, 1960; von Frey, 1885). Although highly effective suture techniques used to connect major vessels were originally perfected by 1912 Nobel Prize winner Alexis Carrel (Carrel, 1905; Carrel, 1907), using similar methods to exogenously conjoin smaller vessels of the microvasculature intra-operatively proved to be an impracticable and unsuccessful way of creating microvascular patency (Acland, 1977; Baxter, 1972; Brooks, 1959). Therefore, regrowth and remodeling of the microvasculature in areas of cellular hypoxia is primarily the work of endogenous cell signaling that results in the emergence of new vasculature from pre-existing vessels, a biological phenomenon termed angiogenesis (Ladoux, 1993; Shweiki, 1992; Stone, 1995).

\section{Angiogenesis}

First described by British surgeon John Hunter in 1787 to characterize new vessel growth from the pre-existing microcirculation after ligation of the carotid artery perfusing a reindeer antler (Kobler, 1960), angiogenesis did not become common terminology until revisited by Arthur Hertig when he described vessel formation in the placenta of pregnant monkeys (Hertig, 1918). As a well known, essential biological event in both normal physiological and divergent pathological processes, the mechanisms of angiogenesis 
continue to be investigated to understand the pathways and components involved in the formation of new vessels and vascular regeneration.

The process of angiogenesis usually takes place in the microvasculature, predominantly in capillaries, but it can also be observed in small venules (Schoefl, 1963). The basic structure of nascent capillary parent vessels consist of a single layer of endothelial cells surrounded by a thin extracellular matrix (ECM) with structurally supportive pericytes wrapped around individual endothelial cells and embedded in the ECM to propagate external signals through cell-cell gap junctions (Bar, 1972; Cuevas, 1984; Florey, 1926; Orlidge, 1987). In addition, the ECM is comprised of proteoglycans, Type I collagen, and elastin that provide additional support for the delicate microvasculature (Form, 1986; Kubota, 1988; Lohler, 1984; Sauter, 1998).

When angiogenic stimulators such as vascular endothelial growth factor (VEGF) and basic fibroblast growth factor (bFGF) are released via proteolysis of the ECM, both VEGF and bFGF bind specific endothelial cell transmembrane receptors activating mitogenesis (Connolly, 1989; Ferrara, 1989; Fisher, 1994; Folkman, 1988; Healy, 1992; Hiraoka, 1998; Jakeman, 1992; Montesano, 1986; Unemori, 1992). These endothelial transmembrane tyrosine kinase receptors, such as VEGF binding VEGFR-2/flk-1 and VEGFR-1/flt-1, and bFGF binding FGFR1/2, become phosphorylated and activate phospholipase-C. Activated phospholipase-C subsequently stimulates the mitogenactivated protein (MAP) kinase extracellular signal-regulated kinases (ERK) 1/2 signal transduction pathway by phosphorylation of its G-protein coupled receptor alpha subunit (Lee, 1989; Takahashi, 1997; Yamane, 1994). After phosphorylation, the alpha subunit 
signals the activation of Ras, which eventually activates MAP kinase transcription factors Myc and cAMP response-element binding protein (CREB) to translocate into the endothelial cell nucleus leading to increased mitogenesis, vascular fenestration, and increased permeability (Berra, 2000; Connolly, 1989; Pearson, 2001; Senger, 1983; Unemori, 1992). These vascular changes are necessary to release extracellular matrix proteolytic enzymes, such as matrix metalloproteinases, which remodel existing ECM structures, and facilitate the secretion of newly assembled ECM components after cellular proliferation forms the beginning of a new microvessel(Fernandez, 1999; Pepper, 1998).

As parent endothelial cells are rapidly multiplying, angiogenic growth factors angiopoietin-1 (ang-1) and angiopoietin-2 (ang-2) are released from the damaged extracellular matrix and bind to endothelial cell surface tie-1and tie-2 tyrosine kinase receptors (Maisonpierre, 1997; Puri, 1995; Sato, 1995; Suri, 1996; Thurston, 1999). Specifically, the ang-1 ligand binds to the endothelial cell tie-2 receptor leading to receptor phosphorylation. This binding prevents excessive vessel leakage due to fenestrations caused by the degradation of cell-cell interaction molecules PECAM/CD31 and VE-cadherin. Limiting vessel permeability allows the vessel to retain adequate structural integrity during the proliferative process (Puri, 1995; Thurston, 1999). Ang-2 activates the endothelial tie-2 receptor to induce the release of pericytes from the basement membrane (Sato, 1995). This disruption of pericyte attachment is expedited by the dissolution of the extracellular matrix by endothelial cell secreted proteolytic enzymes on the side of the vessel closest to the angiogenic stimulus (Ausprunk, 1977; Korff, 2001; Maisonpierre, 1997; Papapetropoulos, 1999). At this juncture, ang-2 
stimulation of the endothelial tie-2 receptor acts concomitantly with VEGF to facilitate endothelial cell sprouting from the area of degraded ECM (Asahara, 1998; Sawamiphak, 2010; Witzenbichler, 1998).

The degraded area of ECM is invaded by proliferating endothelial cells forming a sprout, with a small number of apical cells leading the bulk of new cells in a linear progression. Those cells that follow behind or to the sides of the apical cells are referred to as stalk cells, which divide and elongate as the stalk moves forward (Witzenbichler, 1998). Simultaneously, the sprout interacts with the remodeled ECM as new basement membrane components such as fibronectin, collagen, and laminin are secreted through the parent vessel fenestrations and deposited while maintaining contact with the proliferating endothelial cells (Saunders, 2006; Stratman, 2009).

As the sprout matures, endothelial cellular polarity is maintained due to ang-1/tie1 receptor signaling (Asahara, 1998). The new lumen is constructed when endothelial cells form VE-cadherin/VEGF mediated intercellular adhesions and secreted protease inhibitors such as tissue inhibitors of metalloproteinases (TIMPs) stop the degradation of the ECM, allowing new ECM components to assemble (Form, 1986; Saunders, 2006). As soon as sufficient basement membrane is deposited and endothelial junctions are established, pericytes synthesized after VEGF-stimulation are recruited to position themselves around the new capillary endothelial cells, signifying the maturation of the vessel wall(Stratman, 2009; Yamagishi, 1999). Upon the loop formation from the coalescence of two sprouts or with another vessel branch, blood flow is initiated into the newly formed microvessel. Once the new vessel is patent, the incorporated endothelial 
cells will become dormant for months to years. These quiescent endothelial cells and the surrounding pericytes in the vascular network suppress proliferation unless signaled again by stimulatory mitogens such as VEGF and bFGF (Montesano, 1986; Unemori, 1992).

\section{Murine Ovary}

Re-establishing an adequate angiogenic pathway after surgeries such as murine ovarian allotransplantation allows for the continued maturation and development of primordial follicles into mature follicles and the maintenance of estrus cyclicity (Gosden, 1994). Studies investigating neovascularization after human ovarian xenografts demonstrated a rapid rate of angiogenesis in transplanted ovarian tissue resulting in complete vascular perfusion at the graft-host interface within 48 hours (Nisolle, 2000; Van Eyck, 2010). This is most likely due to the ongoing presence of VEGF and bFGF angiogenic factors responsible for vessel formation during folliculogenesis and development of the corpus luteum during the luteal phase (Boron \& Boulpaep, 2008; Dissen, 1994; Ferrara, 1998; Li 1994). In mice, the ovaries are enclosed in an ovarian bursa which includes an inner mesothelium lining composed of blood vessels and nerves (Treuting \& Dintzis, 2011). The ovarian artery, ovarian vein, and major nerves join the ovary at the narrow opening called the hilum and enter and leave through a small hole in the bursa lining. The ovarian bursa is continuous with the murine oviducts which connect to the uterine horns of a bicornuate uterus (Treuting \& Dintzis, 2011).

In the ovary, the process of folliculogenesis describes the maturation of primordial follicles to preovulatory follicles in response to gonadotropin releasing 
hormone $(\mathrm{GnRH})$ released from the hypothalamus as well as follicle-stimulating hormone (FSH) and lutenizing hormone (LH) released from the anterior pituitary gland (Boron \& Boulpaep, 2008). Proliferation of follicular granulosa cells and the surrounding theca cell layers continue in response to LH and FSH as the follicle develops. As follicles advance from the primary follicle stage through the tertiary stage, increasing nutritional demands stimulate endogenous secretion of VEGF and bFGF from the bursa, ovarian endothelial cells, and granulosa cells to increase vascularization surrounding the developing follicle (Bassett, 1943; Doyle, 2009; Mattioli, 2001; Nilsson, 2001; Zheng, 1994). It has been hypothesized that the introduction of a murine ovary homograft will be met with rapid angiogenesis due to an already large production of VEGF and bFGF from bursa endothelial, thecal, and granulosa cell origins in addition to the increased production stimulated from cellular hypoxia (Kamat, 1995; Koos, 1991; Van Eyck, 2010; Zheng, 1994). Studies have also indicated that tie-1 and tie-2 receptors are present on ovary endothelial cells and bind vascular growth factors ang- 1 and ang- 2 released from bursa mesodermal cells in response to increased VEGF signaling promoting post-operative angiogenesis (Teilmann, 2005). It has also been hypothesized that during the avascular period of local ischemia in the host bursa after ovary transplantation the increased VEGF signaling stimulates both local angiogenesis and the release of bone marrow derived endothelial progenitor cells necessary for postnatal vasculogenesis (Asahara, 1999; Roberts, 2007). 


\section{Vasculogenesis}

Vasculogenesis refers to the formation of nascent vascular structures de novo and is traditionally used to describe new vessel formation in the developing embryo. After the early mesodermal layer is formed via gastrulation (Tam, 1997), mitogens from the fibroblast growth factor (FGF) family stimulate mesodermal stem cells to differentiate into an early hematopoietic precursor, the hemangioblast (Amaya, 1991; Choi, 1998; Coumoul, 2003; Flamme, 1992; Gospodarowicz, 1974; Wilt, 1965). These VEGFR2/flk-1 positive hemangioblasts migrate toward high concentrations of mitogen VEGF, often traveling long distances to specific tissue locations to begin forming a primordial vascular plexus (Drake, 1995; Schuch, 2003; Shalaby, 1995; Shalaby, 1997). After stimulation by VEGF, the hemangioblast proliferates and differentiates into endothelial progenitor cells, or angioblasts, and hematopoietic stem cells (Breier, 1995; Ferrara, 1996; Leung, 1989; Millauer, 1993). Once these cells have reached their extraembryonic destination, the hematopoietic stem cells and angioblasts aggregate to form 'blood islands', with the hematopoietic stem cells in the lumen, surrounded by a fused layer of angioblasts at the periphery (Drake, 2000; Risau, 1988). To form nascent vessel lumina, neighboring blood islands coalesce and the angioblasts merge, differentiating into embryonic endothelial cells with downregulated VEGFR2/flk-1 receptors and upregulated growth factor receptors. These growth factor receptors include CD34 and CD31 prolific angiogenic factors and VE-cadherin, E-selectin extracellular matrix and cell-cell adhesion factors (Doetschman, 1985; Hirakow, 1981). Eventually, the newly established endothelial cells will generate stable cell-cell interactions using CD31 and 
VE-cadherin, and recruit pericytes to stabilize the vessel and stimulate the generation of extracellular matrix components (Bar, 1972).

In vasculogenesis of the ovary, the primitive gonad is formed from the migration of primordial germ cells to the mesothelial layer of the mesoderm and the endothelial cells that line this layer connect these germ cells to the vascular plexus of the primitive microcirculation (Bullejos 2002; Coveney, 2008). More complex ovary vascular structures develop by continued endothelial cell proliferation and branching of these early endothelial vessel formations extending from the larger vascular plexus of the mesonephros (Bullejos 2002; Coveney, 2008). After the female gonad becomes fully vascularized via further vessel reorganization and migration, PECAM-1/CD31 cell-cell adhesions and characteristic angiogenic microvessel branching indicate the end of vasculogenesis (Coveney, 2008; DeLisser, 1997; Horace, 1997).

Recent studies have detected quiescent undifferentiated endothelial progenitor cells similar to early embryonic progenitor cells in the bone marrow and peripheral blood of adult humans (Asahara, 1997; Asahara, 1999; Jin, 2006; Vaughan, 2012). Referred to as angioblasts in the developing embryo, these newly-identified adult circulating endothelial progenitor cells (EPCs) can be summoned and up-regulated in adults by ischemia, cytokines, and growth factors such as VEGF. Once in circulation, EPCs contribute to the production of new vessels in areas of decreasing oxygen tension, elevated blood viscosity or excessive luminal pressure. Research has shown that many of these quiescent EPCs reside in the bone marrow without need for proliferation, and modest amounts are available in circulation to assist in the formation of new capillary 
networks (Asahara, 1999). The bone marrow derived endothelial progenitor cells (BMEPCs) that can be mobilized by mitotic VEGF activation are directed in a chemotaxic manner towards large secretions of VEGF (Jin, 2006). In the mature murine ovary, VEGF is necessary for the formation of the corpus luteum (Ferrara, 1998) and subsequent studies have identified BM-EPCs in the vascularization process during luteal formation and neovascularization in the endometrium (Asahara, 1999). After localization to reproductive tissues, it is hypothesized that BM-EPCs can replicate embryonic pathways of vessel creation to assist with the formation of new capillary beds in areas of vascular injury, such as murine ovary allotransplantation into a host bursa, increasing regional perfusion, and restoring tissue function (Asahara, 1999).

\section{Post-operative analgesia}

Any alteration to angiogenesis, vasculogenesis or the release of BM-EPCs could alter the host's ability to maintain transplanted tissue viability by prolonging wound healing or sufficient organ perfusion. Although many post-operative precautions are taken to ensure the host's comfort, post-operative analgesia has been shown to cause significant reduction in immunosuppressive stress hormone secretion from hypothalamicpituitary axis activation thus resulting in adequate secretion of proinflammatory cytokines required for wound repair (Beilin, 2003; Glaser, 1999; Hubner, 1996; Padgett, 1998; Skjelbred, 1982). It has been demonstrated in various species that providing patients with analgesia after both major and minor procedures is beneficial, and in rodents such as mice, post-operative analgesia decreases the risk of sepsis, stimulates healthy immune 
function, increases animal mobility, and decreases stress-induced delays in wound healing (Hubner, 1996; Padgett, 1998).

The current recommendation given by Institutional Animal Care and Use Committees (IACUC) as well as veterinary medical practitioners is to provide adequate post-operative pain management for laboratory animals undergoing surgical procedures (Kohn, 2007). In an effort to comply with these reasonable guidelines but still maintain reliable research results in studies evaluating surgical transplantation procedures such as the murine ovarian homograft, multiple genres of available analgesia should be evaluated for possible effects on post-operative angiogenesis and vasculogenesis. Currently, the most widely used post-operative analgesics are from either the opioid class or nonsteroidal anti-inflammatory drugs (NSAIDs). Evaluating which of these two types of analgesia will have the least negative effect on angiogenic factors or vasculogenesis endothelial progenitor signaling could be determined by looking at the mechanism of action and reviewing previous literature for evidence of enhanced or inhibited postoperative transplant neovascularization.

\section{Buprenorphine}

The most common opioid used ubiquitously in both human and animal studies, buprenorphine hydrochloride, is a semi-synthetic $\mu$-opioid partial agonist used for the relief of moderate to severe pain (Cowan, 1977). In 1966 John Lewis, lead chemist of the pharmaceutical division of United Kingdom consumer goods company Reckitt \& Colman (currently Reckitt Benckiser) in conjunction with chemist Kenneth Bentley, formulated a 
potent novel analgesic by adding a C-7 side-chain containing a t-butyl group to opiate alkaloid thebaine (Bentley, 1967). Injectable buprenorphine became commercially available in 1978 as an alternative analgesic for severe pain. By 1985, both injectable and sublingual tablets were approved by the FDA and available in the United States. Currently, the Food and Drug administration lists buprenorphine as a schedule III narcotic (DEA, 2002).

Approved for intraperitoneal (IP), intravenous (IV), oral, and intramuscular administration, buprenorphine has a high affinity for central nervous system G-protein coupled $\mu$-opioid receptor subclasses, and it demonstrates a prolonged receptor disassociation rate, which generates low buprenorphine plasma concentrations leading to extended analgesic effects (Boas, 1985; Cowan, 1977; Huang, 2001; Sadee, 1982; Yassen, 2007). After binding to the $\mu$-opioid receptor, buprenorphine disinhibits the presynaptic release of GABA leading to analgesia, sedation, bradypnea, hypotension, and dysphoria (Gal, 1989; North, 1987; Saarialho-Kere, 1987; Vaughn, 1997). Subsequent disruption of G-protein coupled receptor (GPCR) signaling requires inactivation of the G-protein alpha subunit by stimulating GTP hydrolysis rendering the subunit inactive by regulators of Gprotein_signaling (RGSs) and/or desensitization by binding of Arrestin proteins which eliminates further signal transduction by blocking the buprenorphine binding site (Ferguson, 1996; Zhang, 1998).

After thoroughly analyzing all routes of buprenorphine administration, researchers demonstrated that the sublingual and IV routes had the longest half-life at 3-5 hours and the most rapid post-administration bioavailability. Although convenient, 
studies revealed the sublingual application required a higher dose due to an increased hepatic first-pass effect(Brewster, 1981; Bullingham, 1980; Kuhlman, 1996). With a hepatic elimination rate of approximately 40 hours, buprenorphine is deactivated via Ndealkylation by Cytochrome P450-3A4 enzymes in the liver and the resulting metabolite norbuprenorphine is then bound to a glucuronic acid and excreted in feces via bile (Iribarne, 1997; Zhang, 2003).

As one of the most common post-operative analgesics used in medicine today, buprenorphine's parent alkaloid morphine has been analyzed in numerous studies investigating the pro-angiogenic or inhibitory effects of opioids on wound healing and transplant neovascularization. By using morphine instead of buprenorphine specifically, research studies can evaluate the effects of all opioid plant alkaloid derivatives which include thebaine, codeine, and buprenorphine. In early studies by Pasi et al (1991) the chorioallantoic membrane (CAM) of the chicken embryo was used to evaluate the effects of morphine on angiogenesis. By displaying the CAM through shell fenestrations after the third incubation day, Pasi et al inoculated the eggs with control (saline) or morphine in varying doses and counted daily vessel growth. Since Zagon and Mclaughlin (1981) had suggested in earlier research that opioid therapy resulted in the inhibition of murine tumor growth, Pasi et al hypothesized that the inhibitory mechanisms of these opioids on the developing membrane may be due to decreased endothelial cell proliferation leading to slower vessel formation. Pasi et al found morphine treated CAM had decreased neovascularization in a dose dependent manner with the negative effects of morphine easily visible at low doses $(5 \mu \mathrm{g})$ within the first 24 hours, and high-dose morphine (10 
$\mu \mathrm{g}$ and $15 \mu \mathrm{g}$ ) maintaining significant angiostatic effects over the 96-hour observation period. These results suggested that opioids might inhibit cellular mitosis and/or DNA synthesis which would prevent cellular proliferation in tumor formation as seen by Zagon and Mclaughlin (1981).

Although the mechanisms causing these results were still unclear, Balasubramanian et al (2001) evaluated hypoxic cultures of murine heart endothelial cells (mEC), human umbilical vein endothelial cells (HUVECs), and rat cardiomyocytes to analyze how exogenous morphine might interfere with VEGF angiogenic signaling. Normally, endogenous VEGF binds to VEGFR-1/2 (flt-1/flk-1) tyrosine kinase receptors to induce gene expression and ultimately endothelial proliferation resulting in the angiogenic growth of the microvasculature in conditions such as myocardial infarctions and tissue ischemia. After the cells were cultured in hypoxic conditions and treated with either morphine or saline for 24 hours, results demonstrated that VEGF was significantly increased in cells that were treated with saline and exposed to hypoxic conditions, but morphine-treated hypoxic cells showed a dose dependent decrease in VEGF expression. Interestingly, in all cell types, when the $\mu$-receptor antagonist naloxone was applied simultaneously with morphine, the morphine-induced inhibition of VEGF expression was reversed and expression closely resembled the saline-treated hypoxic cell cultures. Their study suggested that morphine interferes with VEGF expression in both hypoxic cardiac myocytes and hypoxic HUVECs, reducing the likelihood of endothelial cell survival in ischemic tissues due to decreases in angiogenesis. 
Roy et al (2003) analyzed the effect of morphine on serum VEGF increases during myocardial infarctions due to decreased oxygen tension and upregulation of the transcription factor hypoxia inducible factor-1 alpha (HIF-1a) in hypoxic tissues. It was hypothesized that morphine administration may inhibit myocyte VEGF expression by inhibiting HIF-1a and/or ERK 1/2 MAP kinase signal transduction pathways leading to decreased endothelial cell proliferation and vessel sprouting. To test this hypothesis, in vitro rat cardiac tissue and cultures of cardiac myocytes were placed in a hypoxic chamber and infused with one dose of either $100 \mathrm{ng} / \mathrm{ml}$ morphine or saline. Results demonstrated morphine-induced inhibition of specific VEGF isotypes and HIF-1a expression and a significant decrease in the binding of HIF-1a to the VEGF activation promoter. In addition, in vivo analysis of hypoxic rat cardiac tissue showed significantly decreased VEGF expression in the tissues surrounding the induced infarct, inhibited HIF1a expression in the same region and a decreased amount of phosphorylated (active) ERK 1/2 when compared to total ERK concentrations. This analysis by Roy et al (2003) reiterates the study by Balasubramanian et al (2001) as both demonstrate morphine's ability to inhibit cardiac myocyte VEGF synthesis and interrupt specific angiogenic signal transduction pathways in hypoxic tissues. When considering buprenorphine, a commonly used morphine derivative, as a post-operative analgesic therapy, possible alterations in mitogen production and subsequent decreases in endothelial cell proliferation need to be evaluated to ensure that proper tissue perfusion is attained.

In addition to studies strictly evaluating morphine's effects on angiogenesis, Lam et al (2008) hypothesized that prolonged use of morphine not only impairs angiogenesis 
but can prevent the mobilization of endothelial progenitor cells in adult vasculogenesis resulting in decreased wound healing. Using a mouse dermal wound model, mice were subjected to excisional wounds and placed in either the intraperitoneal (IP) administered high-dose $20 \mathrm{mg} / \mathrm{kg}$-day morphine or saline treatment groups. Results after 14 days showed an increased number of circulating BM-EPCs in both treatment groups indicating that excisional wounds stimulated their release, but a significant decrease in the amount of circulating BM-EPCs in the morphine treated group was seen compared to control. As a result, delayed wound healing in vivo and quantities of negatively charged toxic superoxide anion $\left(\mathrm{O}_{2}^{-}\right)$in the wound tract were significantly increased in the morphine treated mice. This experiment yields evidence that high systemic doses of morphine negatively influence angiogenesis and endothelial progenitor cell distribution, leading to delayed wound healing and an increase in oxidative stress.

With a large amount of research demonstrating the tendency for morphine to inhibit angiogenesis, vasculogenesis and subsequent new vessel formation, a study by Gupta et al (2002) showed that morphine actually stimulates angiogenesis by activating the MAP kinase ERK1/2 pathway for gene expression; a pathway normally stimulated by VEGF binding VEGFR-1 receptors on endothelial cells. In neuronal cells, this MAP kinase ERK1/2 pathway is stimulated by morphine binding the specific $\mu_{3}$-opioid receptor, suggesting a similar increase in cellular proliferation could be induced if morphine bound a similar $\mu_{3}$-opioid receptor found on vascular endothelial cells (Stefano, 1995). Gupta et al used morphine-treated, saline-treated (control), and VEGF-treated groups of cultured human dermal microvascular endothelial cells (HDMECs), murine 
Matrigel angiogenesis assays, and murine breast tumor xenografts to analyze differences in angiogenesis. Results showed morphine increased HDMEC proliferation in culture comparable to cultured cells incubated in vascular endothelial growth factor (VEGF) alone. In this mouse Matrigel study, morphine-only treated mice had increased endothelial tube formation and neovascular growth similar to VEGF-only treated mice, but at high concentrations the morphine treated Matrigel cultures showed significant endothelial cell cytotoxicity creating aggregates of dead cells with no endothelial tube formation or neovascularization. In addition, results demonstrated morphine induced stimulation of the MAPK/ERK signaling pathway in HDMECs, prevented apoptosis by stimulating cell survival signal Akt and increased breast tumor xenograft volume by amplifying tumor neovascularization. After analyzing these results, Gupta et al concluded that morphine stimulated the MAPK/ERK 1/2 signal transduction pathway in vascular endothelial cells normally targeted by endogenous VEGF, leading to enhanced cellular proliferation and increased angiogenic activity. These findings conflict with results acquired by Roy et al (2003) and Balasubramanian et al (2001), which suggested morphine caused decreased angiogenesis by inhibition of signal transduction pathways including MAPK/ERK 1/2, leading to reduced VEGF production and endothelial cell proliferation in cultures of rat cardiac myocytes, murine heart endothelial cells (mEC), and HUVECs. Although all three studies demonstrated these changes in vascularization by Western Blot analysis for MAPK/ERK 1/2 and Akt proteins and reporter assays for CD31 or VEGF, the inhibitory effects of morphine on VEGF production and angiogenesis could only be reversed with the addition of $\mu$-receptor antagonist naloxone 
in studies by Balasubramanian et al (2001) and Roy et al (2003). In the study by Gupta et al (2002), the addition of naloxone did not inhibit MAPK/ERK 1/2 production and endothelial cell proliferation as would be expected if angiogenesis was stimulated by morphine alone suggesting that separate angiogenic signaling pathways could have been a contributing factor to the reported increases in neovascularization.

A subsequent study by Poonawala et al (2004) theorized that morphine stimulates the production of nitric oxide synthase (NOS) which creates the potent vasodilator nitric oxide (NO) and results in the repair of wounded tissue via tissue granulation, cellular proliferation and angiogenesis. Poonawala et al used a topical application of morphine on a rat open-wound healing model to evaluate possible NO-signaling via cytokine-like stimulation. Morphine and two other opioid derivatives, hydromorphone and fentanyl, were applied to ischemic excisional wounds twice daily. Wounds were grossly observed and at the end of eight days wound scars were collected and evaluated for microvessel density, collagen formation, and nitric oxide synthase (NOS) concentrations. Results indicated that fentanyl out of the three opioid creams had the highest increase in wound healing (66\%) with hydromorphone second (55\%) and morphine third (42\%) compared to control (15\%). For all treatment groups, wound healing was dose dependent with higher concentrations resulting in significant increases in granulation tissue formation and accelerated wound closure. Histologically, fentanyl treated wounds most closely resembled normal tissue and had significant increases in angiogenesis, cell proliferation and collagen content compared to controls. Immunofluorescent staining also demonstrated an upregulation of VEGF receptor Flk-1 on the surface of endothelial cells 
indicating a possible increase in cell proliferation due to augmented VEGF angiogenic signaling. In addition, all three opioids resulted in increased concentrations of NOS in the dissected scar tissue suggesting nitric oxide formation significantly contributed to the accelerated wound healing. Contrary to previous work indicating an inhibition of vessel formation by morphine, this study demonstrates that topically applied opioids can expedite wound healing by increasing endothelial cell proliferation, intracellular signaling and angiogenesis via increased VEGF receptors or nitric oxide signaling in a cytokine-like manner similar to VEGF.

With conflicting data regarding the effect of opioids on angiogenesis, vasculogenesis, and wound healing, alternative post-operative analgesics have to be considered to provide patient comfort and maintain tissue viability, especially in conditions resulting in cellular hypoxia and ischemia, such as organ transplantation. Common alternatives to buprenorphine, morphine, and other opioid derivatives are a group of medications referred to as non-steroidal anti-inflammatory drugs (NSAIDs). These include ibuprofen, naproxen and meloxicam.

\section{Meloxicam}

Meloxicam is an NSAID that exhibits potent analgesic and anti-inflammatory properties with minimal deleterious gastrointestinal and renal effects. Chosen from an arranged drug design search of different tautomerizations and structural substitutions of the original oxicam chemical structure, meloxicam was created by adding a 5-methyl-2thiazolyl at N-1 and a hydroxyl to the 1,2-benzothiazine at C-4 (Amzoiu, 2010; 
Engelhardt, 1995). The addition of the methyl in the thiazolyl group created a third generation bioisosteric oxicam compound resulting in effective analgesia with quickly eliminated metabolites (Schmid, 1995a). Studies have demonstrated efficient, safe pain amelioration with meloxicam administration (Engelhardt, 1995).

Well absorbed through oral, subcutaneous, and intravenous routes, meloxicam has an $89-99 \%$ bioavailability and binds strongly to plasma albumin, reaching a mean maximum plasma concentration within 2-5 hours (Schmid, 1995a). Transported through the vasculature to sites of agonist receptor activation or cell damage, meloxicam binds preferentially to cyclooxygenase-2 (COX-2), a catalytic enzyme that ultimately oxidizes the cleaved membrane phospholipid (20:4w6) arachidonic acid (AA) into the prostanoid precursor prostaglandin $\mathrm{H}_{2}\left(\mathrm{PGH}_{2}\right)$ (Engelhardt, 1996; Vane, 1971). The resulting $\mathrm{PGH}_{2}$ is the substrate for several prostaglandin synthases creating various isoforms of the prostanoid bioactive mediators thromboxane, prostacyclin, and prostaglandin to quickly propagate inflammatory responses in an autocrine and paracrine dependent manner (Boron \& Boulpaep, 2008). When meloxicam binds to COX-2, it inhibits the enzyme's catalytic ability preventing the conversion of $\mathrm{AA}$ into $\mathrm{PGH}_{2}$ and the formation of inflammation-mediating prostanoids (Engelhardt, 1996; Vane, 1971). With decreased inflammation signaling molecules, the pain and symptoms associated with acute and chronic inflammation are alleviated.

The preferential binding selectivity of meloxicam to COX-2 over homologous enzyme cyclooxygenase-1 (COX-1) is what differentiates meloxicam from many of its oxicam-derived NSAID precursors. Prescribed to treat osteoarthritis, rheumatoid arthritis, 
and often recommended for post-operative inflammation and analgesia, meloxicam steady-state plasma concentrations and extended pain relief can be reached within 5-6 hours and maintained with once-daily dosing (Busch, 1998a; Busch, 1989b). With an average elimination half-life of 15-20 hours, meloxicam undergoes extensive hepatic biotransformation into several inactive metabolites before being excreted (Schmid, 1995a). In the liver, the Cytochrome P450-2C9 enzyme metabolizes $60 \%$ of absorbed meloxicam by oxidation reaction into the primary metabolite 5 '-carboxy meloxicam, while both Cytochrome P450-2C9 and Cytochrome P450-3A4 transform the remaining $40 \%$ into three additional inactive metabolites (Chesne, 1998). All four

pharmacologically inert compounds are subsequently excreted in urine and feces (Schmid, 1995a; Schmid, 1995b).

In both murine and human reproductive systems, COX-2 enzymatic activity has been identified in ovarian blood vessels, follicular theca blood vessels, interstitial cells of the ovarian stroma, and the endometrium (Quintana, 2008). In humans, immunostaining of ovarian tissue samples identified intense staining of COX-2 enzymatic activity colocalized with VEGF expression on the outer surface epithelium of ovarian blood vessels, and several studies have observed increases in both COX-2 activity and VEGF in luteal phase ovary during the menstrual cycle (Ferrara, 1998; Li, 1994; Stavreus-Evers, 2005).

In a study by Xin et al (2007), one of the products of COX-2 prostanoid production, prostaglandin $\mathrm{E}_{2}\left(\mathrm{PGE}_{2}\right)$, has been shown to stimulate angiogenesis in the endometrium and ovarian follicles by stimulating VEGF production. Prostaglandin $\mathrm{E}_{2}$ $\left(\mathrm{PGE}_{2}\right)$ has also been shown to simultaneously inhibit vascular endothelial cell apoptosis 
via activation of the Bcl-2 oncogene. Using ovarian tumor inoculated nude mice, meloxicam was administered to inhibit endogenous VEGF and COX-2 activity and subsequent $\mathrm{PGE}_{2}$ production to evaluate their angiogenic effects in vivo. Results demonstrated the inhibition of both $\mathrm{PGE}_{2}$ and VEGF via inactivation of COX-2 significantly reduced tumor size, decreased microvessel density, and increased apoptosis within the ovarian cancer growth site. It was hypothesized by these researchers that the reduced formation of $\mathrm{PGE}_{2}$ due to the inhibition of $\mathrm{COX}-2$ activity by meloxicam led to a decrease in anti-apoptotic proteins such as Bcl-2. These findings corroborated earlier studies by Kendall et al (1996) that demonstrated an overexpression of COX-2 enzyme resulted in increased production of pro-angiogenic factors including VEGF. In addition, Howe et al (2005) performed studies with COX-2 null (-/-) mice that demonstrated decreases in VEGF, ligand ang-1 and ang-2, and VEGF receptor Flk-1. In COX-2 (-/-) mice, these decreases in multiple pro-angiogenic mitogens produced significantly decreased microvessel size and density in genetically induced mammary tumors compared to wildtype (wt) mouse tumors. This study reinforces results by Xin et al (2007) that showed exogenous inhibition of COX-2 by manually administered specific COX-2 inhibitors also reduces microvessel density and VEGF production in vivo.

To evaluate a possible pathway for the NSAID induced decrease in angiogenesis, a study by Jones et al (1999) inoculated human microvascular endothelial cells (HMVECs) and rat aortic endothelial cell Matrigel mesh with non-selective COX-1/2 and selective COX-2 inhibitors. The resulting reduction of formed vascular structures in the Matrigel mesh after administration of both the selective and the non-selective COX 
inhibitor indicated a significant decrease in angiogenesis. In addition, both types of NSAIDs inhibited bFGF and VEGF induced MAP kinase ERK 1/2 activity and ERK2 translocation into the nucleus, both activities being necessary for in vivo and in vitro angiogenesis. Interestingly, exogenously added $\mathrm{PGE}_{2}$ and prostacyclin only resulted in a partial reversal of the angiogenic inhibition caused by co-culturing the cells with NSAIDs. This study provided evidence that prostaglandins generated in endothelial cells by COX2 are involved in the regulation of angiogenesis but act in conjunction with other factors. These findings resemble those found by Schmassmann et al (1998) which demonstrated a decreased $\mathrm{PGE}_{2}$ production in areas of gastric ulcerations in rats that were given a selective COX-2 inhibitor, resulting in decreased angiogenesis and delayed gastric wound healing.

It is important to take into consideration the possibility of anti-angiogenic side effects when considering selective COX-2 inhibitors such as meloxicam for use as postoperative analgesia since recent studies have demonstrated their direct interference with neovascularization by preventing mitogenic signaling. In a study by Leahy et al (2002) time-release pellets containing pro-angiogenic signal bFGF were implanted into the corneal pocket of rats, leading to an augmentation of local angiogenesis. When a COX-2 specific inhibitor was implanted simultaneously, results indicated a decrease in angiogenesis, decreased localized $\mathrm{PGE}_{2}$, enhanced cellular apoptosis, and decreased endothelial cell proliferation, suggesting that COX-2 stimulated prostaglandin production is necessary even in the presence of elevated vascular mitogen bFGF. In a related study, Leahy et al (2002) applied the same selective COX-2 inhibitor to nude mice that had 
received colon cancer cell xenografts and found increased tumor cell apoptosis and decreased endothelial cell proliferation, indicating an inhibition of angiogenesis leading to decreased vascular perfusion of the xenograft tissue.

In a study by Efstathiou et al (2005) using murine endometrium allografts, the effects of selective COX-2 inhibitors on surgically induced endometriosis were evaluated. After autotransplanting $2 \mathrm{~mm}$ sections of endometrium into the abdominal cavities of mice, post-operative injections of either saline (control) or the NSAID celecoxib, a COX2 specific inhibitor, were given. Results demonstrated well-established large, fluid-filled cystic lesions where transplanted tissue was applied indicating endometriosis was successfully induced in animals receiving saline, and reduced or eliminated lesions and cysts where the transplanted tissue was applied in the mice receiving celecoxib indicating a significant decrease in the establishment of the endometrial allografts and subsequent endometriosis. When the NSAID treatment was removed, residual endometrial cells near the transplant area proceeded to cause lesions and cysts typical of endometriosis although the vessel density of the endometrial tissue below the endometrial allografts was not significantly different between the control group and celecoxib group of animals. In addition, when NSAID treatment was initiated in a separate group of animals with already established endometriosis lesions via endometrial allograft, no significant reduction of cysts or lesions at the transplant site was observed. This study suggests that angiogenic inhibition produced by the COX-2 specific NSAID celecoxib does not affect already established vascular pathways but inhibits endometrial blood vessel angiogenesis by decreasing COX-2 mediated prostaglandin production. 
The decrease in angiogenesis via selective COX-2 inhibitors such as meloxicam can be a remarkably potent supplement for the treatment of solid tumors and conditions such as endometriosis, but it can be debilitating for conditions that require sufficient vascularization necessary for tissue viability such as ulcer healing and transplantation. Although meloxicam offers comprehensive pain relief that ameliorates the discomfort of post-operative pain and inflammation, the repercussions of decreasing inflammatory prostaglandin production such as $\mathrm{PGE}_{2}$ could jeopardize the formation of sufficient microvasculature leading to inadequately perfused tissues and an increase in cell death. When considering the mode of action of selective COX-2 inhibitors such as meloxicam, the general research consensus indicates that meloxicam inhibits angiogenesis via the decreased production of important inflammatory prostaglandins. This suggests that meloxicam and other COX-2 specific NSAIDs could decrease vessel formation in murine ovary allografts if given as a post-operative analgesic resulting in poor perfusion and cell death in the transplanted tissue. Alternatively, conflicting results suggest that using buprenorphine or other $\mu$-opioid agonists could either prevent or enhance sufficient neovascularization when given as a post-operative analgesic because morphine derivatives have been implicated in both the inhibition and enhancement of angiogenesis. Comparative studies analyzing the effects of post-operative analgesics meloxicam and buprenorphine on angiogenesis need to be considered to maximize subject comfort and still achieve successful vascularization after surgeries such as murine ovary allotransplantation. 


\section{Vessel identification and quantitation}

Research has shown that cellular hypoxia and inflammation will stimulate the release of endogenous mitogens VEGF, bFGF, and angiopoietins $1 \& 2$ from both the host bursa and grafted ovarian endothelial cells leading to angiogenesis (Dissen 1994; Van Eyck, 2010). In response to this mitogenic cell signaling, pre-existing vessels will begin extracellular matrix degradation, endothelial cell proliferation, and increased branching as angiogenesis progresses (Connolly, 1989; Pepper, 1998). To sufficiently quantify this progression, an endothelial cell surface antigen can be used to identify proliferating endothelial cells and newly formed microvessel networks. The most widely used endothelial cell epitope is the cell-cell adhesion molecule platelet endothelial cell adhesion molecule-1 (PECAM-1) also known as cluster of differentiation 31 (CD31) (Vermeulen, 1996). When compared to other cell surface antigens that only stain medium to large vessels such as VEGF receptor Flk-1, von Wildebrand factor or CD34, CD31 consistently displays a homogenously strong staining of all vessel sizes including microvessels and vessels undergoing active angiogenesis (Pusztaszeri, 2006; Wang, 2008). In addition, CD31 is found in large quantities on endothelial cell surfaces with concentrations at cell-cell junctions, further associating CD31 with its role in cell adhesion and migration during angiogenesis (DeLisser, 1997; Zocchi, 1996). This cell surface antigen is ubiquitous on proliferating endothelial cells and is far less abundant on other types of circulating cells such as leukocytes and platelets (Albelda, 1991). At times, tissue macrophages may be accidentally identified using the CD31 cell surface antigen, but the evaluation of cell morphology can be used to differentiate between cell types 
(McKenney, 2001). With minimal disadvantages, CD31 remains the best surface antigen to use for the identification of angiogenesis and anti-CD31 immunostaining has been published as the international standard for the assessment of microvessel density (Giatromanolaki, 1997; Vermeulen, 1996).

To visualize the CD31 endothelial cell surface antigen, anti-CD31 immunohistochemical techniques can be used to attach a colored reporter label to an unlabeled anti-CD31 antibody bound to the CD31 epitope (Boenisch, 2001; Renshaw, 2010). A common type of clearly identifiable colored reporter label used with light microscopy is the red/brown chromogen 3, 3' diaminobenzidine (DAB) (Boenisch, 2001; Renshaw, 2010). Using this indirect immunohistochemical method to identify endothelial cells involved in angiogenesis reduces non-specific cell surface antigen staining and results in red/brown DAB reporter labeled layers of interlaced vascular endothelial cells outlining new capillary networks that are easily visible with a light microscope (Vandesande, 1988).

The present study elucidates the effects of two types of analgesics on angiogenesis in murine ovary allografts by evaluating total number of vessels, individual vessel parameters such as branch number and length, percent vessel density, and vessel location to determine which class of analgesics would provide adequate pain relief with minimal inhibition of the new vessel formation necessary for successful ovarian transplantation. As described above, the analgesics chosen for evaluation in this study include meloxicam, a non-steroidal anti-inflammatory selective COX-2 inhibitor and the opioid derivative buprenorphine, a potent $\mu$-receptor agonist. It is hypothesized that the 
total number of superficial vessels, vessel elements, and percent vessel density indicative of angiogenesis will show alterations after post-operative administration of both meloxicam and buprenorphine compared to saline controls. When considering the ovarian location that would most likely have the highest vascularized area, the shortrange paracrine activity of mitogens such as VEGF released from hypoxic vascular endothelial cells at the ovary surface suggest that tissue analysis at a depth of approximately $36 \mu \mathrm{m}$ will encompass the highest number of vessels across treatment groups while still remaining decreased when compared to saline controls. Although these hypotheses are manifested from the results of several previous studies evaluating the effects of opioid and NSAID analgesics in various animal models, cell culture types, and using assorted administration protocols, it would be beneficial to identify a particular analgesic as having no significant difference in angiogenesis from a saline control group (Balasubramanian, 2001; Efstathiou, 2005; Gupta, 2002; Jones, 1999; Lam, 2008). These findings show that a specific analgesic could be used to provide ample relief from postoperative discomfort while not impeding adequate angiogenesis to maintain tissue viability and ensure transplantation success. 


\section{MATERIALS AND METHODS}

\section{Animals}

Seven-week old female CBA/J recipient mice were purchased from the Jackson Laboratory (Sacramento, CA) and housed five females per 29 x 22 x 14 cm cage in accordance with University Animal Care Guidelines with approval by the San José State University Institutional Animal Care and Use Committee (approval number 959). Mice were housed under controlled conditions including a 12L:12D fluorescent $60 \mathrm{~lm} / \mathrm{W}$ light cycle and ad libitum access to food (Purina Mouse Chow 5008: 23.5\% protein, 6.5\% fat; Purina Mills, St. Louis, MO) and water (deionized) until animals were approximately 11 months of age (Cargill, 2003; Mason, 2009). Two weeks before surgery dates, donor sixweek old $\mathrm{CBA} / \mathrm{J}$ mice were purchased from Jackson Laboratory and housed in the same conditions. To ensure proper estrus cycling, age matched male CBA/J mice were housed in adjacent cages and under similar conditions with two males per cage (Whitten, 1956).

\section{Ovarian transplantation and treatment administration}

Using the surgical procedures previously reported by Cargill et al (2003), the 11month old recipient mice were anesthetized with an intraperitoneal (IP) $0.65 \mathrm{mg} / \mathrm{kg}$ body weight dose of sodium pentobarbital (Lundbeck Inc., Deerfield, IL). The anesthetized recipient mice were shaved and antiseptically cleaned bilaterally at the dorsolateral abdomen and maintained on a heating pad (Conair, Shelton, CT) while ovariectomized (the bilateral surgical removal of ovaries). Ovaries from eight-week old CBA/J donor mice were surgically placed into the empty ovarian bursa of the aged recipient female and 
the bursa was closed with 7-0 Ethilon nylon filament (Ethicon, San Angelo, TX). The abdominal wall was closed using 5-0 Ethicon chromic gut suture (Ethicon, San Angelo, TX) and wound clips (Becton Dickinson and Company, Sparks, MD) were applied to close the skin. Wound clips were removed seven days post-operatively. Animals were recovered individually in a monitored, heated environment until fully conscious and remained in individual $17 \times 29 \times 13.5 \mathrm{~cm}$ cages until the conclusion of the experiment (Cargill, 2003; Mason, 2009). One recipient mouse died during surgery most likely due to a complication from the sodium pentobarbital anesthetic. This mouse, in addition to a second mouse that died prematurely due to a seizure condition associated with the $\mathrm{CBA} / \mathrm{J}$ mouse strain, were excluded from the study reducing the saline treatment group $n$ to seven (Fuller, 1967).

Pre-operatively, recipient mice were randomly assigned to one of three treatment groups: meloxicam, buprenorphine, or $0.9 \%$ saline control. In the meloxicam treatment group, nine mice received intraperitoneal $5 \mathrm{mg} / \mathrm{kg}$ doses of meloxicam (Boehringer Ingelheim, St. Joseph, MO). In the buprenorphine group, nine recipient mice received an intraperitoneal $0.05 \mathrm{mg} / \mathrm{kg}$ buprenorphine (Reckitt Benckiser, Hull, England) dose, and the remaining eight mice received intraperitoneal 0.9\% saline (Vedco, Inc., St. Joseph, MO) doses in volumes similar to the buprenorphine and meloxicam. Analgesia doses were chosen according to current veterinary recommendations. Doses of meloxicam, buprenorphine, and saline were given every 12 hours for 48 hours post-operatively with the first dose given after ovary allotransplantation and before anesthetic recovery. 


\section{Fixation and preservation of ovaries}

For non-biased double-blind analysis, all female recipient mice were randomly assigned new identification numbers and sacrificed by cervical dislocation between 73-78 days post-transplantation. One ovary from each mouse was placed into individual labeled $5 \mathrm{ml}$ sterile glass vials (Wheaton Science Products, Millville, NJ) containing $4 \mathrm{ml}$ of IHC Zinc fixative (BD Biosciences, San Diego, CA). The vials were sealed with parafilm (Parafilm, Neenah, WI) to prevent leakage and kept at $4^{\circ} \mathrm{C}$ for 24 hours. When incubation was complete new labeled $5 \mathrm{ml}$ sterile glass vials were filled with $4 \mathrm{ml}$ of sterile RNAse-free phosphate buffered saline (PBS) (Boston Bioproducts, Ashland, MA). Fine tissue forceps were used to transfer the ovary from the Zinc fixative to the corresponding vial of PBS, making sure to clean the forceps between each transfer. New vial lids were secured with parafilm and placed in labeled cardboard shipping containers at $4^{\circ} \mathrm{C}$. The labeled ovary vial containers were then packed in ice packs lined styrofoam coolers and shipped overnight to IHC World LLC (Ellicott City, MD) for CD31 immunohistochemistry antibody binding and 3.3'-Diaminobenzidine (DAB) chromogen staining.

\section{CD31 Immunohistochemistry procedure}

Upon receipt of samples the $5 \mathrm{ml}$ labeled vials were removed from $4^{\circ} \mathrm{C}$ and ovaries were transferred to room temperature RNAse-free phosphate buffered saline (PBS) in labeled $1.5 \mathrm{ml}$ microcentrifuge tubes (Fisher Scientific, Fair Lawn, NJ). The

ovaries were washed in PBS-Tween20 (Fisher Scientific, Fair Lawn, NJ) for 30 minutes 
followed by incubation in rabbit anti-mouse CD31 primary antibody (Thermo Scientific Pierce, Rockford, IL) diluted 1:100 using IHC-Tek Antibody Diluent (IHC World, Ellicott City, MD) on a shaker at room temperature for 16 hours. Following the incubation, the ovaries were washed in PBS-Tween20 three times for 30 minutes each and incubated on a shaker in 3\% Peroxidase Blocking Solution (Vector Laboratories, Burlingame, CA) for 20 minutes at room temperature. After an additional three washes in PBS-Tween20 for 30 minutes each, the ovaries were incubated in biotinylated goat anti-rabbit secondary antibody (Thermo Scientific Pierce, Rockford, IL) diluted 1:500 using IHC-Tek Antibody Diluent on a shaker at room temperature for 16 hours. Following this incubation, the ovaries were washed in PBS-Tween 20 three times for one hour each and incubated on a shaker in a 1:500 dilution of HRP-Streptavidin (Biolegend, San Diego, CA) for 16 hours at room temperature. The ovaries were then washed in PBS-Tween 20 three times for one hour each and incubated in a 1:4 dilution of 3.3'Diaminobenzidine (DAB) Chromogen (Fisher Scientific, Fair Lawn, NJ) for 10-15 minutes at room temperature, removing the ovaries when a uniform dark brown color had been achieved. The ovaries were then rinsed with three washes of PBS-Tween 20 at 10 minutes each and placed in new labeled $1.5 \mathrm{ml}$ microcentrifuge tubes containing $1 \mathrm{ml}$ of room temperature 50\% glycerol (Hampton Research, Aliso Viejo, CA) in PBS. The ovaries were incubated in the $50 \%$ glycerol/PBS solution for 10-20 minutes until the ovary sank to the bottom of the tube. The ovaries were removed and placed in a $70 \%$ glycerol in PBS solution and the labeled tubes were stored at $4^{\circ} \mathrm{C}$. The ovaries were 
shipped from IHC World LLC (Ellicott City, MD) overnight to San Jose State University at $4^{\circ} \mathrm{C}$.

\section{Ovarian tissue embedding and slide processing}

For the dehydration procedure before paraffin embedding, the ovaries were removed from the $4^{\circ} \mathrm{C} 70 \%$ glycerol suspension and washed three times with room temperature PBS for 10 minutes each. After washing, ovaries were incubated in labeled $1.5 \mathrm{ml}$ microcentrifuge tubes containing room temperature $70 \%$ ethanol (Histo-chem, Jefferson, AR) twice for one hour each. Ovaries were incubated in $80 \%$ ethanol for one hour, $95 \%$ ethanol (Histo-chem, Jefferson, AR) for one hour and three incubations of $100 \%$ ethanol (Histo-chem, Jefferson, AR) at room temperature for 1.5 hours each. Ovaries were placed into labeled $1.5 \mathrm{ml}$ microtubes containing $100 \%$ xylene (SigmaAldrich, St. Louis, MO) at room temperature and incubated for three washes at 1.5 hours each. The ovaries were placed into individual labeled $200 \mathrm{ml}$ beakers containing $60^{\circ} \mathrm{C}$ Paraplast Plus (Covidien, Mansfield, MA) paraffin wax and incubated for two hours. The paraffin embedded ovaries were then placed into labeled embedding cassettes (Fisher Scientific, Fair Lawn, NJ), covered in Paraplast plus paraffin wax and allowed to dry for six hours. After a minimum of six hours of drying time, the paraffin embedded ovaries were placed into the Leica Histoslide 2000 sliding microtome (Leica Microsystems, Buffalo Grove, IL). To collect the surface layers for vascularization analysis, $18 \mu \mathrm{m}$ ovary sections were taken from the "top" of the wax embedded ovary and mounted onto labeled TruBond 380 microscope slides (TruBond, Woodstock, MD) with a fine tip 
paintbrush. Sectioning continued until the brown DAB staining was limited to the periphery of the remaining ovarian tissue indicating that the surface layers had been removed and the middle of the ovary had been reached. The mid-sections of ovary were sectioned at $40 \mu \mathrm{m}$ and placed on separate labeled Trubond microscope slides for use in another project. The remaining $160-180 \mu \mathrm{m}$ of embedded ovarian tissue was sliced into $18 \mu \mathrm{m}$ sections until all ovary tissue had been sectioned. All 25 ovaries were sectioned, mounted onto labeled TruBond 380 microscope slides, air dried for 30 minutes then baked in a Precision Scientific 25EM oven (Thermo Electron Corporation, Marietta, Ohio) at $45^{\circ} \mathrm{C}$ for 16 hours.

To rehydrate ovary sections, the slides were immersed twice in $100 \%$ xylene for 10 minutes each and then twice in $100 \%$ ethanol for 10 minutes each. Slides were then immersed into $95 \%$ ethanol for five minutes, $70 \%$ ethanol for five minutes and $50 \%$ ethanol for five minutes. The slides were rinsed with deionized water and placed in PBS for 10 minutes. After rehydration, excess PBS was wicked from the surface and back of slide using Kimwipes (Kimberly-Clark, Irving, TX). A 0.5” line of DPX Histology Mountant (Sigma-Aldrich, St. Louis, MO) was placed along the center of each 50 x 24 mm rectangular glass coverslip (Fisher Scientific, Fair Lawn, NJ) and the Trubond slide was inverted and placed tissue section side down onto the mountant and a light pressure was applied to remove trapped air bubbles. Excess mountant was removed from the sides and bottom of the slide. The slide with attached coverslip was placed upright and allowed to dry in a covered tray for 24 hours. 


\section{Image capturing and processing}

Pictures were taken of each tissue section using a Leica EC3 camera (Leica Microsystems, Buffalo Grove, IL) mounted on a Leica DMIL LED inverted microscope (Leica Microsystems, Buffalo Grove, IL). Each $18 \mu \mathrm{m}$ section was photographed at 50100x to capture the whole tissue cross-section and at 400x for identification of individual vessels, with each picture identified by group number, slide number, section number, and picture number.

After all tissue sections were photographed, only images from the third (approximately $54 \mu \mathrm{m}$ from the ovary surface), fifth (approximately $90 \mu \mathrm{m}$ from the ovary surface), and seventh (approximately $126 \mu \mathrm{m}$ from the ovary surface) sections from the "top" of each ovary and third, fifth, and seventh sections from the opposite "bottom" of the ovary were used for subsequent image analysis. For these images, Graphic Converter software version 8.8.2 (Lemke Software, Peine, Germany) was used to crop each individual photo to prevent image overlap and remove shadow resulting in a section of tissue with dark vascular structures present (Figure 1A). Each picture was then opened in Image J software 1.47v 32-bit (National Institute of Health, Bethesda, MD) and the "split channels" command was run. This split the red, green and blue channels of the source image into three separate grayscale images with a white background, leaving the cell data in shades of dark grey. Using the green image, the "invert" command was run, which created a new image consisting of a black background and transformed the cell data to shades of light grey (Figure 1B). The image was saved and the auto threshold was set to "default dark." The upper and lower threshold ratio was then set to 123/255 which 
best replicated the vascular structures from the original cropped images. The image was converted to binary by setting the black background option to "false" and running the "make binary" command with the "thresholded remaining black" command, creating a binary image of blacks and whites (Figure 1C). This binary image represented the overall number of vessels present and was used to evaluate vessel density by calculating the percentage of black pixels per image before the image was converted into the skeletonized representation. The image was saved and the "skeletonize" command then the "invert" command were run, which provided a black background with a white vascular skeleton image (Figure 1D).

Using Analyze Skeleton version 2.0.0 for Image J (Ignacio Arganda-Carreras, Madrid, Spain) the "analyze skeleton" command [2D/3D] was run with the "prune" setting at "none." The results were saved in an Excel version 14.3.9 (Microsoft, Redmond, WA) spreadsheet and "total number of vessels," "total number of branches," "total number of junctions," "average number of branches per vessel," "average number of junctions per vessel," "mean branch length $(\mu \mathrm{m})$, , "mean vessel length $(\mu \mathrm{m})$, , and "percent vessel density" data for each individual image was input into separate Excel spreadsheets organized by ovary group number, section number, and image number (Doukas, 2006). 

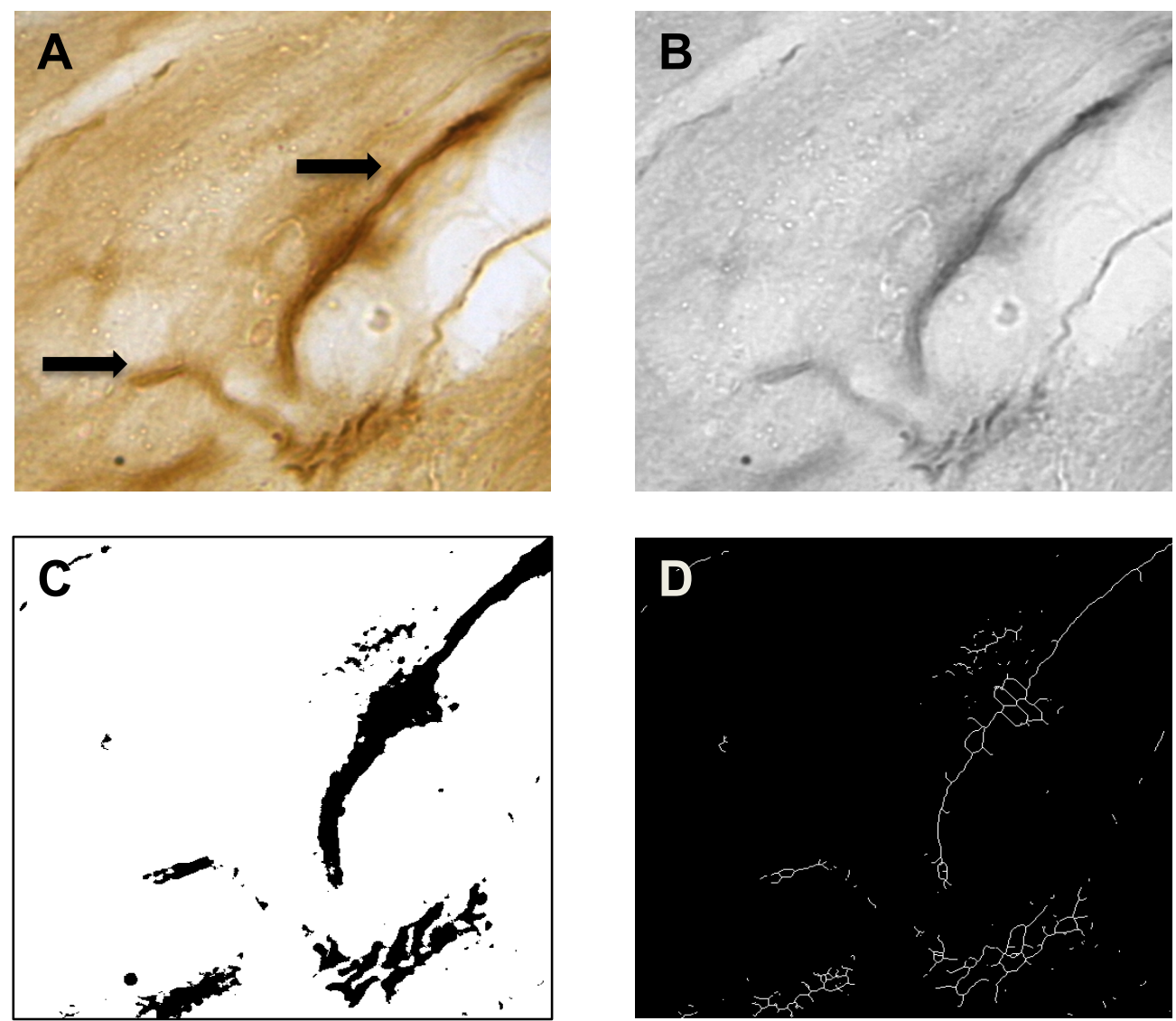

Figure 1. Section from saline-treated murine ovary $90 \mu \mathrm{m}$ from the surface. 400x total magnification. A) DAB stained vascular structures at black arrows, B) inverted black and white image, C) threshold image, D) final black-and-white skeletonized image used to calculate total vessel number, total branch number, and number of junctions.

\section{Statistical Analysis}

After each image had been analyzed, each individual image Excel spreadsheet was condensed into 25 spreadsheets organized by group number only. Numerical data from whole ovary analysis categories "total number of vessels," "total number of branches," "total number of junctions," and "percent vessel density" were condensed onto a single sheet and organized by group number. On a separate sheet, individual 
vessel numerical data from categories "average number of branches per vessel," "average number of junctions per vessel," “mean branch length $(\mu \mathrm{m})$, , and "mean vessel length $(\mu \mathrm{m})$ " were condensed and organized by group number. For both ovary and individual vessel data spreadsheets, mean values were calculated by averaging all the values from each individual image in each group number in each category and all averages were placed into a separate Excel spreadsheet. After all categories had been averaged and the data separated by group number, each group number was condensed further by treatment. One-way Analysis of Variance (ANOVA) and post-hoc Tukey's Honest Significant Difference (HSD) statistical tests were used to compare the calculated means of each category between the saline treatment group $(n=7)$, the buprenorphine treatment group $(n=9)$, and the meloxicam treatment group $(n=9)$, and between the buprenorphine and meloxicam treatment groups. All One-Way ANOVAs and Tukey's HSD pairwise comparisons were performed using SPSS Statistics software (IBM, Armonk, NY).

Before each group was identified by treatment, each group number was also separated by ovary section number (third, fifth, or seventh) and the whole ovary analysis mean for "total number of vessels," "total number of branches," "total number of junctions," "average number of branches per vessel," "average number of junctions per vessel," "mean branch length $(\mu \mathrm{m})$, ," "mean vessel length $(\mu \mathrm{m})$, , and "percent vessel density" were calculated from each image value in each ovary section to compare means between the third, fifth, and seventh sections. For each ovary, polar opposite third section "total number of vessels," "total number of branches," "total number of junctions," "mean branch length $(\mu \mathrm{m})$," "mean vessel length $(\mu \mathrm{m})$, ," "average number of branches 
per vessel," "average number of junctions per vessel," and "percent vessel density" means were averaged and One-Way ANOVA with post-hoc Tukey's HSD statistical tests were used to compare means between treatment groups. In two separate analyses, polar opposite fifth section and polar opposite seventh section "total number of vessels," "total number of branches," "total number of junctions," "average number of branches per vessel," "average number of junctions per vessel," and "percent vessel density" means were compared between treatment groups using One-way ANOVAs and post-hoc Tukey's HSD statistical tests. Since fifth and seventh section means for "mean branch length $(\mu \mathrm{m})$ " and "mean vessel length $(\mu \mathrm{m})$ " did not show homogeneity of variance, results were analyzed using Kruskal-Wallis Analysis of Variance (Kruskal-Wallis ANOVA) non-parametric tests. Kruskal-Wallis non-parametric comparisons were performed using SPSS Statistics software.

For cross-sectional ovary area analysis, the area of both "top" and "bottom" third, fifth, and seventh ovary sections were calculated in millimeters squared $\left(\mathrm{mm}^{2}\right)$. For each ovary, polar opposite third section areas were averaged and compared between treatment groups using One-way ANOVAs and post-hoc Tukey’s HSD statistical tests. One-way ANOVAs and post-hoc Tukey's HSD tests were used to compare the mean area of each polar ovary fifth section between treatment groups and the mean area of each polar ovary seventh section between treatment groups. 


\section{RESULTS}

\section{Superficial Vessel Analysis}

Averaged "total number of vessels" in the third sections (approximately $54 \mu \mathrm{m}$ from the ovary surface), fifth sections (approximately $90 \mu \mathrm{m}$ from the ovary surface), and seventh sections (approximately $126 \mu \mathrm{m}$ from the ovary surface) between the saline control group $(M=31029.9$ vessels, $n=7, S D=10495.4)$, the meloxicam treatment group $(M=43336.9$ vessels, $n=9, S D=9390.3)$, and the buprenorphine treatment group $(M=$ 25512.1 vessels, $n=9, S D=6433.2$ ) were compared using One-Way ANOVA. Results show a significant difference between the saline treatment group and the meloxicam treatment group and between the meloxicam and buprenorphine treatment groups $(F(2$, $22)=9.642, p=0.001$, Figure 2). Tukey's HSD post-hoc pairwise comparisons also demonstrated a significant difference between the buprenorphine treatment group and the meloxicam treatment group $(p=0.001)$ and a significant difference between the saline treatment group and the meloxicam treatment group $(p=0.028)$. Post-hoc comparisons determined no significant difference between the saline and buprenorphine treatment groups $(p=0.494)$. Means and standard deviations (SD) for the total number of vessels per ovary for each treatment group are represented in Table 1. 


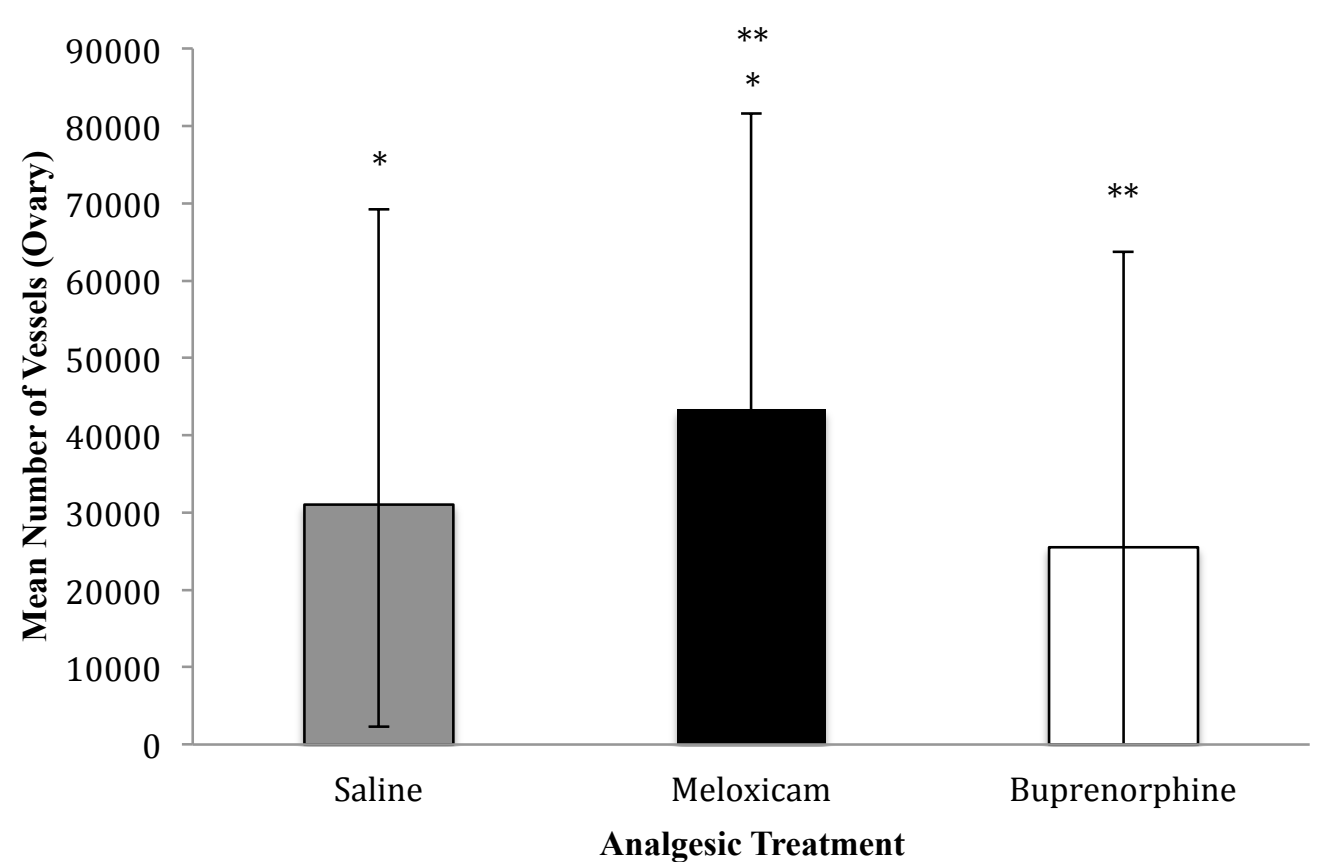

Figure 2. Mean number of vessels per ovary in each treatment group determined by averaging the means from all six sections within each treatment group $(n=25)$. Saline ( $M=31029.9$ vessels, $n=7, S D=10495.4)$, meloxicam $(M=43336.9$ vessels, $n=9, S D=$ 9390.3), buprenorphine ( $M=25512.1$ vessels, $n=9, S D=6433.2$ ). Single asterisks [*] represent significance between saline and meloxicam (One-Way ANOVA $F(2,22)=9.642$, $p=0.028$ ). Double asterisks [**] represent significance between meloxicam and buprenorphine (One-Way ANOVA $p=0.001$ ). Error bars represent $95 \%$ confidence intervals.

Table 1. Mean and Standard Deviations (SD) for total number of vessels per ovary, total number of vessel branches per ovary, total number of vessel junctions per ovary, and percent vessel density [skeletonized area $(\mu \mathrm{m}) /$ section area $(\mu \mathrm{m}) \mathrm{x} 100$ ] for each treatment. Each mean represents an average of the ovary $(n=25)$ section means per treatment. Saline $(n=7)$, meloxicam $(n=9)$, buprenorphine $(n=9)$. Single asterisks [*] represent significance $p=0.02-0.05$. Double asterisks [**] represent significance $p<0.02$. 


\begin{tabular}{c|cc|cc|cc|cc}
$\begin{array}{c}\text { Analgesic } \\
\text { Treatment }\end{array}$ & \multicolumn{2}{|c|}{$\begin{array}{c}\text { Total Number of } \\
\text { Vessels per ovary }\end{array}$} & \multicolumn{2}{|c|}{$\begin{array}{c}\text { Total Number of } \\
\text { Vessel Branches per } \\
\text { ovary }\end{array}$} & \multicolumn{2}{|c|}{$\begin{array}{c}\text { Total Number of } \\
\text { Vessel Junctions per } \\
\text { ovary }\end{array}$} & \multicolumn{2}{|c}{$\begin{array}{c}\text { Percent } \\
\text { Vessel } \\
\text { Density }\end{array}$} \\
\hline \multirow{3}{*}{\begin{tabular}{c} 
Saline \\
\cline { 2 - 9 }
\end{tabular}} & Mean & SD & \multicolumn{2}{|c|}{ Mean } & SD & Mean & SD & \multicolumn{2}{c}{ Mean } & SD \\
\cline { 2 - 9 } Meloxicam & $31029.9^{*}$ & 10495.4 & 158272.8 & 64472.9 & 69504.9 & 29540.2 & 19.7 & 7.2 \\
Buprenorphine & $43336.9^{* * * *}$ & 9390.3 & $194854.8^{*}$ & 36750.4 & $82408.4^{*}$ & 15892.5 & 17.1 & 4.9 \\
& $25512.1^{* *}$ & 6433.2 & $128819.7^{*}$ & 42821.2 & $56447.7^{*}$ & 20448.8 & 18.8 & 4.7
\end{tabular}

The total number of vessel branches per ovary means between the saline treatment group $(M=158272.8$ branches, $n=7, S D=64472.9)$, the meloxicam treatment group ( $M=$ 194854.8 branches, $n=9, S D=36750.4)$, and the buprenorphine treatment group $(M=$ 128819.7 branches, $n=9, S D=42821.2$ ) were compared using One-Way ANOVA, means and standard deviation represented in Table 1. Results show a significant difference between the three treatment groups $(F(2,22)=4.296, p=0.027$, Figure 3$)$ with Tukey's HSD post-hoc comparisons demonstrating the significance was specifically between the buprenorphine treatment group and the meloxicam treatment group ( $p=$ 0.021). No significant difference was observed between the saline treatment group and the buprenorphine treatment group $(p=0.454)$ and saline and meloxicam treatment groups $(p=0.303)$. 


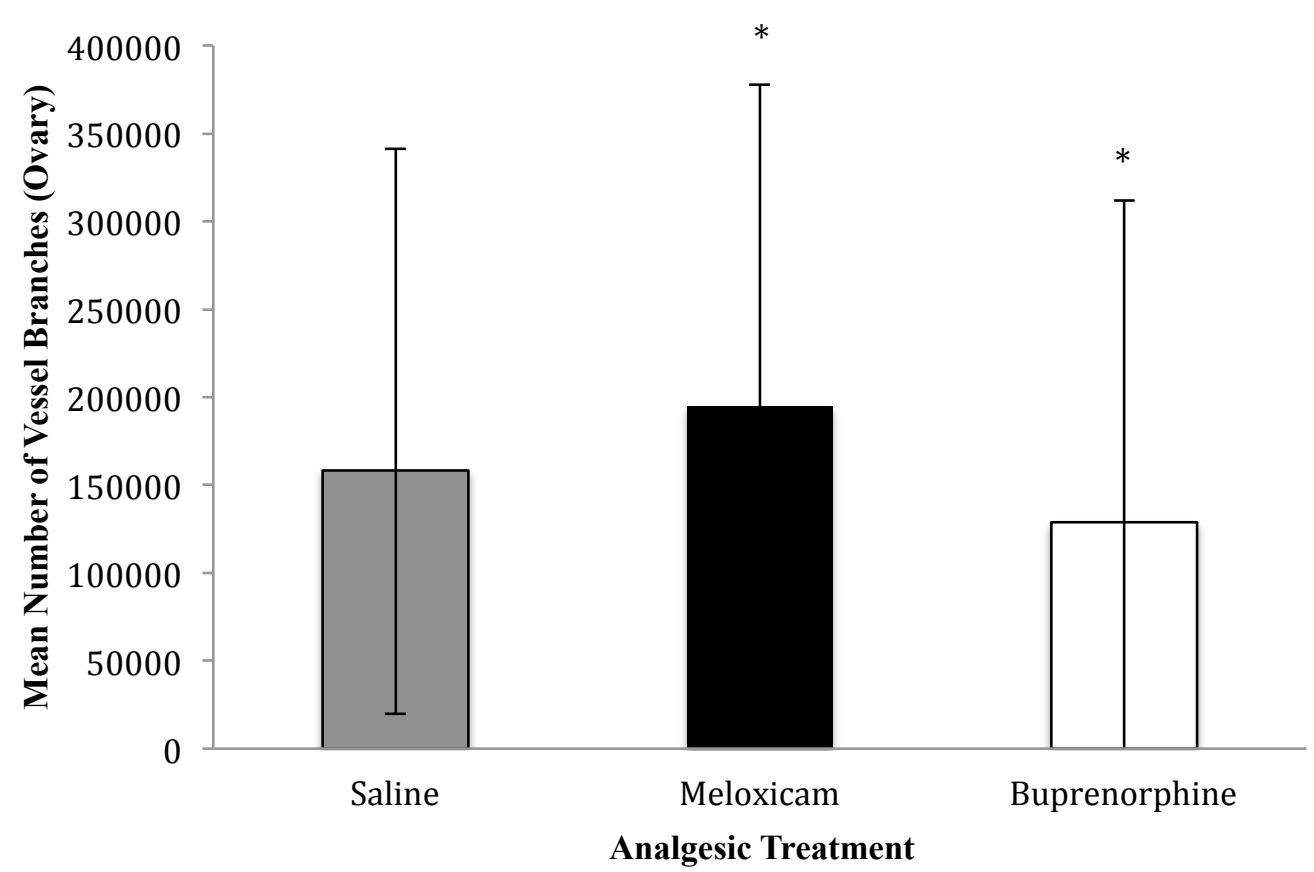

Figure 3. Mean number of vessel branches per treatment group determined by averaging the means from each ovary within each treatment group $(n=25)$. Saline $(M=158272.8$ branches, $n=7, S D=64472.9)$, meloxicam $(M=194854.8$ branches, $n=9, S D=36750.4)$, buprenorphine $(M=128819.7$ branches, $n=9, S D=42821.2)$. Single asterisks [*] represent significance between meloxicam and buprenorphine (One-Way ANOVA $F(2,22)=4.296, p=0.021)$. Error bars represent $95 \%$ confidence intervals.

To compare the total number of junctions where the main vessel structure and extending branches connect, the total number of junctions per ovary were averaged and the saline treatment group $(M=69504.9$ junctions, $n=7, S D=29540.2)$, meloxicam treatment group $(M=82408.4$ junctions, $n=9, S D=15892.5)$, and buprenorphine $(M=$ 56447.7 junctions, $n=9, S D=20448.8$ ) were compared by One-Way ANOVA. Results indicated no significant difference in the total number of junctions between the main vessel structure and extending branches across the three treatment groups $(F(2,22)=$ 3.147, $p=0.063$, Figure 4). Tukey's HSD post-hoc comparisons between the 
buprenorphine treatment group and the meloxicam treatment group showed a significant difference ( $p=0.05)$, but pairwise comparisons between the saline treatment group and the buprenorphine treatment group $(p=0.477)$, and saline and meloxicam treatment groups $(p=0.485)$ were not significantly different. The averaged means and the standard deviations of the total number of junctions per treatment group are represented in Table 1.

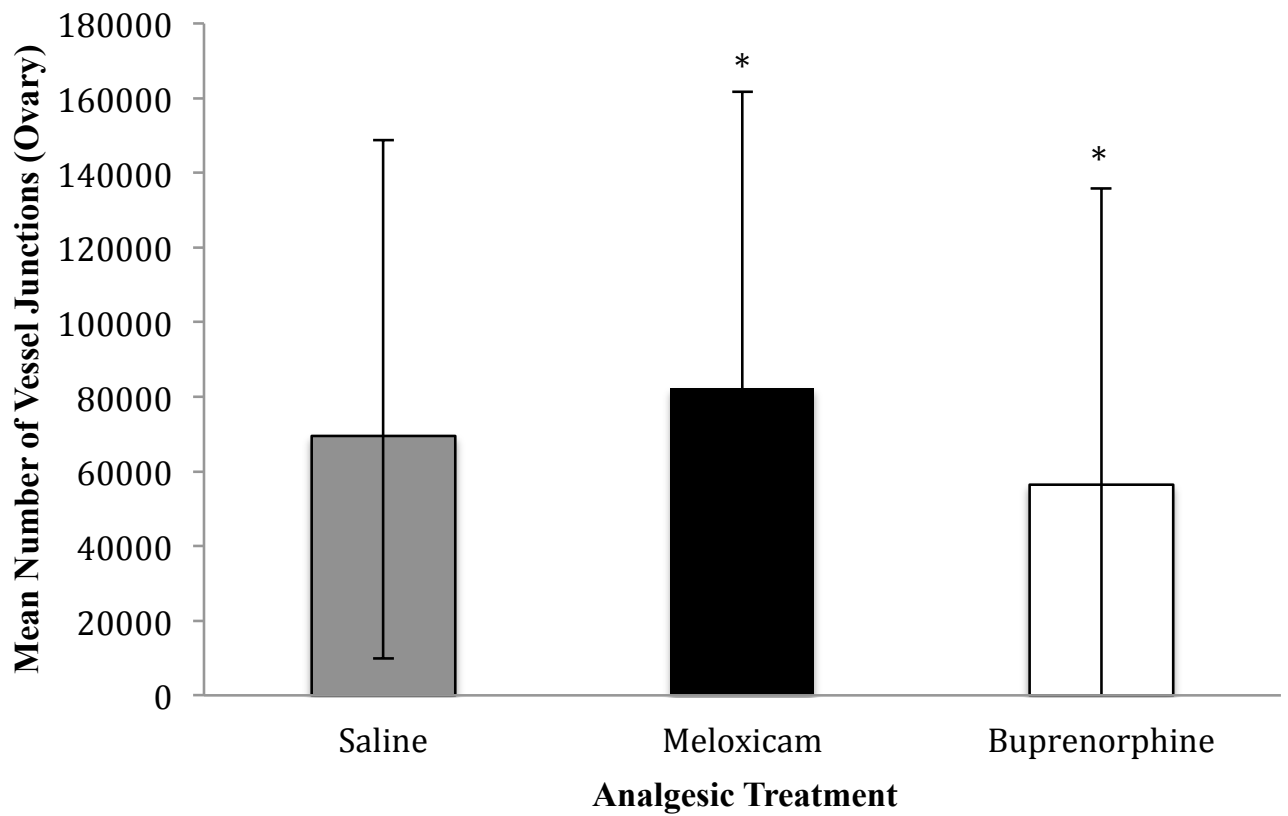

Figure 4. Mean number of main vessel and branch junctions per treatment group determined by averaging the means from each ovary within each treatment group $(n=25)$. Saline $(M=69504.9$ junctions, $n=7, S D=29540.2)$, meloxicam $(M=82408.4$ junctions, $n=9, S D=15892.5)$, buprenorphine $(M=56447.7$ junctions, $n=9, S D=20448.8)$. Single asterisks [ $\left.{ }^{*}\right]$ represent significance between meloxicam and buprenorphine (One-Way ANOVA $F(2,22)=3.147, p=0.05)$. Error bars represent $95 \%$ confidence intervals.

There were no significant differences in percent vessel density when measured using the skeletonized area $(\mu \mathrm{m})$ divided by the section area $(\mu \mathrm{m})$ between the saline 
treatment group $(M=19.71 \%, n=7, S D=7.2)$, the meloxicam treatment group $(M=$ $17.1 \%, n=9, S D=4.9)$, and the buprenorphine treatment group $(M=18.8 \%, n=9, S D=$ 4.7) when compared using a One-Way ANOVA $(F(2,22)=0.453, p=0.642$, Figure 5). The averages of the means from each ovary separated by treatment group are represented in Table 1.

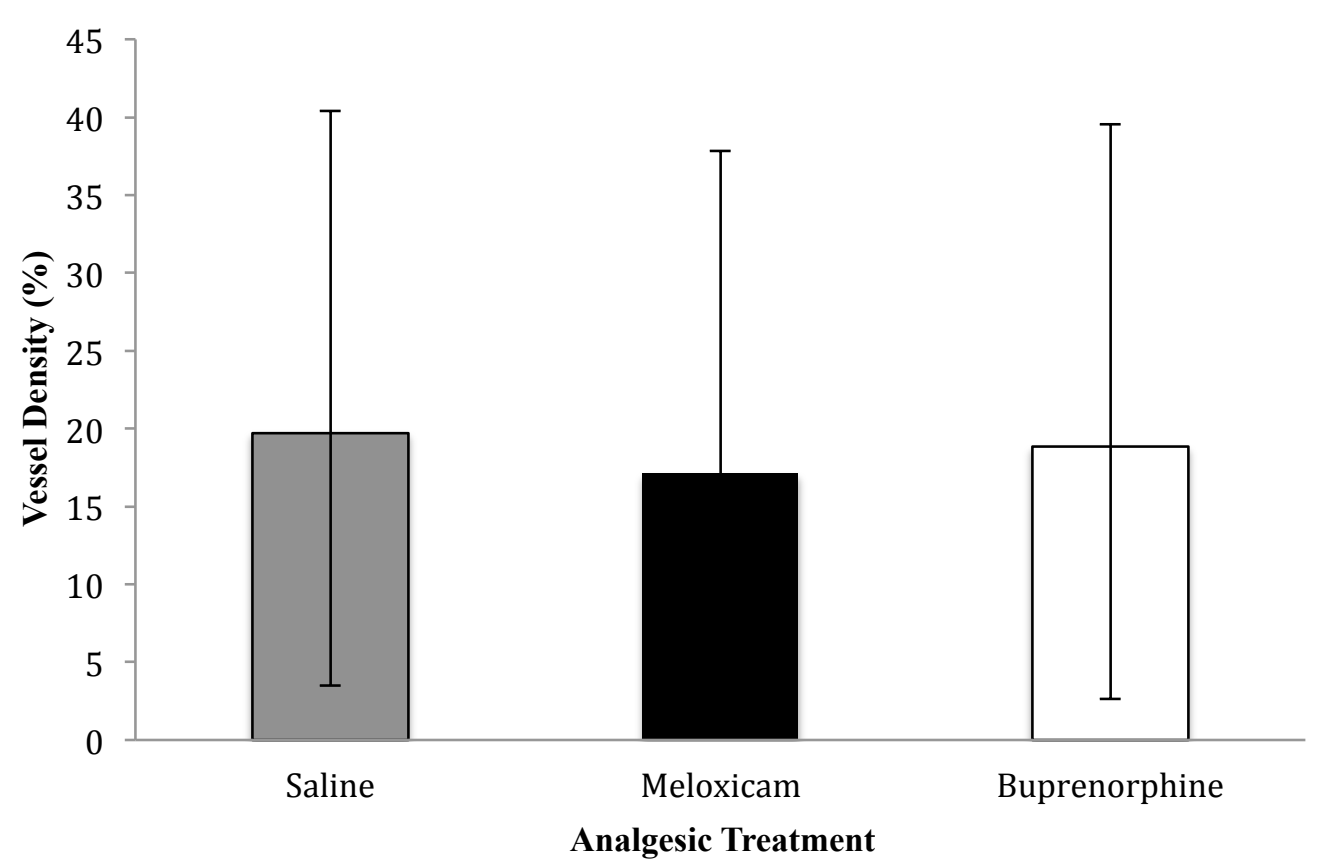

Figure 5. Mean percent vessel density [skeletonized area $(\mu \mathrm{m}) /$ section area $(\mu \mathrm{m}) \mathrm{x} 100$ ] per ovary determined by averaging the means from each ovary within each treatment group $(n=25)$. Saline $(M=19.71 \%, n=7, S D=7.2)$, meloxicam $(M=17.1 \%, n=9, S D=$ 4.9), buprenorphine ( $M=18.8 \%, n=9, S D=4.7)$. Error bars represent $95 \%$ confidence intervals. 


\section{Individual Section Analysis}

The means of the total number of vessels from the third, fifth, and seventh $18 \mu \mathrm{m}$ representative sections taken from each ovary pole were averaged and means per treatment group were compared using One-Way ANOVA. The averaged means and the standard deviations for the total number of vessels in each third, fifth, and seventh section per treatment group are represented in Table 2. After averaging the total vessel means from each polar third section there was no significant difference between the saline treatment group $(M=4651.71$ vessels, $n=7, S D=2145.7)$, the meloxicam treatment group $(M=5541.56$ vessels, $n=9, S D=1410.7)$, and the buprenorphine treatment group $(M=4287.94$ vessels, $n=9, S D=2213)($ One-Way ANOVA $F(2,22)=0.987, p=0.389)$,

Figure 6).

Table 2. Mean and Standard Deviations (SD) for the averaged total number of vessels per third (approximately $54 \mu \mathrm{m}$ from the surface), fifth (approximately $90 \mu \mathrm{m}$ from the surface), and seventh (approximately $126 \mu \mathrm{m}$ from the surface) opposite polar sections per ovary. Each mean represents an average of the means for each appropriate section per ovary $(n=25)$ per treatment. Saline $(n=7)$, meloxicam $(n=9)$, buprenorphine $(n=9)$. Single asterisks [*] represent significance $p=0.01-0.05$. Double asterisks $\left[{ }^{* *}\right]$ represent significance $p<0.01$.

\begin{tabular}{|c|c|c|c|c|c|c|}
\hline \multirow[t]{2}{*}{ Treatment } & \multicolumn{2}{|c|}{$\begin{array}{l}\text { Total Number of } \\
\text { Vessels per Third } \\
\text { Section }(54 \mu \mathrm{m})\end{array}$} & \multicolumn{2}{|c|}{$\begin{array}{l}\text { Total Number of } \\
\text { Vessels per Fifth } \\
\text { Section }(90 \mu \mathrm{m})\end{array}$} & \multicolumn{2}{|c|}{$\begin{array}{l}\text { Total Number of } \\
\text { Vessels per } \\
\text { Seventh Section } \\
(126 \mu \mathrm{m})\end{array}$} \\
\hline & Mean & SD & Mean & $\mathrm{SD}$ & Mean & $\mathrm{SD}$ \\
\hline Saline & 4651.71 & 2145.7 & $5540.5^{*}$ & 2272.5 & 5400.35 & 1626.9 \\
\hline Meloxicam & 5541.56 & 1410.7 & $8357.39^{* ; * *}$ & 1903.5 & $7769.5^{* *}$ & 2054.9 \\
\hline Buprenorphine & 4287.94 & 2213 & $4582.83^{* *}$ & 1042 & $4470.5^{* *}$ & 1893.9 \\
\hline
\end{tabular}




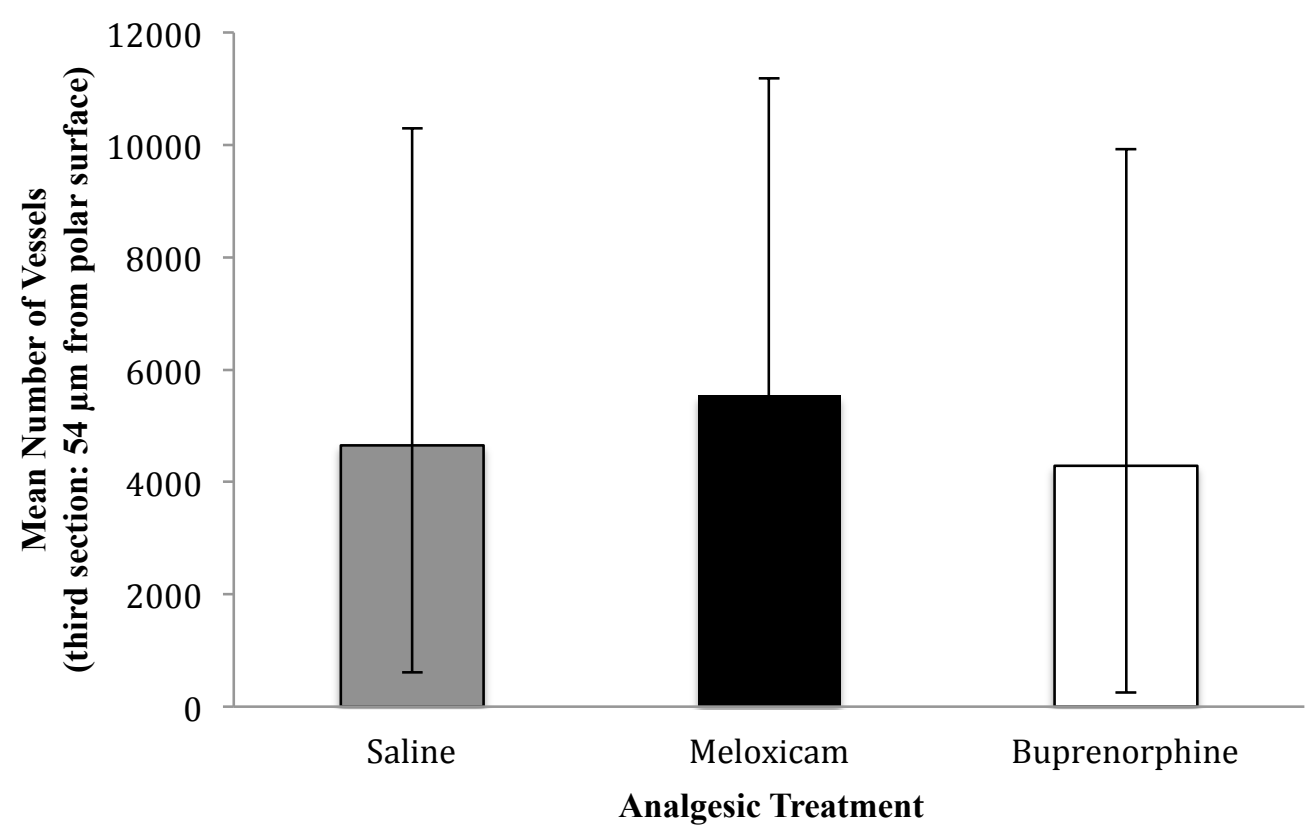

Figure 6. Mean total number of vessels determined by averaging the means from polar third sections (approximately $54 \mu \mathrm{m}$ from the ovary surface) within each treatment group $(n=25)$. Saline $(M=4651.71$ vessels, $n=7, S D=2145.7)$, meloxicam $(M=5541.56$ vessels, $n=9, S D=1410.7)$, buprenorphine $(M=4287.94$ vessels, $n=9, S D=2213)$. Error bars represent $95 \%$ confidence intervals.

One-Way ANOVA was used to compare the averaged total number of vessels from each fifth ovary section from opposite poles per ovary between the saline treatment group $(M=5540.5$ vessels, $n=7, S D=2272.5)$, the meloxicam treatment group $(M=$ 8357.39 vessels, $n=9, S D=1903.5)$, and the buprenorphine treatment group $(M=$ 4582.83 vessels, $n=9, S D=1042$ ). Results showed there was a significant difference in the total number of vessels across the three treatment groups $(F(2,22)=10.969, p<0.001$, Figure 7). Post-hoc Tukey's HSD showed a significant difference between the saline and meloxicam treatment groups $(p=0.012)$ and between the meloxicam and buprenorphine 
treatment groups $(p<0.001)$. No significant difference in the total number of vessels was shown between the saline and buprenorphine treatment groups' fifth sections $(p=0.539)$.

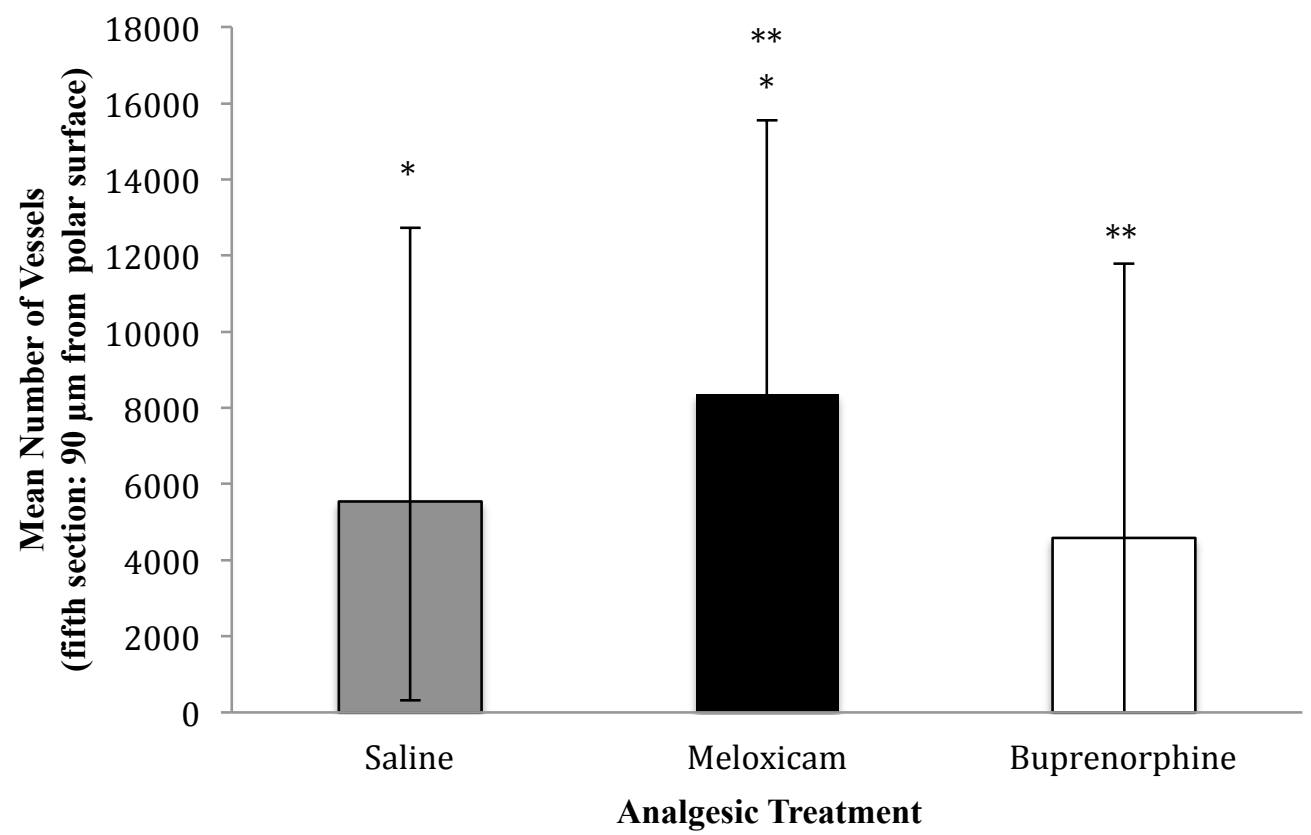

Figure 7. Mean total number of vessels determined by averaging the means from polar fifth sections (approximately $90 \mu \mathrm{m}$ from the ovary surface) within each treatment group $(n=25)$. Saline $(M=5540.5$ vessels, $n=7, S D=2272.5)$, meloxicam $(M=8357.39$ vessels, $n=9, S D=1903.5)$, buprenorphine $(M=4582.83$ vessels, $n=9, S D=1042)$. Single asterisks [*] represent a significant difference between saline and meloxicam $($ One-Way ANOVA $F(2,22)=10.969, p=0.012)$. Double asterisks [**] represent a significant difference between meloxicam and buprenorphine (One-Way ANOVA $p<$ 0.001). Error bars represent $95 \%$ confidence intervals.

One-Way ANOVA was used to compare the averaged total number of vessels from each seventh section per ovary between the saline treatment group $(M=5400.35$ vessels, $n=7, S D=1626.9)$, the meloxicam treatment group $(M=7769.5$ vessels, $n=9$, $S D=2054.9)$, and the buprenorphine treatment group $(M=4470.5$ vessels, $n=9, S D=$ 
1893.9). Results showed a significant difference in the total number of vessels between seventh sections across the three treatment groups $(F(2,22)=7.241, p=0.004$, Figure 8). Tukey's HSD post-hoc pairwise comparisons demonstrated a significant difference between the meloxicam and buprenorphine treatment groups $(p=0.003)$. No significant difference in the total number of vessels was shown between the saline and buprenorphine treatment groups $(p=0.598)$ and saline and meloxicam treatment groups' seventh sections $(p=0.052)$.

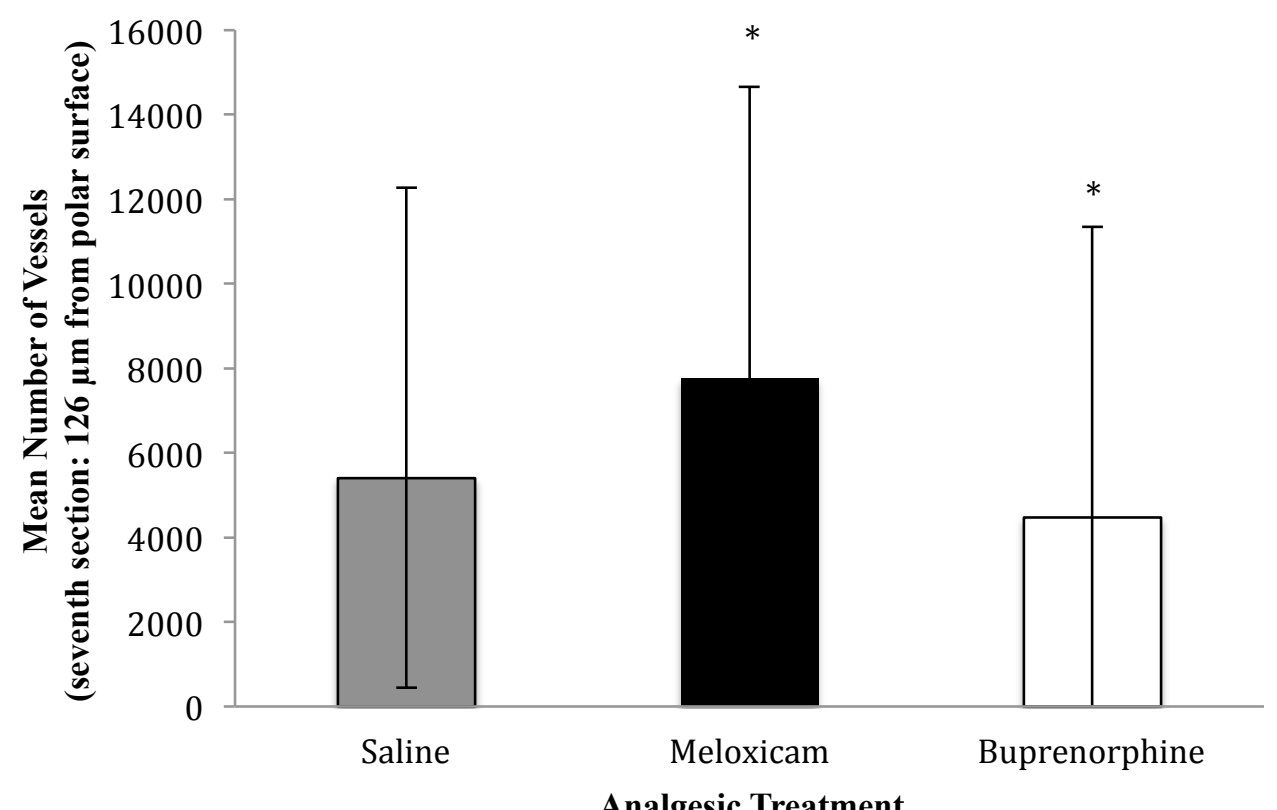

Figure 8. Mean total number of vessels determined by averaging the means from polar seventh sections (approximately $126 \mu \mathrm{m}$ from the ovary surface) within each treatment group $(n=25)$. Saline $(M=5400.35$ vessels, $n=7, S D=1626.9)$, meloxicam $(M=7769.5$ vessels, $n=9, S D=2054.9)$, buprenorphine ( $M=4470.5$ vessels, $n=9, S D=1893.9$ ). Asterisks [*] represent a significant difference between buprenorphine and meloxicam (One-Way ANOVA $F(2,22)=7.241, p=0.004)$. Error bars represent $95 \%$ confidence intervals. 
The mean total branch number from each polar third section was averaged and compared across treatment groups using One-Way ANOVA. Results demonstrated no significant difference between the saline treatment group ( $M=23357.7$ branches, $n=7$, $S D=11451)$, the meloxicam treatment group $(M=26330.1$ branches, $n=9, S D=6137.8)$, and the buprenorphine treatment group ( $M=24035.1$ branches, $n=9, S D=13109.1)$ $(F(2,22)=0.267, p=0.783)$. The averaged means and the standard deviations for the total number of branches in each third, fifth, and seventh section per treatment group are represented in Table 3.

Table 3. Mean and Standard Deviations (SD) for the averaged total number of branches per third (approximately $54 \mu \mathrm{m}$ from the surface), fifth (approximately $90 \mu \mathrm{m}$ from the surface), and seventh (approximately $126 \mu \mathrm{m}$ from the surface) opposite polar sections per ovary. Each mean represents an average of the means for each appropriate section per ovary $(n=25)$ per treatment. Saline $(n=7)$, meloxicam $(n=9)$, buprenorphine $(n=9)$. Single asterisks $\left[{ }^{*}\right]$ represent significance $p=0.001$. Double asterisks $[* *]$ represent significance $p<0.001$.

\begin{tabular}{c|cc|cc|cc} 
Treatment & \multicolumn{2}{|c|}{$\begin{array}{c}\text { Total Number of } \\
\text { Branches per Third } \\
\text { Section }(54 \mu \mathrm{m})\end{array}$} & \multicolumn{2}{|c|}{$\begin{array}{c}\text { Total Number of } \\
\text { Branches per Fifth } \\
\text { Section }(90 \mu \mathrm{m})\end{array}$} & \multicolumn{2}{|c}{$\begin{array}{c}\text { Total Number of } \\
\text { Branches per } \\
\text { Seventh Section } \\
(126 \mu \mathrm{m})\end{array}$} \\
\hline \multirow{3}{*}{ Saline } & 23357.7 & 11451.0 & $29721.4^{*}$ & 2145.7 & 48790.0 & 18639.7 \\
\cline { 2 - 7 } Meloxicam & 26330.1 & 6137.8 & $69727.2^{* ; * *}$ & 15058.1 & 51038.6 & 17543.9 \\
Buprenorphine & 24035.1 & 13109.1 & $21727.9^{* *}$ & 5122.3 & 44957.6 & 13346.5
\end{tabular}

The total branch number means from the fifth $18 \mu \mathrm{m}$ representative sections taken from each ovary pole were averaged and means were compared across treatment groups 
using One-Way ANOVA. Results indicated a significant difference between the saline treatment group $(M=29721.4$ branches, $n=7, S D=2145.7)$, the meloxicam treatment group $(M=69727.2$ branches, $n=9, S D=15058.1)$, and the buprenorphine treatment group $(M=21727.9$ branches, $n=9, S D=5122.3)(F(2,22)=41.462, p=0.001$, Figure 9$)$. Post-hoc Tukey's HSD test showed a significant difference between the saline and meloxicam treatment groups $(p=0.001)$ and between the meloxicam and buprenorphine treatment groups $(p<0.001)$.

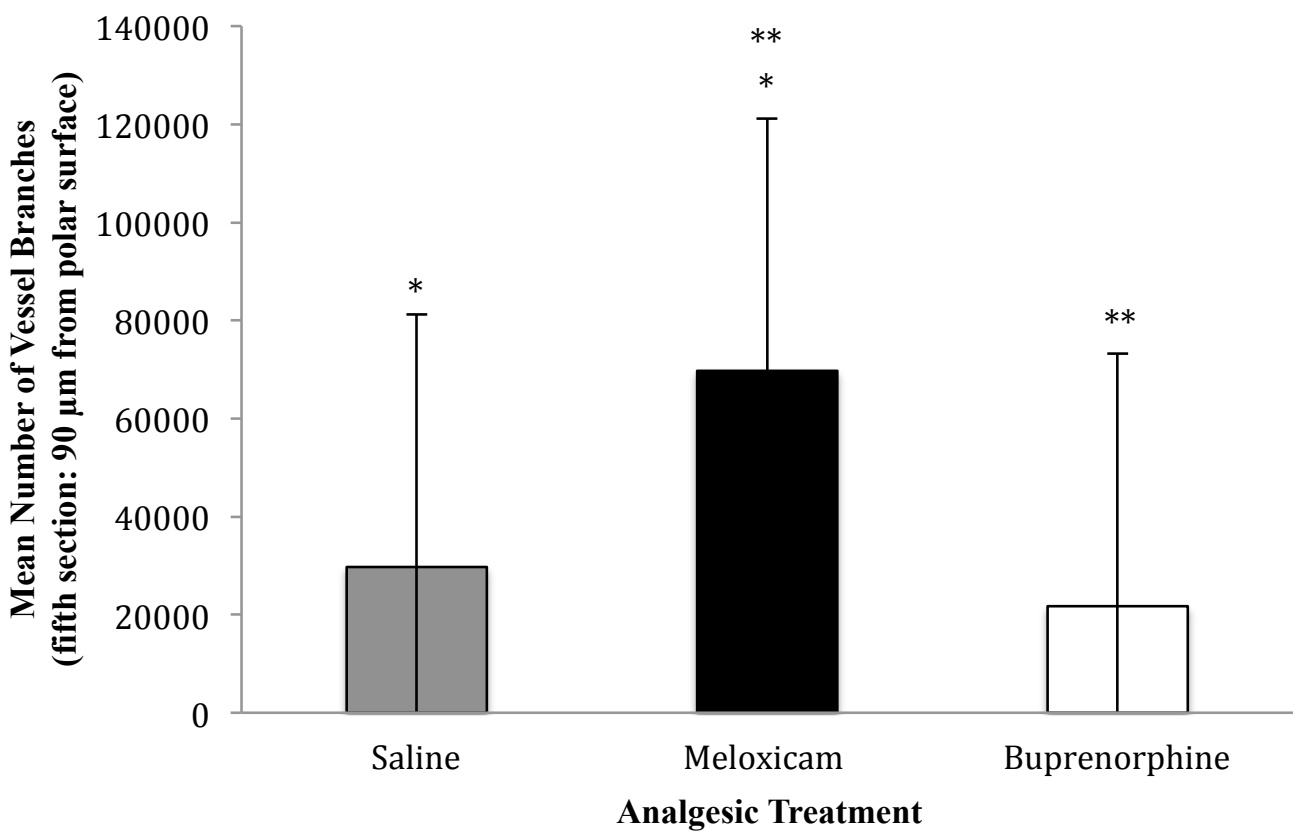

Figure 9. Mean total number of vessel branches determined by averaging the means from polar fifth sections (approximately $90 \mu \mathrm{m}$ from the ovary surface) within each treatment group $(n=25)$. Saline $(M=29721.4$ branches, $n=7, S D=2145.7)$, meloxicam $(M=69727.2$ branches, $n=9, S D=15058.1)$, buprenorphine $(M=21727.9$ branches, $n=9$, $S D=5122.3)$. Single asterisks [*] represent a significant difference between saline and meloxicam (One-Way ANOVA $F(2,22)=41.462, p=0.001)$. Double asterisks [**] represent a significant difference between meloxicam and buprenorphine (One-Way ANOVA $p<0.001)$. Error bars represent $95 \%$ confidence intervals. 
The mean total branch number from each polar seventh section was averaged and no significant difference between the saline treatment group $(M=48790.0$ branches, $n=7$, $S D=18639.7)$, the meloxicam treatment group $(M=51038.6$ branches, $n=9, S D=$ 17543.9), and the buprenorphine treatment group $(M=44957.6$ branches, $n=9, S D=$ 13346.5) (One-Way ANOVA $F(2,22)=0.200, p=0.387)$ was demonstrated.

The total number of junctions where the main vessel structure and extending branches connect from the third, fifth, and seventh polar opposite sections were averaged and means per treatment group were compared using One-Way ANOVA. The averaged means and the standard deviations for the total number of junctions in each third, fifth, and seventh section per treatment group are represented in Table 4. There was no significant difference when mean third sections were compared between the saline, meloxicam and buprenorphine treatment groups (One-Way ANOVA $F(2,22)=0.291, p=$ 0.827). Results indicated no significant difference when comparing mean fifth ovary section total number of junctions means across treatment groups (One-Way ANOVA $F(2,22)=9.12, p=0.371)$. Results comparing mean seventh polar ovary sections across treatment groups demonstrated no significant results (One-Way ANOVA $F(2,22)=4.623$, $p=0.771)$. 
Table 4. Mean and Standard Deviations (SD) for the average total number of junctions per vessel per treatment group. Each mean represents an average of the means for each ovary $(n=25)$ per treatment. Saline $(n=7)$, meloxicam $(n=9)$, buprenorphine $(n=9)$.

\begin{tabular}{|c|c|c|c|c|c|c|}
\hline \multirow[t]{2}{*}{ Treatment } & \multicolumn{2}{|c|}{$\begin{array}{l}\text { Total Number of } \\
\text { Junctions per Third } \\
\text { Section }(54 \mu \mathrm{m})\end{array}$} & \multicolumn{2}{|c|}{$\begin{array}{l}\text { Total Number of } \\
\text { Junctions per Fifth } \\
\text { Section }(90 \mu \mathrm{m})\end{array}$} & \multicolumn{2}{|c|}{$\begin{array}{l}\text { Total Number of } \\
\text { Junctions per } \\
\text { Seventh Section } \\
(126 \mu \mathrm{m})\end{array}$} \\
\hline & Mean & SD & Mean & $\mathrm{SD}$ & Mean & SD \\
\hline Saline & 10239.3 & 5153.1 & 15204.6 & 5994.1 & 22924.3 & 4096.9 \\
\hline Meloxicam & 11263.5 & 2752.9 & 18996.3 & 5744.2 & 29125.4 & 7560.2 \\
\hline Buprenorphine & 9920.8 & 5948.8 & 11351.0 & 3757.8 & 20104.6 & 4060.3 \\
\hline
\end{tabular}

The percent vessel density means from the third, fifth, and seventh $18 \mu \mathrm{m}$ representative sections taken from each ovary pole were averaged and means per treatment group were compared. One-Way ANOVA was used to analyze the mean percent vessel density from each polar third section resulting in no significant difference between the saline treatment group $(M=19.86 \%, n=7, S D=9.34)$, the meloxicam treatment group $(M=20.28 \%, n=9, S D=5.12)$, and the buprenorphine treatment group $(M=21.79 \%, n=9, S D=7.59)($ One-Way ANOVA $F(2,22)=0.158, p=0.855)$. OneWay ANOVA was used to compare the percent vessel density mean between each fifth ovary section from opposite poles per ovary between the saline treatment group $(M=$ $21.61 \%, n=7, S D=7.51)$, the meloxicam treatment group $(M=32.74 \%, n=9, S D=$ 11.57), and the buprenorphine treatment group $(M=18.41 \%, n=9, S D=5.33)$. Results showed a significant difference in the mean percent vessel density across the three 
treatment groups $(F(2,22)=6.738, p=0.005$, Figure 10). Post-hoc Tukey's HSD showed a significant difference between the saline and meloxicam treatment groups $(p=0.045)$ and between the meloxicam and buprenorphine treatment groups $(p=0.005)$. Percent vessel density from each polar seventh section was also averaged. Results demonstrated no significant difference between the saline treatment group $(M=28.54 \%, n=7, S D=$ 7.09), the meloxicam treatment group $(M=30.69 \%, n=9, S D=8.49)$, and the buprenorphine treatment group $(M=31.65 \%, n=9, S D=6.02)$ (One-Way ANOVA $F(2,22)=0.263, p=0.108)$. The averaged means and the standard deviations for the mean percent vessel density in each third, fifth, and seventh section per treatment group are represented in Table 5.

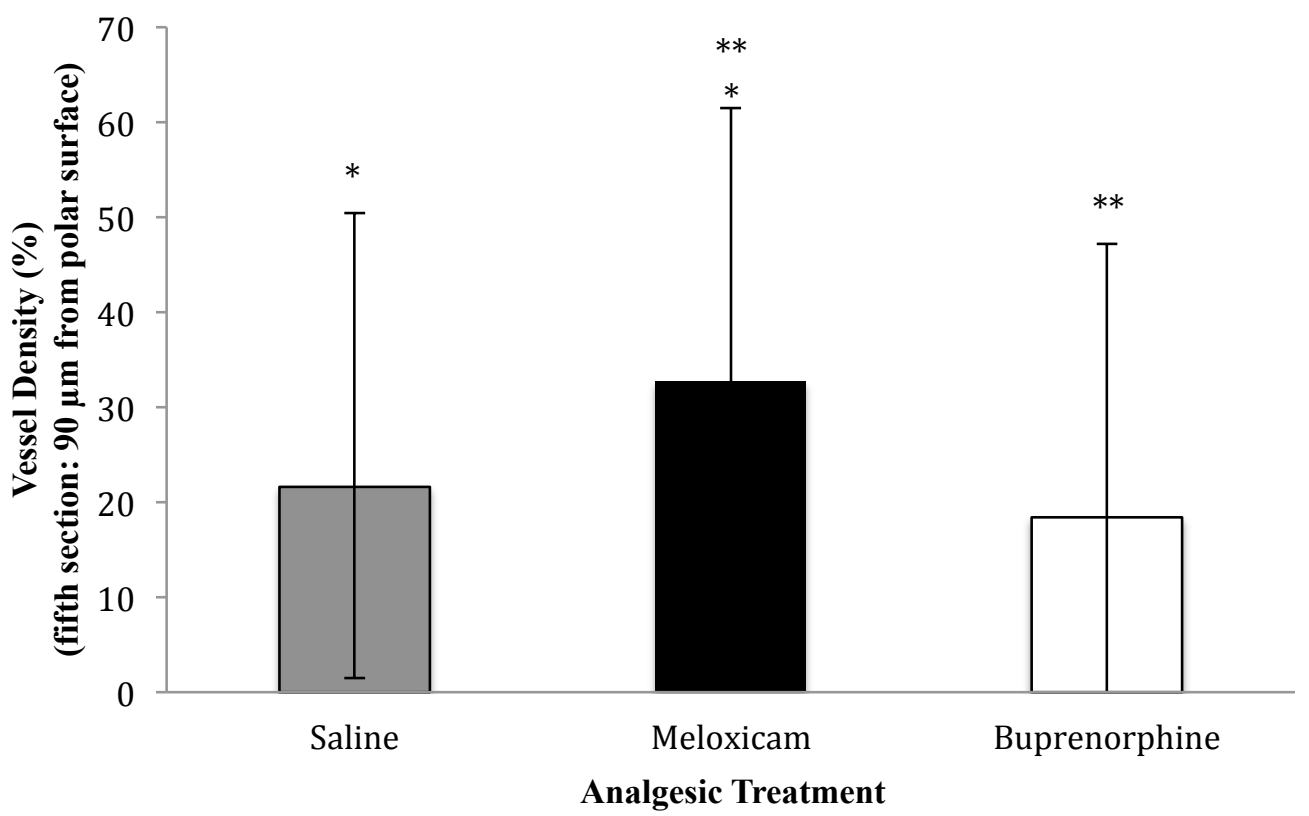


Figure 10. Mean percent vessel density determined by averaging the means from polar fifth sections (approximately $90 \mu \mathrm{m}$ from the ovary surface) within each treatment group $(n=25)$. Saline $(M=21.61 \%, n=7, S D=7.51)$, meloxicam $(M=32.74 \%, n=9, S D=$ 11.57), buprenorphine $(M=18.41 \%, n=9, S D=5.3)$. Single asterisks [*] represent a significant difference between saline and meloxicam (One-Way ANOVA $F(2,22)=6.738$, $p=0.005)$. Double asterisks [**] represent a significant difference between meloxicam and buprenorphine (One-Way ANOVA $p=0.005$ ). Error bars represent 95\% confidence intervals.

Table 5. Mean and Standard Deviations (SD) for the percent vessel density [skeletonized area $(\mu \mathrm{m}) /$ section area $(\mu \mathrm{m}) \times 100$ ] per third, fifth, and seventh opposite polar sections per ovary. Each mean represents an average of the means for each appropriate section per ovary $(n=25)$ per treatment. Saline $(n=7)$, meloxicam $(n=9)$, buprenorphine $(n=9)$. Single asterisks $\left[{ }^{*}\right]$ represent significance $p=0.01-0.05$. Double asterisks $[* *]$ represent significance $p<0.01$.

\begin{tabular}{|c|c|c|c|c|c|c|}
\hline \multirow[t]{2}{*}{ Treatment } & \multicolumn{2}{|c|}{$\begin{array}{c}\text { Third Section }(54 \mu \mathrm{m}) \\
\text { Percent Vessel } \\
\text { Density }\end{array}$} & \multicolumn{2}{|c|}{$\begin{array}{c}\text { Fifth Section }(90 \mu \mathrm{m}) \\
\text { Percent Vessel } \\
\text { Density }\end{array}$} & \multicolumn{2}{|c|}{$\begin{array}{c}\text { Seventh Section } \\
(126 \mu \mathrm{m}) \text { Percent } \\
\text { Vessel Density }\end{array}$} \\
\hline & Mean & $\mathrm{SD}$ & Mean & $\mathrm{SD}$ & Mean & $\mathrm{SD}$ \\
\hline Saline & 19.86 & 9.34 & $21.61^{*}$ & 7.51 & 28.54 & 7.09 \\
\hline Meloxicam & 20.28 & 5.12 & $32.74^{* ; * *}$ & 11.57 & 30.69 & 8.49 \\
\hline Buprenorphine & 21.79 & 7.59 & $18.41^{* *}$ & 5.3 & 31.65 & 6.02 \\
\hline
\end{tabular}

\section{Vessel Branch and Junction Analysis}

The number of branches on each vessel per section were averaged and each individual section mean was averaged to obtain an average branches per vessel mean for each ovary. Each ovary mean was averaged per treatment group and compared using a One-Way ANOVA. Results showed there was no significant difference in the average 
number of branches per vessel means between the saline treatment group $(M=5.541$ branches, $n=7, S D=0.8842)$, the meloxicam treatment group $(M=4.913$ branches, $n=9$, $S D=0.6582)$, and the buprenorphine treatment group $(M=5.537$ branches, $n=9, S D=$ 0.9783 ) (One-Way ANOVA $F(2,22)=1.566, p=0.231$, Figure 11). Post-hoc Tukey's HSD comparisons also did not show any significant differences between the treatment groups $(p=0.325, p=1.000, p=0.283)$. The average number of branches per vessel means and standard deviations (SD) per treatment group are represented in Table 6.

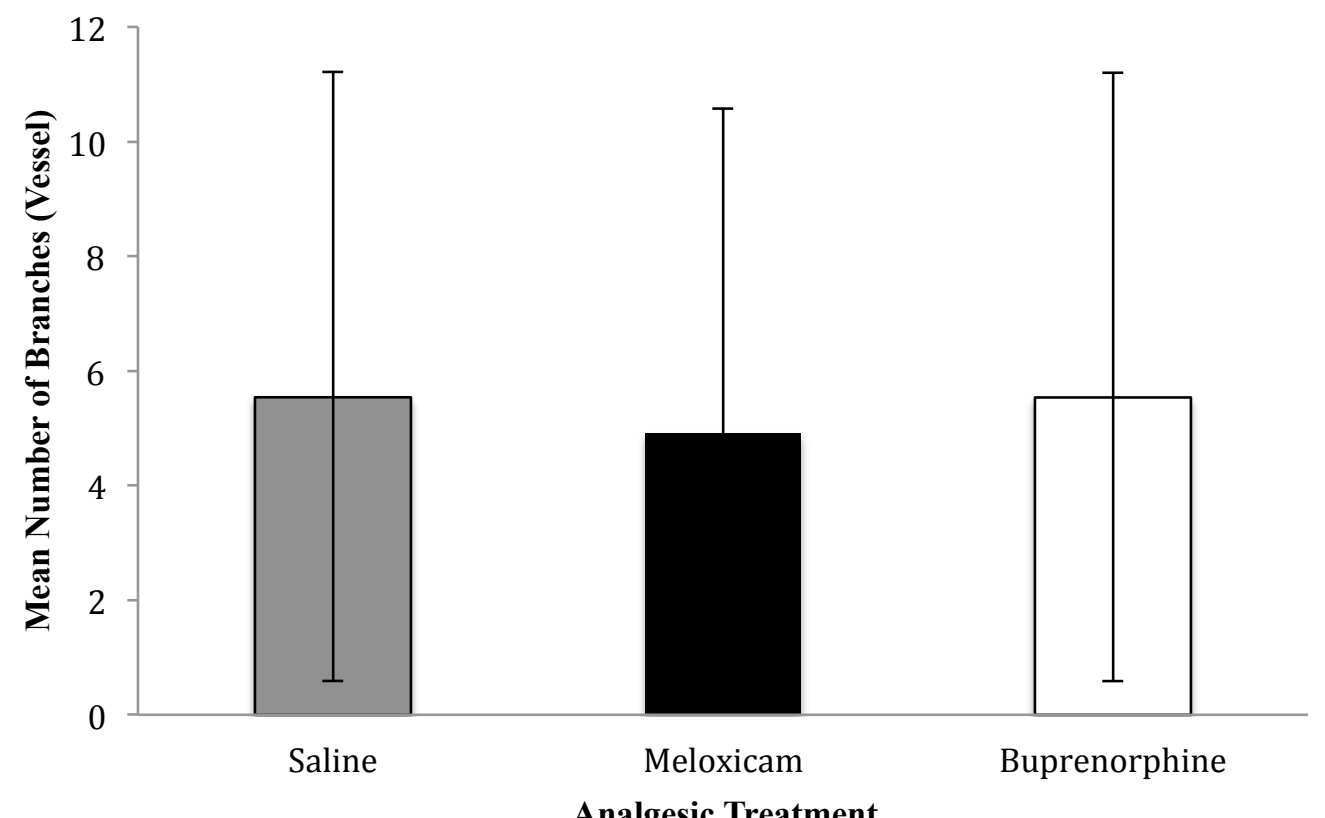

Figure 11. Mean average number of branches per vessel determined by averaging the mean number of branches per vessel from each ovary within each treatment group $(n=$ $25)$. Saline $(M=5.541$ branches, $n=7, S D=0.8842)$, meloxicam $(M=4.913$ branches, $n=$ $9, S D=0.6582)$, buprenorphine $(M=5.537, n=9, S D=0.9783)$. Error bars represent $95 \%$ confidence intervals. 
Table 6. Mean and Standard Deviations (SD) for the average total number of branches per vessel per treatment group. Each mean represents an average of the means for each ovary $(n=25)$ per treatment. Saline $(n=7)$, meloxicam $(n=9)$, buprenorphine $(n=9)$.

\begin{tabular}{c|cc|cc}
\multirow{2}{*}{ Treatment } & \multicolumn{2}{|c|}{$\begin{array}{c}\text { Average Number of } \\
\text { Branches per vessel }\end{array}$} & \multicolumn{2}{c}{$\begin{array}{c}\text { Average Number of } \\
\text { Junctions per vessel }\end{array}$} \\
\hline \multirow{2}{*}{ Saline } & \multicolumn{2}{|c|}{ Mean } & SD & \multicolumn{2}{|c}{ Mean } & SD \\
\cline { 2 - 5 } Meloxicam & 5.541 & 0.8842 & 2.491 & 0.4776 \\
Buprenorphine & 4.913 & 0.6582 & 2.134 & 0.3664 \\
& 5.537 & 0.9783 & 2.491 & 0.538
\end{tabular}

The number of vessel and branch junction points for each vessel per section was averaged and each individual section mean was averaged to obtain an average number of junctions per vessel mean for each ovary. Each ovary mean was averaged per treatment group and the means compared using a One-Way ANOVA. Results showed there was no significant difference in the total number of junctions per vessel means between the saline treatment group $(M=2.491$ junctions, $n=7, S D=0.4776)$, the meloxicam treatment group $(M=2.134$ junctions, $n=9, S D=0.3664)$, and the buprenorphine treatment group $(M=2.491$ junctions, $n=9, S D=0.538)$ (One-Way ANOVA $F(2,22)=$ 1.691, $p=0.207$, Figure 12). Post-hoc Tukey's HSD pairwise comparisons also did not show any significant differences between the treatment groups $(p=0.301, p=1.000, p=$ 0.256). The number of junctions per vessel means and standard deviations per treatment group are represented in Table 6. 


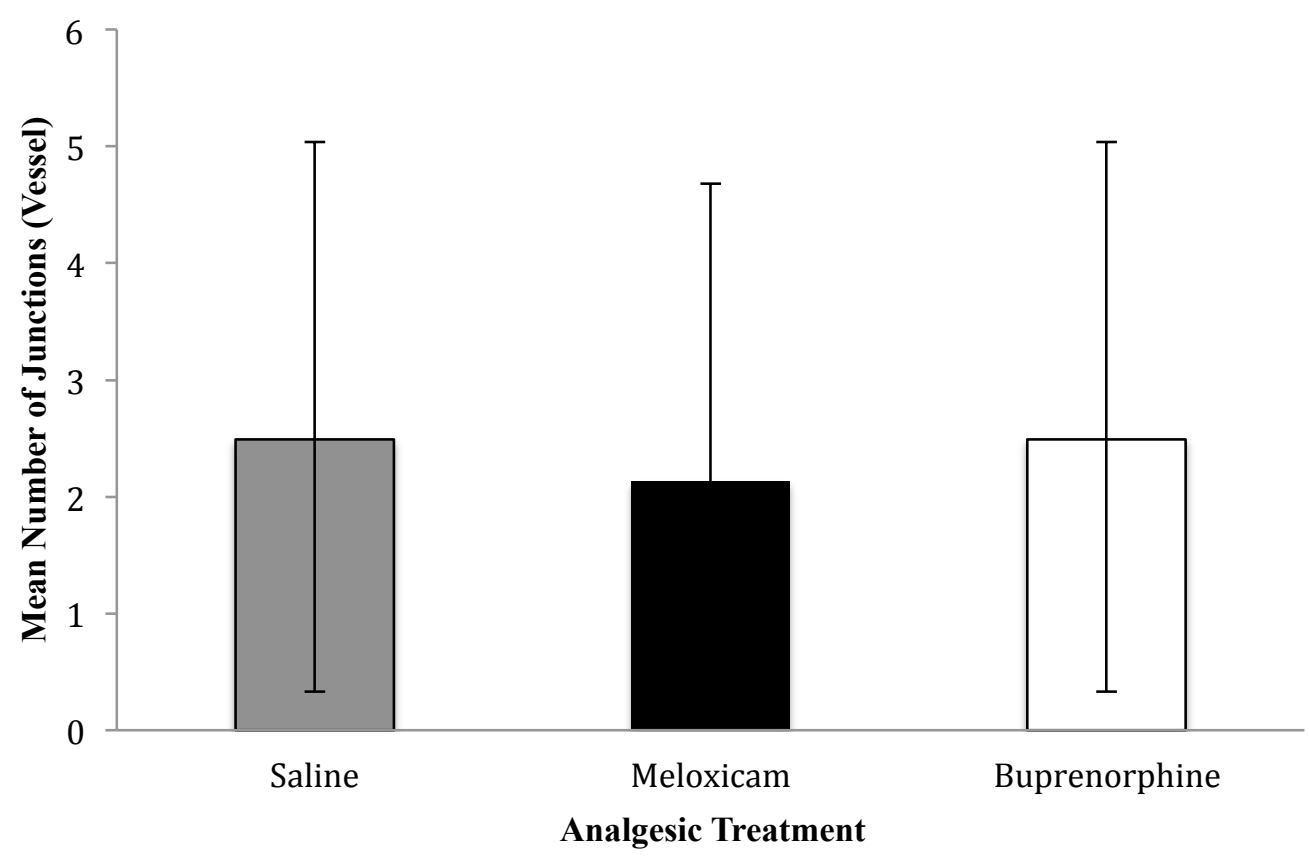

Figure 12. Mean average number of junctions per vessel determined by averaging the means from each ovary within each treatment group $(n=25)$. Saline $(M=2.491$ junctions, $n=7, S D=0.4776)$, meloxicam $(M=2.134$ junctions, $n=9, S D=0.3664)$, buprenorphine $(M=2.491$ junctions, $n=9, S D=0.538)$. Error bars represent $95 \%$ confidence intervals.

All vessel lengths $(\mu \mathrm{m})$ per ovary section image were counted and a mean vessel length per image was calculated. Each image mean vessel length was averaged to find the mean vessel length per ovary per treatment group. The average vessel length $(\mu \mathrm{m})$ means and standard deviations per treatment group are represented in Table 7 . The average vessel length per treatment group resulted in an average vessel length of 1.973 $\mu \mathrm{m}$ for the saline treatment group $(n=7, S D=0.3004), 1.752 \mu \mathrm{m}$ for the meloxicam treatment group $(n=9, S D=0.5165)$, and $2.095 \mu \mathrm{m}$ for the buprenorphine treatment group $(n=9, S D=0.5282)$. Results of a One-Way ANOVA comparing vessel lengths 
$(\mu \mathrm{m})$ across treatment groups showed no significant differences $(F(2,22)=1.217, p=$

0.315 , Figure 13).

Table 7. Means and Standard Deviations (SD) for the average vessel length $(\mu \mathrm{m})$ per ovary, third, fifth and seventh sections averaged per treatment group. Each mean represents an average of the means for each ovary $(n=25)$ per treatment. Saline $(n=7)$, meloxicam $(n=9)$, buprenorphine $(n=9)$. Single asterisks $\left[^{*}\right]$ represent significance $p=$ 0.01-0.05.

\begin{tabular}{|c|c|c|c|c|c|c|c|c|}
\hline \multirow[t]{2}{*}{ Treatment } & \multicolumn{2}{|c|}{$\begin{array}{l}\text { Average Vessel } \\
\text { Length }(\mu \mathrm{m}) \text { per } \\
\text { Ovary }\end{array}$} & \multicolumn{2}{|c|}{$\begin{array}{l}\text { Average Vessel } \\
\text { Length }(\mu \mathrm{m}) \text { per } \\
\text { Third Section }\end{array}$} & \multicolumn{2}{|c|}{$\begin{array}{l}\text { Average Vessel } \\
\text { Length }(\mu \mathrm{m}) \text { per } \\
\text { Fifth Section }\end{array}$} & \multicolumn{2}{|c|}{$\begin{array}{l}\text { Average Vessel } \\
\text { Length }(\mu \mathrm{m}) \text { per } \\
\text { Seventh Section }\end{array}$} \\
\hline & Mean & SD & Mean & SD & Mean & SD & Mean & SD \\
\hline Saline & 1.973 & 0.3004 & 2.101 & 1.117 & $2.1236^{*}$ & 0.1936 & 1.925 & 0.4923 \\
\hline Meloxicam & 1.752 & 0.5165 & 1.833 & 0.5511 & $3.4254^{*}$ & 1.1154 & 1.756 & 0.6102 \\
\hline Buprenorphine & 2.095 & 0.5282 & 2.362 & 0.6328 & $1.9908^{*}$ & 0.5834 & 2.063 & 0.6889 \\
\hline
\end{tabular}

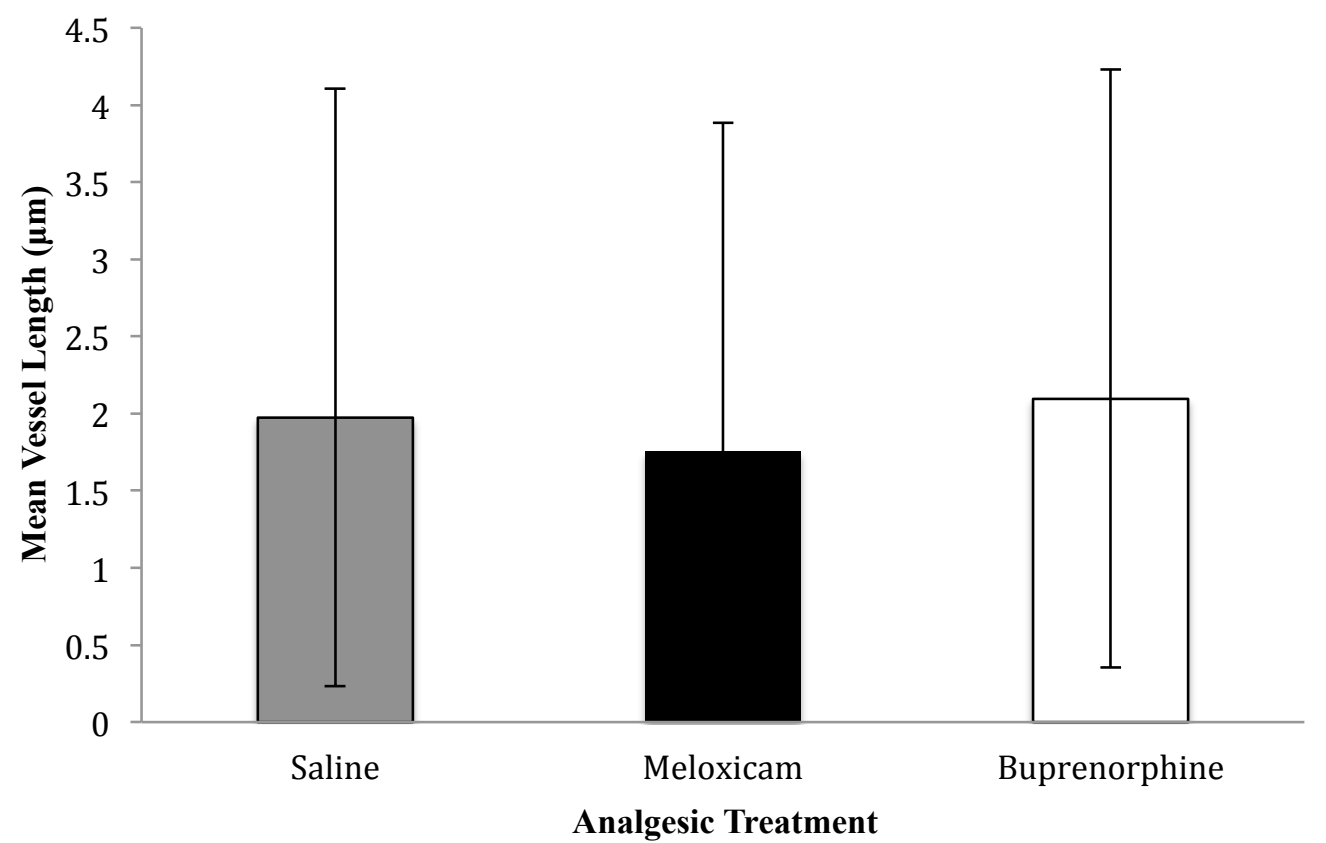


Figure 13. Mean vessel length $(\mu \mathrm{m})$ per ovary per treatment determined by averaging the means from each ovary within each treatment group $(n=25)$. Saline $(M=1.973 \mu \mathrm{m}, n=7$, $S D=0.3004)$, meloxicam $(M=1.752 \mu \mathrm{m}, n=9, S D=0.5165)$, buprenorphine $(M=2.095$ $\mu \mathrm{m}, n=9, S D=0.5282$ ). Error bars represent $95 \%$ confidence intervals.

The mean vessel length $(\mu \mathrm{m})$ per third, fifth, and seventh $18 \mu \mathrm{m}$ sections were averaged and means per treatment group were compared. The average vessel length $(\mu \mathrm{m})$ means and standard deviations for third, fifth, and seventh ovary sections per treatment group are represented in Table 7. A Kruskal-Wallis ANOVA was used for section mean vessel length $(\mu \mathrm{m})$ comparisons since the data violated the assumptions of homogeneity of variance for a One-Way ANOVA. No significant difference in the mean vessel length $(\mu \mathrm{m})$ was shown when each polar third section mean was compared between treatment groups (Kruskal-Wallis ANOVA: $F(2,22)=1.059, p=0.364)$. When comparing the mean vessel length $(\mu \mathrm{m})$ per fifth ovary section from opposite poles per ovary, Kruskal-Wallis ANOVA results indicated a significant difference in between the saline treatment group $(n=7, S D=0.1936)$, the meloxicam treatment group $(n=9, S D=$ 1.1156), and the buprenorphine treatment group $(n=9, S D=1.991)(F(2,22)=8.424, p=$ 0.015). Mean vessel length $(\mu \mathrm{m})$ from each polar seventh section was also compared across treatment groups with no significant results (Kruskal-Wallis ANOVA $F(2,22)=$ $5.143, p=0.277)$.

In addition, all branch lengths $(\mu \mathrm{m})$ per ovary section image were counted and a mean branch length per image was calculated. Each image mean branch length was averaged to find the mean branch length per ovary per treatment group. The average 
branch length $(\mu \mathrm{m})$ means and standard deviations per treatment group are represented in Table 8. The average of branch length $(\mu \mathrm{m})$ per treatment group resulted in an average branch length of $0.431 \mu \mathrm{m}$ in the saline treatment group $(n=7, S D=0.0721), 0.4176 \mu \mathrm{m}$ in the meloxicam treatment group $(n=9, S D=0.1248)$, and $0.4433 \mu \mathrm{m}$ in the buprenorphine treatment group $(n=9, S D=0.0914)$. One-Way ANOVA analysis comparing the average branch lengths between treatment groups did not show any significant differences across the three groups $(F(2,22)=0.147, p=0.864$, Figure 14.)

Table 8. Means and Standard Deviations (SD) for the average branch length $(\mu \mathrm{m})$ per ovary, third, fifth, and seventh sections averaged per treatment group. Each mean represents an average of the means for each ovary $(n=25)$ per treatment. Saline $(n=7)$, meloxicam $(n=9)$, buprenorphine $(n=9)$.

\begin{tabular}{|c|c|c|c|c|c|c|c|c|}
\hline \multirow[t]{2}{*}{ Treatment } & \multicolumn{2}{|c|}{$\begin{array}{l}\text { Average Branch } \\
\text { Length }(\mu \mathrm{m}) \text { per } \\
\text { Ovary }\end{array}$} & \multicolumn{2}{|c|}{$\begin{array}{l}\text { Average Branch } \\
\text { Length }(\mu \mathrm{m}) \text { per } \\
\text { Third Section }\end{array}$} & \multicolumn{2}{|c|}{$\begin{array}{l}\text { Average Branch } \\
\text { Length }(\mu \mathrm{m}) \text { per } \\
\text { Fifth Section }\end{array}$} & \multicolumn{2}{|c|}{$\begin{array}{l}\text { Average Branch } \\
\text { Length }(\mu \mathrm{m}) \text { per } \\
\text { Seventh Section }\end{array}$} \\
\hline & Mean & SD & Mean & SD & Mean & SD & Mean & SD \\
\hline Saline & 0.4310 & 0.0721 & 0.4922 & 0.2006 & 0.4622 & 0.0653 & 0.4405 & 0.1138 \\
\hline Meloxicam & 0.4176 & 0.1248 & 0.4284 & 0.1392 & 0.4198 & 0.2621 & 0.4227 & 0.1456 \\
\hline Buprenorphine & 0.4433 & 0.0914 & 0.4837 & 0.0697 & 0.4732 & 0.1033 & 0.4650 & 0.1069 \\
\hline
\end{tabular}




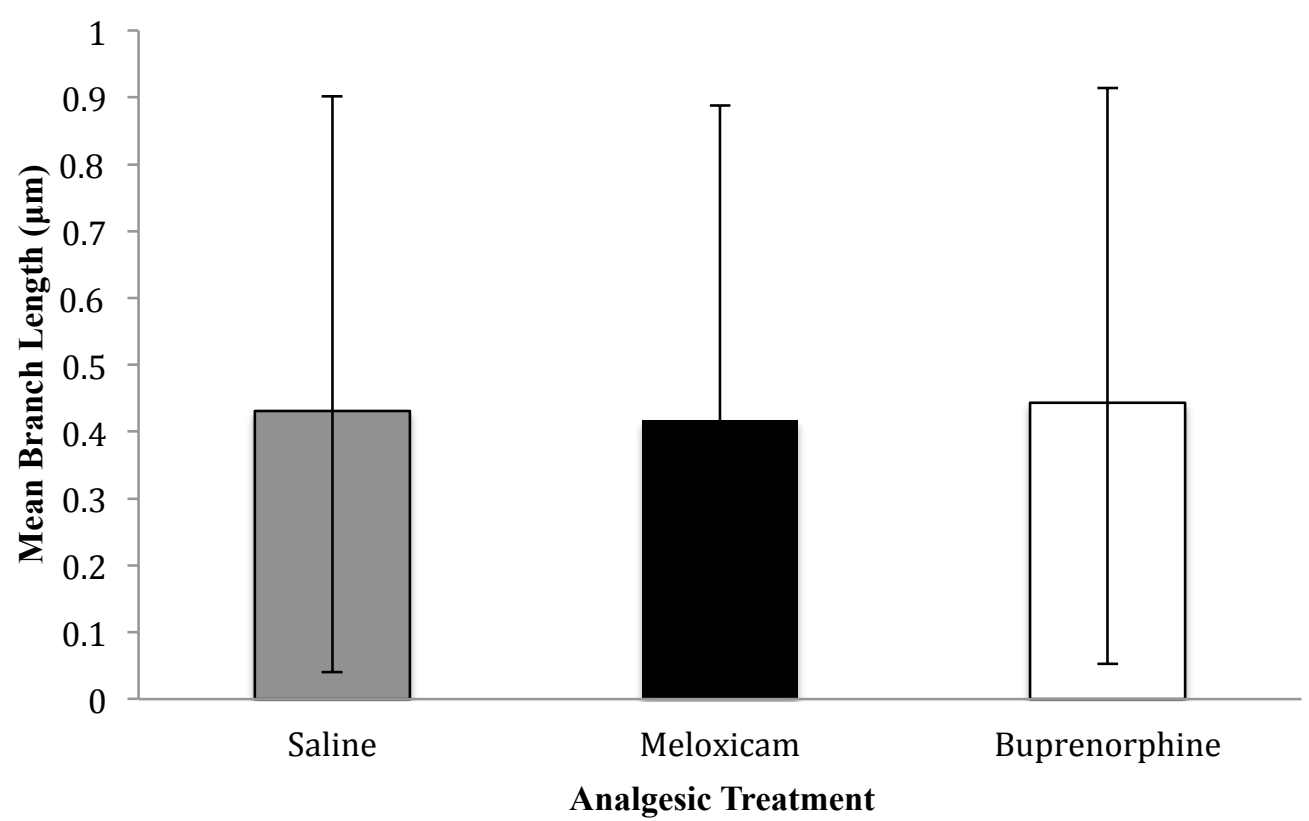

Figure 14. Mean branch length $(\mu \mathrm{m})$ per ovary per treatment determined by averaging the means from each ovary within each treatment group $(n=25)$. Saline $(M=.431 \mu \mathrm{m}$, $n=7, S D=0.0721)$, meloxicam $(M=0.4176 \mu \mathrm{m}, n=9, S D=0.1248)$, buprenorphine ( $M=$ $0.4433 \mu \mathrm{m}, n=9, S D=0.0914)$. Error bars represent $95 \%$ confidence intervals.

Mean branch lengths $(\mu \mathrm{m})$ per third, fifth, and seventh $18 \mu \mathrm{m}$ sections were averaged and means per treatment group were compared using a Kruskal-Wallis ANOVA. The average branch length $(\mu \mathrm{m})$ means and standard deviations per treatment group are represented in Table 8 . No significant difference in the mean vessel length $(\mu \mathrm{m})$ was shown when each polar third section mean was compared between treatment groups (Kruskal-Wallis ANOVA: $F(2,22)=0.872, p=0.183)$. Mean branch length $(\mu \mathrm{m})$ from each polar fifth section was compared across treatment groups with no significant results (Kruskal-Wallis ANOVA: $F(2,22)=5.143, p=0.277)$ and the mean branch length $(\mu \mathrm{m})$ 
comparison of seventh section depths across treatment groups were not significant (Kruskal-Wallis ANOVA: $F(2,22)=9.33, p=0.405)$.

\section{Ovary Area Analysis}

There was no significant difference when the cross-sectional area of the individual third, fifth, and seventh $18 \mu \mathrm{m}$ sections were averaged and compared across treatment groups using One-Way ANOVAs. The average section area $\left(\mathrm{mm}^{2}\right)$ means and standard deviations for third, fifth, and seventh ovary sections per treatment group are represented in Table 9. The average third section cross-sectional area of the saline treatment group was $0.221 \mathrm{~mm}^{2}(n=7, S D=0.131)$, the meloxicam treatment group was $0.219 \mathrm{~mm}^{2}(n=9, S D=0.113)$, and the buprenorphine group was $0.235 \mathrm{~mm}^{2}(n=9, S D=$ 0.162). Results demonstrated no significant difference between third section crosssectional areas when compared between treatment groups $(F(2,22)=0.036, p=0.965)$. The average fifth section cross-sectional area of the saline treatment group was 0.449 $\mathrm{mm}^{2}(n=7, S D=0.165)$, the meloxicam treatment group was $0.599 \mathrm{~mm}^{2}(n=9, S D=$ $0.269)$, and the buprenorphine group was $0.471 \mathrm{~mm}^{2}(n=9, S D=0.206)$. Results demonstrated no significant difference between fifth section cross-sectional areas across treatment groups $(F(2,22)=1.145, p=0.337)$. The average seventh section crosssectional area of the saline treatment group was $0.674 \mathrm{~mm}^{2}(n=7, S D=0.304)$, the meloxicam treatment group was $0.752 \mathrm{~mm}^{2}(n=9, S D=0.411)$, and the buprenorphine group was $0.645 \mathrm{~mm}^{2}(n=9, S D=0.253)$. Results demonstrated no significant difference between seventh section cross-sectional areas across treatment groups $(F(2,22)=1.145$, 
$p=0.337$ ). In addition, the third, fifth, and seventh cross-sectional area means were averaged together to give a mean surface area per ovary. One-Way ANOVA was used to compare ovary area means between the saline treatment group $\left(M=0.448 \mathrm{~mm}^{2}, n=7\right.$, $S D=0.141)$, the meloxicam treatment group $\left(M=0.445 \mathrm{~mm}^{2}, n=9, S D=0.180\right)$, and the buprenorphine treatment group $\left(M=0.529 \mathrm{~mm}^{2}, n=9, S D=0.207\right)$. Results demonstrated no significant difference in mean ovary surface areas across treatment groups (One-Way ANOVA: $F(2,22)=0.608, p=0.553$, Figure 15$)$. The average ovary surface area $\left(\mathrm{mm}^{2}\right)$ means and standard deviations per treatment group are represented in Table 9.

Table 9. Means and Standard Deviations (SD) for the average ovary surface area $\left(\mathrm{mm}^{2}\right)$, average third section area $\left(\mathrm{mm}^{2}\right)$, average fifth section area $\left(\mathrm{mm}^{2}\right)$, and average seventh section area $\left(\mathrm{mm}^{2}\right)$ averaged per treatment group. Each mean represents an average of the means for each ovary $(n=25)$ per treatment. Saline $(n=7)$, meloxicam $(n=9)$, buprenorphine $(n=9)$.

\begin{tabular}{|c|c|c|c|c|c|c|c|c|}
\hline \multirow[t]{2}{*}{ Treatment } & \multicolumn{2}{|c|}{$\begin{array}{c}\text { Average Ovary } \\
\text { Surface Area }\left(\mathrm{mm}^{2}\right)\end{array}$} & \multicolumn{2}{|c|}{$\begin{array}{l}\text { Average Third } \\
\text { Section Area } \\
\left(\mathrm{mm}^{2}\right)\end{array}$} & \multicolumn{2}{|c|}{$\begin{array}{c}\text { Average Fifth } \\
\text { Section Area } \\
\left(\mathrm{mm}^{2}\right)\end{array}$} & \multicolumn{2}{|c|}{$\begin{array}{c}\text { Average Seventh } \\
\text { Section Area } \\
\left(\mathrm{mm}^{2}\right)\end{array}$} \\
\hline & Mean & SD & Mean & SD & Mean & SD & Mean & SD \\
\hline Saline & 0.448 & 0.141 & 0.221 & 0.131 & 0.449 & 0.165 & 0.674 & 0.304 \\
\hline Meloxicam & 0.445 & 0.180 & 0.219 & 0.113 & 0.599 & 0.269 & 0.752 & 0.411 \\
\hline Buprenorphine & 0.529 & 0.207 & 0.235 & 0.162 & 0.471 & 0.206 & 0.645 & 0.253 \\
\hline
\end{tabular}




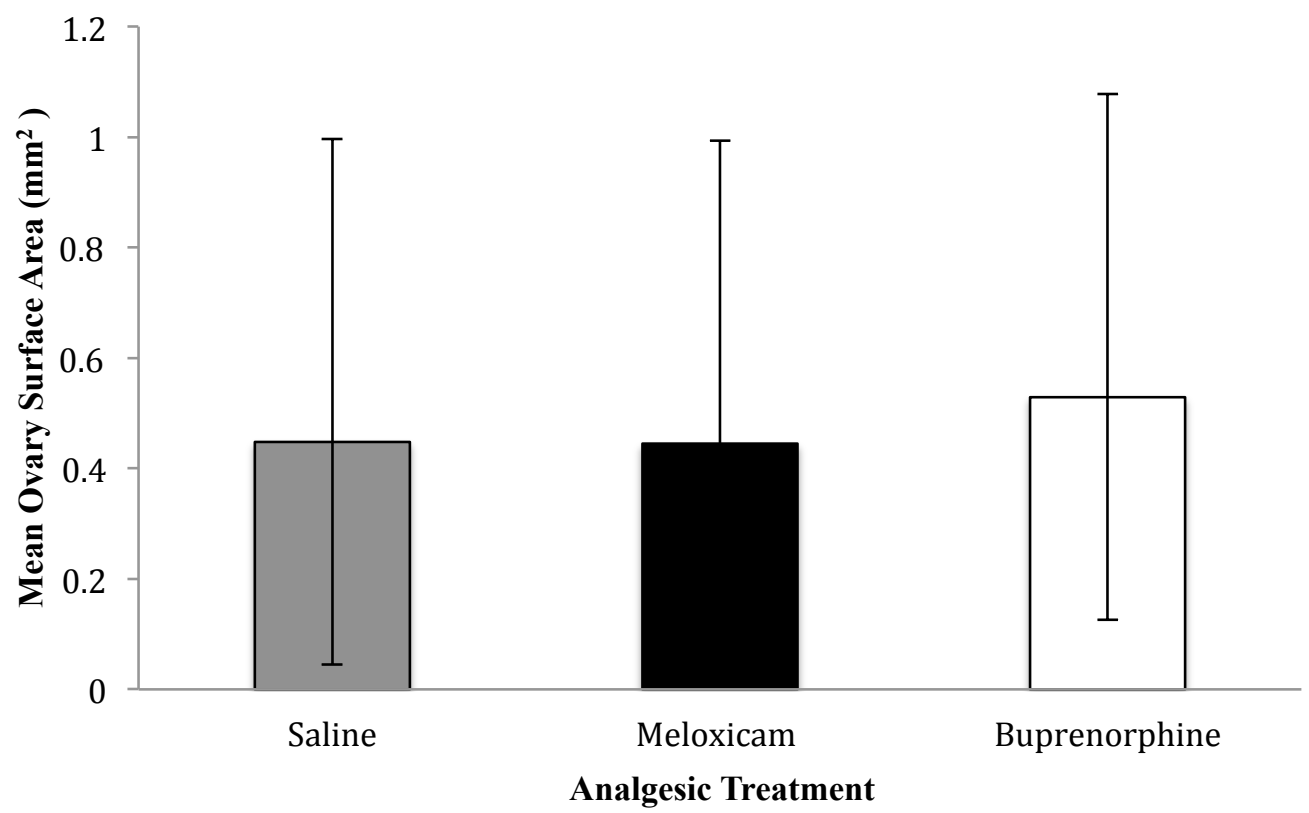

Figure 15. Mean ovary surface area $\left(\mathrm{mm}^{2}\right)$ per ovary per treatment determined by averaging the means from each ovary within each treatment group $(n=25)$. Saline $(M=$ $\left.0.448 \mathrm{~mm}^{2}, n=7, S D=0.141\right)$, meloxicam $\left(M=0.445 \mathrm{~mm}^{2}, n=9, S D=0.180\right)$, buprenorphine $\left(M=0.529 \mathrm{~mm}^{2}, n=9, S D=0.207\right)$. Error bars represent $95 \%$ confidence intervals. 


\section{DISCUSSION}

The results of the present study indicate a difference between the mean total number of vessels per ovary when comparing the saline treatment group to the meloxicam treatment group and between the meloxicam and buprenorphine treatment groups. When comparing the mean total number of vessels, mean total branch number, and mean percent vessel density between each of the treatment groups by ovary section, a significant difference was found between the fifth (approximately $90 \mu \mathrm{m}$ from the ovary surface) sections of the saline and meloxicam treatment groups and the meloxicam and buprenorphine treatment groups. Between the seventh (approximately $126 \mu \mathrm{m}$ from the ovary surface) sections, there was a significant difference in the mean total number of vessels between the meloxicam and buprenorphine treatment groups only. In addition, a significant difference was found when comparing the seventh section total number of branches and total number of junctions per ovary means between the meloxicam treatment group and the buprenorphine treatment group.

When using a murine model to evaluate angiogenesis following ovarian allotransplantation, the use of an analgesic such as meloxicam or buprenorphine is recommended to reduce deleterious post-operative complications caused by pain and inflammation. Our results indicate that meloxicam would be the preferential analgesic for post-ovarian transplantation pain management due to the significant increase in total number of vessels present per ovary and in the total number of vessels present at a depth of 72-90 $\mu \mathrm{m}$ when compared to the saline treatment control group. The significant number of vessels observed with post-operative meloxicam administration suggests that 
an increased amount of angiogenesis occurred after ovary allotransplantation reducing the possibility of altered blood flow to the donor ovary and increasing chances of recovering normal estrus cyclicity while providing adequate analgesia.

This is the first known study to specifically evaluate the effects of analgesics such as buprenorphine and meloxicam on post-operative ovary allotransplantation angiogenesis in aged female mice; our results can be compared to previous research that examined the effects of these drug's parent groups, morphine and COX-2 inhibitors, on angiogenesis in other tissue types. When comparing the results of the present study with the aforementioned type of previous angiogenesis research, the significant findings are markedly different.

While the present study demonstrates no significant difference in the total number of vessels between the buprenorphine treatment group and the saline treatment control group, several studies looking at the effects of opioids on angiogenesis demonstrated significant contradicting increases and decreases in new vessel formation (Lam, 2008; Poonawala, 2005). When comparing research methodologies, it is possible that differences in tissue staining, vessel analysis software, or drug dosage could have caused the variations in results. For example, a study by Lam et al (2008) evaluating the effects of high-dose morphine on angiogenesis in mice showed a significant decrease in angiogenesis and delayed wound healing with the IP administration of a $20 \mathrm{mg} / \mathrm{kg} \cdot$ day morphine dose given for 14 consecutive days compared to the IP administration of a similar dose of saline control for 14 days. The morphine dosing guidelines chosen by Lam et al were based on previous mouse and rat models of morphine dependence and 
demonstrated continual high morphine and morphine metabolite serum concentrations with $20 \mathrm{mg} / \mathrm{kg}$.day dosing. Comparatively, the present study administered the veterinarian recommended dose for adequate post-operative pain relief which consisted of a $0.05 \mathrm{mg} / \mathrm{kg}$ dose of buprenorphine every 12 hours for 48 consecutive hours resulting in a significant decrease in the number of vessels in the saline and buprenorphine treatment groups compared to the meloxicam treatment group. In addition, both the present study and the study by Lam et al used CD31-antibody stained tissue sections for identification of vascularization for subsequent angiogenesis quantification. Although identical CD31-antibody immunohistochemistry (IHC) was used in both studies, Lam et al employed a subcutaneous Matrigel (extracellular environment simulation) mesh to facilitate new microvessel formations instead of organ transplantation as was done presently.

In a contradictory study by Poonawala et al (2005), high-dose morphine administration resulted in a significant increase in angiogenesis and reduction in healing time when administered topically to excisional and incisional wounds. To identify angiogenesis, tissue samples used by Poonawala et al were fluorescently 4'-6'-diamino2-phenylindole (DAPI) stained and vessel quantitation was done using Adobe Photoshop software whereas the present study used a DAB stain and Image $\mathrm{J}$ software for vascularization analysis. Differences in the accuracy of the software algorithms used for vessel identification could account for the decrease in vessel formation in the saline and buprenorphine groups compared to the meloxicam group seen in the present study 
compared to the increase in angiogenesis after topical morphine treatment seen by Poonawala et al.

The present results show a significant increase in angiogenesis in the meloxicam treatment group compared to saline control contradicting previous research that overwhelmingly demonstrated a statistically significant decrease in angiogenesis after treatment with specific COX-2 inhibitors (Howe, 2005; Jones, 1999; Schmassmann, 1998; Xin, 2007). It is possible that differences in drug dosage, type of tissue analyzed, and type of selective COX-2 inhibitor could be responsible for the dissimilarities in research results between studies. For example, Leahy et al (2002) observed a significant decrease in angiogenesis after performing the same IHC CD31-antibody staining/DAB chromogen protocol for vessel identification as was done in the present study. Although the method of vessel identification was similar, Leahy et al used celecoxib in a rat cornea model compared to meloxicam in a murine ovarian tissue transplant model as done presently. The main difference between the selective COX- 2 inhibitor celecoxib and the selective COX-2 inhibitor meloxicam is the addition of a side-chain sulfonamide group. This allows celecoxib's large molecular structure to inhibit enzymatic activity by strongly binding to the central active site on the COX-2 enzyme compared to the top of the active site where meloxicam binds causing full potency $\left(\mathrm{T}_{\max }\right)$ to be reached within 2 hours. In addition, celecoxib is exceedingly bioavailable through oral routes with minimal gastrointestinal effects at high doses (Penning, 1997). Although celecoxib may effectively ameliorate pain in patients with osteoarthritis, rheumatoid arthritis, and spinal fusion, the addition of the sulfonamide side-chain is more likely to cause systemic and 
tissue reactions and increases risk of infarction. When comparing animal models, the rat cornea model is used due to excellent visualization of new vessel formation but angiogenic and mitogenic stimulation via VEGF or bFGF are usually exogenously administered. In the murine ovarian allotransplantation model, hypoxia and inflammation in the transplanted tissue stimulate an endogenous cascade of angiogenic factors such as VEGF, bFGF, $\mathrm{COX}-2$, and $\mathrm{PGE}_{2}$ leading to rapid vessel formation. With many factors acting in response to the ovary transplantation, dissimilarities in observed results between the present study and Leahy et al could emanate from the differences between endogenous versus exogenous angiogenesis stimulation. In a completely in vitro study, Jones et al (1999) used rat aortic endothelial cells and HUVECs in a Matrigel mesh culture with the sulfonamide-containing selective COX-2 inhibitor NS-398 resulting in a statistically significant decrease in microvessel formation compared to the present in vivo study demonstrating an increase in new vessel formation in transplanted murine ovarian tissue. In Jones et al (1999), the Matrigel mesh was used since it provides an environment that mimics a normal in vivo extracellular environment for cultured rat aortic endothelial cells or HUVECs which will subsequently form capillary-like web structures on the mesh by releasing endogenous angiogenesis stimulating growth factors such as VEGF and bFGF. The secretion of these cellular mitogens on the mesh will allow the cultured cells to anastomose, creating a network of endothelial cells that represent normal endogenous angiogenic processes. To observe alterations in angiogenesis using this model, 25 to $100 \mu \mathrm{M}$ of the selective COX- inhibitor NS-398 was added to the cell culture Matrigel mesh and the formation of capillary structures was 
photographed after incubation. When compared to the present study, contradictions in observed results could be from the significantly different tissue model used between studies. Although the Matrigel mesh extracellular environment provides excellent observation of capillary structure formation, the use of ovary transplantation in the present study exposes the transplanted ovarian tissue to hypoxia induced growth factor secretion, inflammatory cytokine cascade, and invading leukocytes which could have both acute and long-term angiogenic effects compared to the swift response of the rat aortic cells and HUVECs on the Matrigel mesh environment. The mechanism of action differences between selective COX-2 inhibitors as well as differences between chosen tissue models could have influenced observed results between the increase in vessel formation in the meloxicam-treated mice in the present study and the decrease in angiogenesis in the NS-398 treated cell culture in Jones et al.

In the normal female murine reproductive cycle, maturation of primordial follicles into Graafian follicles requires the formation of superficial vascular networks that surround the developing follicle in order to deliver necessary nutrients and remove metabolic wastes (Boron \& Boulpaep, 2008). Previous studies observed a significant decrease in angiogenesis after both morphine and meloxicam administration using aortic, intestinal, and umbilical vein cell cultures on Matrigel mesh. Although these cell cultures are fantastic for studying cellular responses to hypoxia and inflammation, their representative tissues are not normally subjected to an upregulated prostaglandin production via COX-2 inflammation response and MAP kinase (MAPK) signaling that is ongoing in normal ovarian folliculogenesis (Kuwano, 2004). COX-2 has been identified 
on outer ovarian surface epithelium and studies have shown that increases in both COX-2 activity and a product of COX-2 prostanoid production, prostaglandin $\mathrm{E}_{2}\left(\mathrm{PGE}_{2}\right)$, can increase angiogenesis in ovarian follicles by stimulating VEGF production in the luteal phase ovary during the menstrual cycle by signaling the MAPK pathway for angiogenesis at the transcription level (Ferrara, 1998; Li, 1994; Stavreus-Evers, 2005; Xin, 2007). In addition to normal physiological COX-2 enzymatic activity, studies have shown that normal folliculogenesis can be considered an inflammatory event with increased production of pro-inflammatory cytokines such as interleukin-1 $\beta$ (IL-1 $\beta$ ), a macrophage derived cytokine, that participates in follicular rupture and stimulates VEGF and interleukin-6 (IL-6) from ovarian stromal cells (Brannstrom, 1993; Lebovic, 2000). The synthesis and expression of IL-1 $\beta$ and its receptor have been identified in human ovarian granulosa cells and increased IL- $1 \beta$ can induce ovulation in rat and rabbit ovaries in vivo (Brannstrom 1993; Peterson, 1993; Takehara, 1994). In the present study, male mice were housed in adjacent cages to ensure proper estrous cycling (Whitten, 1956) while females housed together normally tend to have synchronized estrus cycles. This suggests that the pre-operative levels of IL-1 $\beta, \mathrm{COX}-2, \mathrm{PGE}_{2}, \mathrm{VEGF}$, and MAPK activated mitogenesis could have been at normal physiological levels before ovary allotransplantation and analgesia administration. Due to the normal ongoing activity of these angiogenic factors, veterinary recommended pain management dosages for buprenorphine and meloxicam could fail to inhibit neovascularization and vascular bed remodeling in the newly transplanted ovaries. 
Post-transplantation, the normal inflammatory response could have increased physiological levels of $\mathrm{COX}-2, \mathrm{PGE}_{2}$ production, and IL-1 $\beta$, which in turn stimulated increased VEGF and ultimately MAP kinase signaling in multiple areas such as outer epidermis, abdominal wall musculature, ovarian bursa, donor ovary, and around the foreign suture material. After the post-operative administration of meloxicam, selective COX-2 inhibition should have swiftly decreased the production of $\mathrm{PGE}_{2}$ and subsequent production of VEGF, ubiquitously reducing MAP kinase signaling and the production of secreted angiogenic factors leading to the inhibition of angiogenesis. Contradictorily, our data demonstrated a significant increase in angiogenesis after post-operative treatment with meloxicam, suggesting the pro-angiogenic effects of other inflammatory cytokines such as IL- $1 \beta$ could have amplified the production of VEGF in the absence of COX-2 activity. In previous studies, IL- $1 \beta$ has been shown to rapidly stimulate angiogenesis in mouse corneas in vivo and in cell culture in vitro both independently and by enhancing COX-2 expression resulting in increased $\mathrm{PGE}_{2}$ production, stimulating VEGF and subsequent MAPK vascular endothelial cell mitogenesis (Kirtikara, 2000; Kuwano, 2004). Although some selective COX-2 inhibitors have been shown to inhibit IL-1 $\beta$ activation of VEGF, the possibility of elevated levels of COX-2, $\mathrm{PGE}_{2}, \mathrm{IL}-1 \beta$, and VEGF present in normal estrus cycling in addition to the standard post-operative inflammatory response elevation of the same factors may explain the significant increase in the meloxicam group vessel formation and no significant decrease in the buprenorphine group vessel formation if the veterinarian recommended meloxicam doses were insufficient to inhibit a significant amount of angiogenic signaling (Kuwano, 2004). 
Compared to similar studies looking at selective COX-2 inhibition of angiogenesis, IP administered doses ranged from $20 \mathrm{mg} / \mathrm{kg} \cdot$ day to $5 \mathrm{mg} / \mathrm{kg}$.day while a $5 \mathrm{mg} / \mathrm{kg}$ dose was given twice daily to the animals in the present study. Differences in administration time could also have altered inhibition of angiogenesis since Lam et al (2008) administered morphine regularly for 14 days compared with the 48 hours as done in the present study. Although the increase in cytokine IL-1 $\beta$ and subsequent VEGF stimulation or short duration of standard meloxicam post-operative dosing could explain the difference in results between the meloxicam and buprenorphine treatment groups, they fail to adequately explain the lack of elevated angiogenesis in the saline treatment group. This result could be explained by evaluating the relationship between meloxicam induced COX-2 inhibition and the anterior pituitary secreted gonadotropins follicle-stimulating hormone (FSH) and luteinizing hormone (LH).

In animals with normal, physiologically attached ovaries, sex hormone regulation is controlled through secretion of the neurohormone gonadotropin-releasing hormone (GnRH) by the hypothalamus. The secreted GnRH travels through the hypophyseal portal system and stimulates the gonadotrophs within the anterior pituitary gland to secrete FSH and LH into peripheral circulation. Anterior pituitary released LH binds to thecal cells in the ovary, stimulating the production of androgens. In granulosa cells, FSH binds and stimulates the estrogen synthetase conversion of androgens into estrogens during FSH-stimulated folliculogenesis. Increased estrogens released into circulation from the maturing ovarian follicle inhibit additional secretion of GnRH through the longloop feedback mechanism of sex hormone regulation until estrogen levels begin to 
decline. During the murine ovary allotransplantation, the new ovary is placed into the host bursa without reattaching either the blood vessels of the inner mesothelium lining or the ovarian artery and ovarian vein at the hilum. Removal of direct vascular communication with the ovary causes a reduction in delivered LH and FSH resulting in a decrease in the systemic circulating steroid hormone estrogen supplied by the ovary during the murine estrous cycle. In response to diminishing circulating estrogen, $\mathrm{GnRH}$ stimulates the secretion of FSH and LH due to the removal of estrogen's negative feedback. In a previous study by Dissen et al (1994), rat ovaries were removed and autotransplanted adjacent to a jugular vein. Within 48 hours, post-operative increases in both FSH and LH could be detected in response to decreasing estrogen levels. In addition, ovarian VEGF and transforming growth factor $\beta$ (TGF- $\beta$ ) mRNA levels increased within 24 hours. Using FSH and LH antagonists, Dissen et al determined that angiogenic factors VEGF and TGF- $\beta$ are upregulated when gonadotropin secretion is elevated. In a separate study by Davis et al (1999), mice with a COX-2 null (-/-) mutation exhibited higher levels of pituitary FSH and LH when compared to wildtype $(\mathrm{COX}-2+/+)$ mice. When comparing Davis et al and Dissen et al with the present study, the increased number of vessels seen in the meloxicam treatment group may be due to elevated levels of gonadotropins associated with both COX-2 enzymatic activity inhibition and a post-operative ovary transplantation gonadotropin surge.

While this is the first known study to look at the effects of post-operative meloxicam administration on vessel formation after ovary allotransplantation, our results indicating an increase in angiogenesis could also be a response to the aged state of the 
recipient mice, restrictive or regulating effects of the murine ovarian bursa, or a possible cooperative response due to an unknown relationship between the ovary and meloxicam. Other factors that could have affected results include the smaller number of saline treatment control animals $(n=7)$ as compared to the buprenorphine treatment group $(n=$ $9)$ and the meloxicam treatment group $(n=9)$. This inequality could have accounted for the lack of significant decrease in angiogenesis between saline and buprenorphine groups and the significant increase in angiogenesis between the meloxicam and the saline control group demonstrated in similar research (Balasubramanian, 2001; Lam, 2008; Roy, 2003). The large calculated confidence intervals also indicate a relatively small number of animals per treatment group which could have influenced the results due to an increase in Type 1 error. Counting older vessels as new vessel formations or counting the same vessel twice could also have influenced the total number of vessels when comparing the meloxicam and buprenorphine treatment groups.

Several limitations could have impacted the results of the present study. When looking at surface vascularization of a semi-transparent, round, three-dimensional tissue specimen such as an ovary, it can be difficult to differentiate between true surface vessel formations and previously established vessels relatively close to the surface. For the present study, the ovaries were sectioned to evaluate surface vascularization by analyzing vessel formations from third, fifth, and seventh polar representative layers, but future studies might benefit from in vivo tissue perfusion of fluorescent or colored dye immediately before sacrifice to evaluate all superficial vessel formations and to visually confirm true surface vascularization from established vessel formations directly below 
the surface that could falsely increase the number of counted vessels. In the present study, an effort was made to correctly calculate the total number of vessels and all vessel components within each third, fifth, and seventh polar opposite ovary sections and computer software was employed to remove counting bias and process each image swiftly and uniformly as was done in previous studies (Chantrain, 2003; Doukas, 2006; Seaman, 2011; Vickerman, 2009). In studies that did not use computer automated vessel analysis but also used CD31 cell surface antigen to identify tissue microvessels, other methods of vessel counting were utilized such as the Chalkley count or taking random "hotspot" counts (Fox, 1995; Vermeulen, 1996; Vermeulen, 2002). Future studies could benefit from a computer automated count and a simultaneous Chalkley count comparison to confirm microvessel density analysis or a separate comparison using a different software program such as MetaMorph, VESGEN 2D, or Adobe Photoshop. Additionally, several studies that used CD31 antibody to identify vascular endothelial cells used a hematoxylin or methyl green counterstain which could be helpful to confirm identification of CD31-antibody identified, DAB-stained vascular endothelial cells and should be considered for use in future studies looking at endothelial cell identification (Jennings, 2012; Li, 2005).

The effects of analgesia on post-operative transplantation angiogenesis can benefit from further evaluation and separate corroborative studies. The results of the present study can be verified by performing comparable investigations that employ alternate vessel quantification methods and novel superficial vessel identification techniques while utilizing larger sample sizes. Successful transplantation relies on 
adequate angiogenesis for swift perfusion of new tissues while sufficient post-operative pain management can benefit the animal and research results by limiting discomfort. While the current study supports the use of meloxicam as a potent analgesic that would not negatively affect transplant success, further research and separate independent verification is warranted before adding meloxicam to future murine ovarian allotransplantation protocols. 


\section{References Cited}

Acland, R. D., \& Trachtenberg, L. (1977). The histopathology of small arteries following experimental microvascular anastomosis. Plastic and Reconstructive Surgery, 60(6), 868-875.

Albelda, S. M., Muller, W. A., Buck, C. A., \& Newman, P. J. (1991). Molecular and cellular properties of PECAM-1 (endoCAM/CD31): a novel vascular cell-cell adhesion molecule. The Journal of Cell Biology, 114(5), 1059-1068.

Amaya, E., Musci, T. J., \& Kirschner, M. W. (1991). Expression of a dominant negative mutant of the FGF receptor disrupts mesoderm formation in Xenopus embryos. Cell, 66(2), 257-270.

Amzoiu, D. C., Amzoiu, E., \& Popescu, F. (2010). Oxicams structural characteristics determined by molecular modeling methods. Substance, 36(2), 101-105.

Arthur T. Hertig papers, 1918-1986 (inclusive), 1922-1976 (bulk). H MS c11. Harvard Medical Library, Francis A. Countway Library of Medicine, Boston, Mass.

Asahara, T., Murohara, T., Sullivan, A., Silver, M., van der Zee, R., Li, T., ... \& Isner, J. M. (1997). Isolation of putative progenitor endothelial cells for angiogenesis. Science, 275(5302), 964-966.

Asahara, T., Takahashi, T., Masuda, H., Kalka, C., Chen, D., Iwaguro, H., ... \& Isner, J. M. (1999). VEGF contributes to postnatal neovascularization by mobilizing bone marrow-derived endothelial progenitor cells. The EMBO Journal, 18(14), 39643972 .

Asahara, T., Chen, D., Takahashi, T., Fujikawa, K., Kearney, M., Magner, M., ... \& Isner, J. M. (1998). Tie2 receptor ligands, angiopoietin-1 and angiopoietin-2, modulate VEGF-induced postnatal neovascularization. Circulation Research, 83(3), 233240.

Asahara, T., Masuda, H., Takahashi, T., Kalka, C., Pastore, C., Silver, M., ... \& Isner, J. M. (1999). Bone marrow origin of endothelial progenitor cells responsible for postnatal vasculogenesis in physiological and pathological neovascularization. Circulation Research, 85(3), 221-228.

Ausprunk, D. H., \& Folkman, J. (1977). Migration and proliferation of endothelial cells in preformed and newly formed blood vessels during tumor angiogenesis. Microvascular Research, 14(1), 53-65. 
Balasubramanian, S., Ramakrishnan, S., Charboneau, R., Wang, J., Barke, R. A., \& Roy, S. (2001). Morphine sulfate inhibits hypoxia-induced vascular endothelial growth factor expression in endothelial cells and cardiac myocytes. Journal of Molecular and Cellular Cardiology, 33(12), 2179-2187.

Bär, T., \& Wolff, J. R. (1972). The formation of capillary basement membranes during internal vascularization of the rat's cerebral cortex. Zeitschrift für Zellforschung und Mikroskopische Anatomie, 133(2), 231-248.

Bassett, D. L. (1943). The changes in the vascular pattern of the ovary of the albino rat during the estrous cycle. American Journal of Anatomy, 73(2), 251-291.

Baxter, T. J., Henderson, P. N., \& Bennett, R. C. (1972). The histopathology of small vessels following microvascular repair. British Journal of Surgery, 59(8), 617-622.

Beilin, B., Bessler, H., Mayburd, E., Smirnov, G., Dekel, A., Yardeni, I., \& Shavit, Y. (2003). Effects of preemptive analgesia on pain and cytokine production in the postoperative period. Anesthesiology, 98(1), 151-155.

Bentley, K. W., \& Hardy, D. G. (1967). Novel analgesics and molecular rearrangements in the morphine-thebaine group. III. Alcohols of the 6, 14-endoethenotetrahydrooripavine series and derived analogs of N-allylnormorphine andnorcodeine. Journal of the American Chemical Society, 89(13), 3281-3292.

Berra, E., Milanini, J., Richard, D. E., Le Gall, M., Viñals, F., Gothié, E., ... \& Pouysségur, J. (2000). Signaling angiogenesis via p42/p44 MAP kinase and hypoxia. Biochemical Pharmacology, 60(8), 1171-1178.

Boas, R. A., \& Villiger, J. W. (1985). Clinical actions of fentanyl and buprenorphine the significance of receptor binding. British Journal of Anaesthesia, 57(2), 192-196.

Boenisch, T. (Ed.). (2001). Immunohistochemical staining methods education guide. $\left(3^{\text {rd }}\right.$ ed.). Carpinteria, CA; Dako Corp.

Boron, W. F., \& Boulpaep, E. L. (Eds.) (2009) Medical Physiology: a cellular and molecular approach. Philadelphia, PA: Saunders/Elsevier.

Brännström, M., Wang, L., \& Norman, R.J. (1993). Effects of cytokines on prostaglandin production and steroidogenesis of incubated preovulatory follicles of the rat. Biology of Reproduction, 48(1), 165-171. 
Breier, G., Clauss, M., \& Risau, W. (1995). Coordinate expression of vascular endothelial growth factor receptor-1 (flt-1) and its ligand suggests a paracrine regulation of murine vascular development. Developmental Dynamics, 204(3), 228-239.

Brewster, D., Humphrey, M. J., \& Mcleavy, M. A. (1981). The systemic bioavailability of buprenorphine by various routes of administration. Journal of Pharmacy and Pharmacology, 33(1), 500-506.

Brodie, T. G. (1903). The perfusion of surviving organs. The Journal of Physiology, 29(3), 266-275.

Brooks, J. R., \& Gifford, G. H. (1959). Pancreatic homotransplantation. Plastic and Reconstructive Surgery, 23(1), 100-102.

Bullejos, M., Bowles, J., \& Koopman, P. (2002). Extensive vascularization of developing mouse ovaries revealed by caveolin-1 expression. Developmental Dynamics, 225(1), 95-99.

Bullingham, R. E., McQuay, H. J., Moore, A., \& Bennett, M. R. (1980). Buprenorphine kinetics. Clinical Pharmacology \& Therapeutics, 28(5), 667-672.

Busch, U., \& Engelhardt, G. (1989a). Distribution of [14C] meloxicam in joints of rats with adjuvant arthritis. Drugs under Experimental and Clinical Research, 16(2), 49-52.

Busch, U., Schmid, J., Heinzel, G., Schmaus, H., Baierl, J., Huber, C., \& Roth, W. (1998b). Pharmacokinetics of meloxicam in animals and the relevance to humans. Drug Metabolism and Disposition, 26(6), 576-584.

Cargill, S. L., Carey, J. R., Müller, H. G., \& Anderson, G. (2003). Age of ovary determines remaining life expectancy in old ovariectomized mice. Aging Cell, 2(3), 185-190.

Carrel, A., \& Guthrie, C. C. (1905). The transplantation of veins and organs. American Journal of Medicine, 10:1101-1102.

Carrel A. (1907). The surgery of blood vessels. Johns Hopkins Hospital Bulletin, 18(190), $18-28$.

Chantrain, C. F., DeClerck, Y. A., Groshen, S., \& McNamara, G. (2003). Computerized quantification of tissue vascularization using high-resolution slide scanning of whole tumor sections. Journal of Histochemistry and Cytochemistry, 51(2), 151158 . 
Chesne, C., Guyomard, C., Guillouzo, A., Schmid, J., Ludwig, E., \& Sauter, T. (1998). Metabolism of meloxicam in human liver involves cytochromes P4502C9 and 3A4. Xenobiotica, 28(1), 1-13.

Choi, K., Kennedy, M., Kazarov, A., Papadimitriou, J. C., \& Keller, G. (1998). A common precursor for hematopoietic and endothelial cells. Development, 125(4), $725-732$.

Connolly, D. T., Heuvelman, D. M., Nelson, R., Olander, J. V., Eppley, B. L., Delfino, J. J., ... \& Feder, J. (1989). Tumor vascular permeability factor stimulates endothelial cell growth and angiogenesis. Journal of Clinical Investigation, 84(5), 1470 .

Coumoul, X., \& Deng, C. X. (2003). Roles of FGF receptors in mammalian development and congenital diseases. Birth Defects Research Part C: Embryo Today, 69(4), 286-304.

Coveney, D., Cool, J., Oliver, T., \& Capel, B. (2008). Four-dimensional analysis of vascularization during primary development of an organ, the gonad. Proceedings of the National Academy of Sciences, 105(20), 7212-7217.

Cowan, A., Lewis, J. W., \& Macfarlane, I. R. (1977). Agonist and antagonist properties of buprenorphine, a new antinociceptive agent. British Journal of Pharmacology, 60(4), 537-545.

Cuevas, P., Gutierrez-Diaz, J. A., Reimers, D., Dujovny, M., Diaz, F. G., \& Ausman, J. I. (1984). Pericyte endothelial gap junctions in human cerebral capillaries. Anatomy and Embryology, 170(2), 155-159.

Davis, B. J., Lennard, D. E., Lee, C. A., Tiano, H. F., Morham, S. G., Wetsel, W. C., \& Langenbach, R. (1999). Anovulation in cyclooxygenase-2-deficient mice is restored by prostaglandin E2 and interleukin-1 $\beta$. Endocrinology, 140(6), 26852695.

DeLisser, H. M., Christofidou-Solomidou, M., Strieter, R. M., Burdick, M. D., Robinson, C. S., Wexler, R. S., ... \& Albelda, S. M. (1997). Involvement of endothelial PECAM-1/CD31 in angiogenesis. The American Journal of Pathology, 151(3), 671-677.

Dissen, G. A., Lara, H. E., Fahrenbach, W. H., Costa, M. E., \& Ojeda, S. R. (1994). Immature rat ovaries become revascularized rapidly after autotransplantation and show a gonadotropin-dependent increase in angiogenic factor gene expression. Endocrinology, 134(3), 1146-1154. 
Doetschman, T. C., Eistetter, H., Katz, M., Schmidt, W., \& Kemler, R. (1985). The in vitro development of blastocyst-derived embryonic stem cell lines: formation of visceral yolk sac, blood islands and myocardium. Journal of Embryology and Experimental Morphology, 87(1), 27-45.

Doukas, C. N., Maglogiannis, I., Chatziioannou, A., \& Papapetropoulos, A. (2006). Automated angiogenesis quantification through advanced image processing techniques. Engineering in Medicine and Biology Society, 1(1), 2345-2348.

Doyle, L. K. (2009). Role of vascular endothelial growth factor (VEGF) in granulosa cell function: Involvement of heterotrimeric G-protein signalling pathways (Doctoral dissertation). Fitzwilliam College; Univ of Cambridge.

Drake, C. J., \& Little, C. D. (1995). Exogenous vascular endothelial growth factor induces malformed and hyperfused vessels during embryonic neovascularization. Proceedings of the National Academy of Sciences, 92(17), 7657-7661.

Drake, C. J., \& Fleming, P. A. (2000). Vasculogenesis in the day 6.5 to 9.5 mouse embryo. Blood, 95(5), 1671-1679.

Drug Enforcement Administration (DEA), Department of Justice. (2002). Schedules of controlled substances: rescheduling of buprenorphine from schedule $\mathrm{V}$ to schedule III. Final rule. Federal Register, 67(194), 62354-62370.

Efstathiou, J. A., Sampson, D. A., Levine, Z., Rohan, R. M., Zurakowski, D., Folkman, J., ... \& Rupnick, M. A. (2005). Nonsteroidal anti-inflammatory drugs differentially suppress endometriosis in a murine model. Fertility and Sterility, 83(1), 171-181.

Engelhardt, G., Homma, D., Schlegel, K., Utzmann, R., \& Schnitzler, C. (1995). Antiinflammatory, analgesic, antipyretic and related properties of meloxicam, a new non-steroidal anti-inflammatory agent with favourable gastrointestinal tolerance. Inflammation Research, 44(10), 423-433.

Engelhardt, G., Bögel, R., Schnitzler, C. H. R., \& Utzmann, R. (1996). Meloxicam: Influence on arachidonic acid metabolism: Part II. In vivo findings. Biochemical Pharmacology, 51(1), 29-38.

Ferguson, S. S., Downey, W. E., Colapietro, A. M., Barak, L. S., Ménard, L., \& Caron, M. G. (1996). Role of $\beta$-arrestin in mediating agonist-promoted $\mathrm{G}$ protein-coupled receptor internalization. Science, 271(5247), 363-366. 
Fernandez, H. A., Kallenbach, K., Seghezzi, G., Grossi, E., Colvin, S., Schneider, R., ... \& Galloway, A. (1999). Inhibition of endothelial cell migration by gene transfer of tissue inhibitor of metalloproteinases-1. Journal of Surgical Research, 82(2), 156-162.

Ferrara, N., \& Henzel, W. J. (1989). Pituitary follicular cells secrete a novel heparinbinding growth factor specific for vascular endothelial cells. Biochemical and Biophysical Research Communications, 161(2), 851-858.

Ferrara, N., Carver-Moore, K., Chen, H., Dowd, M., \& Lu, L. (1996). Heterozygous embryonic lethality induced by targeted inactivation of the VEGF gene. Nature, $380(6573), 439-42$.

Ferrara, N., Chen, H., Davis-Smyth, T., \& Gerber, H. P. (1998). Vascular endothelial growth factor is essential for corpus luteum angiogenesis. Nature Medicine, 4(3), 336-340.

Fisher, C., Gilbertson-Beadling, S., Powers, E. A., Petzold, G., Poorman, R., \& Mitchell, M. A. (1994). Interstitial collagenase is required for angiogenesis in vitro. Developmental Biology, 162(2), 499-510.

Flamme, I., \& Risau, W. (1992). Induction of vasculogenesis and hematopoiesis in vitro. Development, 116(2), 435-439.

Florey, H. W., \& Carleton, H. M. (1926). Rouget cells and their function. Proceedings of the Royal Society of London. Series B, Containing Papers of a Biological Character, 23-31.

Folkman, J., Klagsbrun, M., Sasse, J., Wadzinski, M., Ingber, D., \& Vlodavsky, I. (1988). A heparin-binding angiogenic protein--basic fibroblast growth factor--is stored within basement membrane. The American Journal of Pathology, 130(2), 393-400.

Form, D. M., Pratt, B. M., \& Madri, J. A. (1986). Endothelial cell proliferation during angiogenesis. In vitro modulation by basement membrane components. Laboratory Investigation; a Journal of Technical Methods and Pathology, 55(5), 521-530.

Fox, S. B., Leek, R. D., Weekes, M. P., Whitehouse, R. M., Gatter, K. C., \& Harris, A. L. (1995). Quantitation and prognostic value of breast cancer angiogenesis: comparison of microvessel density, Chalkley count, and computer image analysis. The Journal of Pathology, 177(3), 275-283. 
Fuller, J. L., \& Sjursen, F. H. (1967). Audiogenic seizures in eleven mouse strains. Journal of Heredity. 58(3), 135-140.

Gal, T. J. (1989). Naloxone reversal of buprenorphine-induced respiratory depression. Clinical Pharmacology and Therapeutics, 45(1), 66-71.

Giatromanolaki, A., Koukourakis, M. I., Theodossiou, D., Barbatis, K., O'Byrne, K., Harris, A. L., \& Gatter, K. C. (1997). Comparative evaluation of angiogenesis assessment with anti-factor-VIII and anti-CD31 immunostaining in non-small cell lung cancer. Clinical Cancer Research, 3(12), 2485-2492.

Glaser, R., Kiecolt-Glaser, J. K., Marucha, P. T., MacCallum, R. C., Laskowski, B. F., \& Malarkey, W. B. (1999). Stress-related changes in proinflammatory cytokine production in wounds. Archives of General Psychiatry, 56(5), 450-456.

Gosden, R. G., Baird, D. T., Wade, J. C., \& Webb, R. (1994). Restoration of fertility to oophorectomized sheep by ovarian autografts stored at-196 C. Human Reproduction, 9(4), 597-603.

Gospodarowicz, D. (1974). Localisation of a fibroblast growth factor and its effect alone and with hydrocortisone on 3T3 cell growth. Nature, 249, 123-127.

Gupta, K., Kshirsagar, S., Chang, L., Schwartz, R., Law, P. Y., Yee, D., \& Hebbel, R. P. (2002). Morphine stimulates angiogenesis by activating proangiogenic and survival-promoting signaling and promotes breast tumor growth. Cancer Research, 62(15), 4491-4498.

Healy, A. M., \& Herman, I. M. (1992). Density-dependent accumulation of basic fibroblast growth factor in the subendothelial matrix. European Journal of Cell Biology, 59(1), 56-67.

Hirakow, R., \& Hiruma, T. (1981). Scanning electron microscopic study on the development of primitive blood vessels in chick embryos at the early somite-stage. Anatomy and Embryology, 163(3), 299-306.

Hiraoka, N., Allen, E., Apel, I. J., Gyetko, M. R., \& Weiss, S. J. (1998). Matrix metalloproteinases regulate neovascularization by acting as pericellular fibrinolysins. Cell, 95(3), 365-377.

Howe, L. R., Chang, S. H., Tolle, K. C., Dillon, R., Young, L. J., Cardiff, R. D., ... \& Dannenberg, A. J. (2005). HER2/neu-induced mammary tumorigenesis and angiogenesis are reduced in cyclooxygenase-2 knockout mice. Cancer Research, 65(21), 10113-10119. 
Huang, P., Kehner, G. B., Cowan, A., \& Liu-Chen, L. Y. (2001). Comparison of pharmacological activities of buprenorphine and norbuprenorphine: norbuprenorphine is a potent opioid agonist. Journal of Pharmacology and Experimental Therapeutics, 297(2), 688-695.

Hübner, G., Brauchle, M., Smola, H., Madlener, M., Fässler, R., \& Werner, S. (1996). Differential regulation of pro-inflammatory cytokines during wound healing in normal and glucocorticoid-treated mice. Cytokine, 8(7), 548-556.

Iribarne, C., Picart, D., Dréano, Y., Bail, J. P., \& Berthou, F. (1997). Involvement of cytochrome P450 3A4 in N-dealkylation of buprenorphine in human liver microsomes. Life Sciences, 60(22), 1953-1964.

Jakeman, L. B., Winer, J., Bennett, G. L., Altar, C. A., \& Ferrara, N. (1992). Binding sites for vascular endothelial growth factor are localized on endothelial cells in adult rat tissues. Journal of Clinical Investigation, 89(1), 244-253.

Jennings, R. N., Miller, M. A., \& Ramos-Vara, J. A. (2012). Comparison of CD34, CD31, and Factor VIII-related antigen immunohistochemical expression in feline vascular neoplasms and CD34 expression in feline nonvascular neoplasms. Veterinary Pathology, 49(3), 532-537.

Jin, H., Aiyer, A., Su, J., Borgstrom, P., Stupack, D., Friedlander, M., \& Varner, J. (2006). A homing mechanism for bone marrow-derived progenitor cell recruitment to the neovasculature. Journal of Clinical Investigation, 116(3), 652-662.

Jones, M. K., Wang, H., Peskar, B. M., Levin, E., Itani, R. M., Sarfeh, I. J., \& Tarnawski, A. S. (1999). Inhibition of angiogenesis by nonsteroidal anti-inflammatory drugs: insight into mechanisms and implications for cancer growth and ulcer healing. Nature Medicine, 5(12), 1418-1423.

Kamat, B. R., Brown, L. F., Manseau, E. J., Senger, D. R., \& Dvorak, H. F. (1995). Expression of vascular permeability factor/vascular endothelial growth factor by human granulosa and theca lutein cells. Role in corpus luteum development. The American Journal of Pathology, 146(1), 157-165.

Kendall, R. L., Wang, G., \& Thomas, K. A. (1996). Identification of a natural soluble form of the vascular endothelial growth factor receptor, FLT-1, and its heterodimerization with KDR. Biochemical and Biophysical Research Communications, 226(2), 324-328. 
Kirtikara, K., Raghow, R., Laulederkind, S. J., Goorha, S., Kanekura, T., \& Ballou, L. R. (2000). Transcriptional regulation of cyclooxygenase-2 in the human microvascular endothelial cell line, HMEC-1: control by the combinatorial actions of AP2, NF-IL-6 and CRE elements. Molecular and Cellular Biochemistry, 203(1-2), 41-51.

Kobler, J. (1960). The reluctant surgeon: a biography of John Hunter. Garden City, NY: Doubleday \& Company, Inc.

Kohn, D. F., Martin, T. E., Foley, P. L., Morris, T. H., Swindle, M. M., Vogler, G. A., \& Wixson, S. K. (2007). Guidelines for the assessment and management of pain in rodents and rabbits. Journal of the American Association for Laboratory Animal Science, 46(2), 97-108.

Koos, R. D., Olson, C. E., \& Ma, C. (1991). Hypoxia stimulates expression of the gene for vascular endothelial growth factor (VEGF), a putative angiogenic factor, by granulosa cells of the ovarian follicle, a site of angiogenesis. The Journal of Cell Biology, 15(3), 2444-2447.

Korff, T., Kimmina, S., Martiny-Baron, G., \& Augustin, H. G. (2001). Blood vessel maturation in a 3-dimensional spheroidal coculture model: direct contact with smooth muscle cells regulates endothelial cell quiescence and abrogates VEGF responsiveness. The FASEB Journal, 15(2), 447-457.

Kubota, Y., Kleinman, H. K., Martin, G. R., \& Lawley, T. J. (1988). Role of laminin and basement membrane in the morphological differentiation of human endothelial cells into capillary-like structures. The Journal of Cell Biology, 107(4), 15891598 .

Kuhlman, J. J., Lalani, S., Magluilo, J., Levine, B., Darwin, W. D., Johnson, R. E., \& Cone, E. J. (1996). Human pharmacokinetics of intravenous, sublingual, and buccal buprenorphine. Journal of Analytical Toxicology, 20(6), 369-378.

Kuwano, T., Nakao, S., Yamamoto, H., Tsuneyoshi, M., Yamamoto, T., Kuwano, M., \& Ono, M. (2004). Cyclooxygenase 2 is a key enzyme for inflammatory cytokineinduced angiogenesis. The FASEB Journal, 18(2), 300-310.

Ladoux, A., \& Frelin, C. (1993). Hypoxia is a strong inducer of vascular endothelial growth factor mRNA expression in the heart. Biochemical and Biophysical Research Communications, 195(2), 1005-1010. 
Lam, C. F., Chang, P. J., Huang, Y. S., Sung, Y. H., Huang, C. C., Lin, M. W., ... \& Tsai, Y. C. (2008). Prolonged use of high-dose morphine impairs angiogenesis and mobilization of endothelial progenitor cells in mice. Anesthesia and Analgesia, 107(2), 686-692.

Leahy, K. M., Ornberg, R. L., Wang, Y., Zweifel, B. S., Koki, A. T., \& Masferrer, J. L. (2002). Cyclooxygenase-2 inhibition by celecoxib reduces proliferation and induces apoptosis in angiogenic endothelial cells in vivo. Cancer Research, 62(3), 625-631.

Lebovic, D. I., Bentzien, F., Chao, V. A., Garrett, E. N., Meng, Y. G., \& Taylor, R. N. (2000). Induction of an angiogenic phenotype in endometriotic stromal cell cultures by interleukin-1ß. Molecular Human Reproduction, 6(3), 269-275.

Lee, P. L., Johnson, D. E., Cousens, L. S., Fried, V. A., \& Williams, L. T. (1989). Purification and complementary DNA cloning of a receptor for basic fibroblast growth factor. Science, 245(4913), 57-60.

Leung, D. W., Cachianes, G., Kuang, W. J., Goeddel, D. V., \& Ferrara, N. (1989). Vascular endothelial growth factor is a secreted angiogenic mitogen. Science, 246(4935), 1306-1309.

Li, X. F., Gregory, J., \& Ahmed, A. (1994). Immunolocalisation of vascular endothelial growth factor in human endometrium. Growth Factors, 11(4), 277-282.

Li, Z. J., Wang, Z. Z., Zheng, Y. Z., Xu, B., Yang, R. C., Scadden, D. T., \& Han, Z. C. (2005).Kinetic expression of platelet endothelial cell adhesion molecule (PECAM-1/CD31) during embryonic stem cell differentiation. Journal of Cellular Biochemistry, 95(3), 559-570.

Löhler, J., Timpl, R., \& Jaenisch, R. (1984). Embryonic lethal mutation in mouse collagen I gene causes rupture of blood vessels and is associated with erythropoietic and mesenchymal cell death. Cell, 38(2), 597-607.

Maisonpierre, P. C., Suri, C., Jones, P. F., Bartunkova, S., Wiegand, S. J., Radziejewski, C., ... \& Yancopoulos, G. D. (1997). Angiopoietin-2, a natural antagonist for Tie2 that disrupts in vivo angiogenesis. Science, 277(5322), 55-60.

Mason, J. B., Cargill, S. L., Anderson, G. B., \& Carey, J. R. (2009). Transplantation of young ovaries to old mice increased life span in transplant recipients. The Journals of Gerontology Series A: Biological Sciences and Medical Sciences, 64(12), 1207-1211. 
Mattioli, M., Barboni, B., Turriani, M., Galeati, G., Zannoni, A., Castellani, G., ... \& Scapolo, P. A. (2001). Follicle activation involves vascular endothelial growth factor production and increased blood vessel extension. Biology of Reproduction, 65(4), 1014-1019.

McGuire, L., Heffner, K., Glaser, R., Needleman, B., Malarkey, W., Dickinson, S., ... \& Kiecolt-Glaser, J. K. (2006). Pain and wound healing in surgical patients. Annals of Behavioral Medicine, 31(2), 165-172.

McKenney, J. K., Weiss, S. W., \& Folpe, A. L. (2001). CD31 expression in intratumoral macrophages: a potential diagnostic pitfall. The American Journal Of Surgical Pathology, 25(9), 1167-1173.

Millauer, B., Wizigmann-Voos, S., Schnürch, H., Martinez, R., Møller, N. P. H., Risau, W., \& Ullrich, A. (1993). High affinity VEGF binding and developmental expression suggest Flk-1 as a major regulator of vasculogenesis and angiogenesis. Cell, 72(6), 835-846.

Montesano, R., Vassalli, J. D., Baird, A., Guillemin, R., \& Orci, L. (1986). Basic fibroblast growth factor induces angiogenesis in vitro. Proceedings of the National Academy of Sciences, 83(19), 7297-7301.

Nilsson, E., Parrott, J. A., \& Skinner, M. K. (2001). Basic fibroblast growth factor induces primordial follicle development and initiates folliculogenesis. Molecular and Cellular Endocrinology, 175(1), 123-130.

North, R. A., Williams, J. T., Surprenant, A., \& Christie, M. J. (1987). Mu and delta receptors belong to a family of receptors that are coupled to potassium channels. Proceedings of the National Academy of Sciences, 84(15), 5487-5491.

Nisolle, M., Casanas-Roux, F., Qu, J., Motta, P., \& Donnez, J. (2000). Histologic and ultrastructural evaluation of fresh and frozen-thawed human ovarian xenografts in nude mice. Fertility and Sterility, 74(1), 122-129.

Orlidge, A., \& D'Amore, P. A. (1987). Inhibition of capillary endothelial cell growth by pericytes and smooth muscle cells. The Journal of Cell Biology, 105(3), 14551462.

Padgett, D. A., Marucha, P. T., \& Sheridan, J. F. (1998). Restraint stress slows cutaneous wound healing in mice. Brain, Behavior, and Immunity, 12(1), 64-73. 
Papapetropoulos, A., Garcia-Carde, G., Dengler, T. J., Maisonpierre, P. C., Yancopoulos, G. D., \& Sessa, W. C. (1999). Direct actions of angiopoietin-1 on human endothelium: evidence for network stabilization, cell survival, and interaction with other angiogenic growth factors. Laboratory Investigation, 79(1), 213-224.

Pasi, A., Qu, B., Steiner, R., Senn, H. J., Bär, W., \& Messiha, F. S. (1991). Angiogenesis: modulation with opioids. General Pharmacology: The Vascular System, 22(6), 1077-1079.

Pearson, G., Robinson, F., Beers Gibson, T., Xu, B. E., Karandikar, M., Berman, K., \& Cobb, M. H. (2001). Mitogen-activated protein (MAP) kinase pathways: regulation and physiological functions 1. Endocrine Reviews, 22(2), 153-183.

Penning, T. D., Talley, J. J., Bertenshaw, S. R., Carter, J. S., Collins, P. W., Docter, S., ... $\&$ Isakson, P. C. (1997). Synthesis and biological evaluation of the 1, 5diarylpyrazole class of cyclooxygenase-2 inhibitors: identification of 4-[5-(4methylphenyl)-3-(trifluoromethyl)-1 H-pyrazol-1-yl] benzenesulfonamide (SC58635, celecoxib). Journal of Medicinal Chemistry, 40(9), 1347-1365.

Pepper, M. S., Mandriota, S. J., Jeltsch, M., Kumar, V., \& Alitalo, K. (1998). Vascular endothelial growth factor (VEGF)-C synergizes with basic fibroblast growth factor and VEGF in the induction of angiogenesis in vitro and alters endothelial cell extracellular proteolytic activity. Journal of Cellular Physiology, 177(3), 439452.

Peterson, C. M., Hales, H. A., Hatasaka, H. H., Mitchell, M. D., Rittenhouse, L., \& Jones, K. P. (1993). Interleukin-1 beta (IL-1 beta) modulates prostaglandin production and the natural IL-1 receptor antagonist inhibits ovulation in the optimally stimulated rat ovarian perfusion model. Endocrinology, 133(5), 2301-2306.

Poonawala, T., Levay-Young, B. K., Hebbel, R. P., \& Gupta, K. (2005). Opioids heal ischemic wounds in the rat. Wound Repair and Regeneration, 13(2), 165-174.

Puri, M. C., Rossant, J., Alitalo, K., Bernstein, A., \& Partanen, J. (1995). The receptor tyrosine kinase TIE is required for integrity and survival of vascular endothelial cells. The EMBO Journal, 14(23), 5884-5891.

Pusztaszeri, M. P., Seelentag, W., \& Bosman, F. T. (2006). Immunohistochemical expression of endothelial markers CD31, CD34, von Willebrand factor, and Fli-1 in normal human tissues. Journal of Histochemistry and Cytochemistry, 54(4), 385-395. 
Quintana, R., Kopcow, L., Marconi, G., Young, E., Yovanovich, C., \& Paz, D. A. (2008). Inhibition of cyclooxygenase-2 (COX-2) by meloxicam decreases the incidence of ovarian hyperstimulation syndrome in a rat model. Fertility and Sterility, 90(4), 1511-1516.

Renshaw, S. (Ed.). (2007). Immunohistochemistry. Oxfordshire, UK: Scion Publishing Ltd.

Risau, W., Sariola, H. A., Zerwes, H. G., Sasse, J., Ekblom, P., Kemler, R., \& Doetschman, T. (1988). Vasculogenesis and angiogenesis in embryonic-stem-cellderived embryoid bodies. Development, 102(3), 471-478.

Roberts, A. E., Arbogast, L. K., Friedman, C. I., Cohn, D. E., Kaumaya, P. T., \& Danforth, D. R. (2007). Neutralization of endogenous vascular endothelial growth factor depletes primordial follicles in the mouse ovary. Biology of Reproduction, 76(2), 218-223.

Roy, S., Balasubramanian, S., Wang, J., Chandrashekhar, Y., Charboneau, R., \& Barke, R. (2003). Morphine inhibits VEGF expression in myocardial ischemia. Surgery, 134(2), 336-344.

Saarialho-Kere, U., Mattila, M. J., Paloheimo, M., \& Seppälä, T. (1987). Psychomotor, respiratory and neuroendocrinological effects of buprenorphine and amitriptyline in healthy volunteers. European Journal of Clinical Pharmacology, 33(2), 139146.

Sadée, W., Rosenbaum, J. S., \& Herz, A. (1982). Buprenorphine: differential interaction with opiate receptor subtypes in vivo. Journal of Pharmacology and Experimental Therapeutics, 223(1), 157-162.

Sato, T. N., Tozawa, Y., Deutsch, U., Wolburg-Buchholz, K., Fujiwara, Y., GendronMaguire, M., ... \& Qin, Y. (1995). Distinct roles of the receptor tyrosine kinases Tie-1 and Tie-2 in blood vessel formation. Nature, 376(6535), 70-74.

Sauter, B., Foedinger, D., Sterniczky, B., Wolff, K., \& Rappersberger, K. (1998). Immunoelectron microscopic characterization of human dermal lymphatic microvascular endothelial cells: differential expression of CD31, CD34, and type IV collagen with lymphatic endothelial cells vs blood capillary endothelial cells in normal human skin, lymphangioma, and hemangioma in situ. Journal of Histochemistry and Cytochemistry, 46(2), 165-176. 
Saunders, W. B., Bohnsack, B. L., Faske, J. B., Anthis, N. J., Bayless, K. J., Hirschi, K. K., \& Davis, G. E. (2006). Coregulation of vascular tube stabilization by endothelial cell TIMP-2 and pericyte TIMP-3. The Journal of Cell Biology, 175(1), 179-191.

Sawamiphak, S., Seidel, S., Essmann, C. L., Wilkinson, G. A., Pitulescu, M. E., Acker, T., \& Acker-Palmer, A. (2010). Ephrin-B2 regulates VEGFR2 function in developmental and tumor angiogenesis. Nature, 465(7297), 487-491.

Schmassmann, A., Peskar, B. M., Stettler, C., Netzer, P., Stroff, T., Flogerzi, B., \& Halter, F. (1998). Effects of inhibition of prostaglandin endoperoxide synthase-2 in chronic gastrointestinal ulcer models in rats. British Journal of Pharmacology, 123(5), 795-804.

Schmid, J., Busch, U., Trummlitz, G., Prox, A., Kaschke, S., \& Wachsmuth, H. (1995a). Meloxicam: metabolic profile and biotransformation products in the rat. Xenobiotica, 25(11), 1219-1236.

Schmid, J., Busch, U., Heinzel, G., Bozler, G., Kaschke, S., \& Kummer, M. (1995b). Pharmacokinetics and metabolic pattern after intravenous infusion and oral administration to healthy subjects. Drug Metabolism and Disposition, 23(11), 1206-1213.

Schoefl, G. I. (1963). Studies on inflammation. Virchows Archiv für pathologische Anatomie und Physiologie und für klinische Medizin, 337(2), 97-141.

Schuch, G., Heymach, J. V., Nomi, M., Machluf, M., Force, J., Atala, A., ... \& Soker, S. (2003). Endostatin inhibits the vascular endothelial growth factor-induced mobilization of endothelial progenitor cells. Cancer Research, 63(23), 8345-8350.

Seaman, M. E., Peirce, S. M., \& Kelly, K. (2011). Rapid analysis of vessel elements (RAVE): a tool for studying physiologic, pathologic and tumor angiogenesis. PloS One, 6(6), e20807.

Senger, D. R., Galli, S. J., Dvorak, A. M., Perruzzi, C. A., Harvey, V. S., \& Dvorak, H. F. (1983). Tumor cells secrete a vascular permeability factor that promotes accumulation of ascites fluid. Science, 219(4587), 983-985.

Shalaby, F., Rossant, J., Yamaguchi, T. P., Gertsenstein, M., Wu, X. F., Breitman, M. L., \& Schuh, A. C. (1995). Failure of blood-island formation and vasculogenesis in Flk-1-deficient mice. Nature, 376(6535), 62-66. 
Shalaby, F., Ho, J., Stanford, W. L., Fischer, K. D., Schuh, A. C., Schwartz, L., ... \& Rossant, J. (1997). A requirement for Flk1 in primitive and definitive hematopoiesis and vasculogenesis. Cell, 89(6), 981-990.

Shweiki, D., Itin, A., Soffer, D., \& Keshet, E. (1992). Vascular endothelial growth factor induced by hypoxia may mediate hypoxia-initiated angiogenesis. Nature, 359(6398), 843-845.

Skjelbred, P., \& Løkken, P. (1982). Post-operative pain and inflammatory reaction reduced by injection of a corticosteroid. European Journal of Clinical Pharmacology, 21(5), 391-396.

Starzl, T. E., Kaupp Jr, H. A., Brock, D. R., Lazarus, R. E., \& Johnson, R. V. (1960). Reconstructive problems in canine liver homotransplantation with special reference to the postoperative role of hepatic venous flow. Surgery, Gynecology and Obstetrics, 111(1), 733-743.

Stavreus-Evers, A., Koraen, L., Scott, J. E., Zhang, P., \& Westlund, P. (2005). Distribution of cyclooxygenase-1, cyclooxygenase-2, and cytosolic phospholipase $\mathrm{A}_{2}$ in the luteal phase human endometrium and ovary. Fertility and Sterility, 83(1), 156-162.

Stefano, G. B., Hartman, A., Bilfinger, T. V., Magazine, H. I., Liu, Y., Casares, F., \& Goligorsky, M. S. (1995). Presence of the opiate receptor in endothelial cells coupling to nitric oxide production and vasodilation. Journal of Biological Chemistry, 270(51), 30290-30293.

Stone, J., Itin, A., Alon, T., Pe'Er, J., Gnessin, H., Chan-Ling, T., \& Keshet, E. (1995). Development of retinal vasculature is mediated by hypoxia-induced vascular endothelial growth factor (VEGF) expression by neuroglia. The Journal of Neuroscience, 15(7), 4738-4747.

Stratman, A. N., Malotte, K. M., Mahan, R. D., Davis, M. J., \& Davis, G. E. (2009). Pericyte recruitment during vasculogenic tube assembly stimulates endothelial basement membrane matrix formation. Blood, 114(24), 5091-5101.

Suri, C., Jones, P. F., Patan, S., Bartunkova, S., Maisonpierre, P. C., Davis, S., ... \& Yancopoulos, G. D. (1996). Requisite role of angiopoietin-1, a ligand for the TIE2 receptor, during embryonic angiogenesis. Cell, 87(7), 1171-1180.

Takehara, Y., Dharmarajan, A. M., Kaufman, G., \& Wallach, E. E. (1994). Effect of interleukin-1 beta on ovulation in the in vitro perfused rabbit ovary. Endocrinology, 134(4), 1788-1793. 
Takahashi, T., \& Shibuya, M. (1997). The $230 \mathrm{kDa}$ mature form of KDR/Flk-1 (VEGF receptor-2) activates the PLC- $\gamma$ pathway and partially induces mitotic signals in NIH3T3 fibroblasts. Oncogene, 14(17), 2079-2089.

Tam, P. P., \& Behringer, R. R. (1997). Mouse gastrulation: the formation of a mammalian body plan. Mechanisms of Development, 68(1), 3-25.

Teilmann, S. C., \& Christensen, S. T. (2005). Localization of the angiopoietin receptors Tie-1 and Tie-2 on the primary cilia in the female reproductive organs. Cell Biology International, 29(5), 340-346.

Thurston, G., Suri, C., Smith, K., McClain, J., Sato, T. N., Yancopoulos, G. D., \& McDonald, D. M. (1999). Leakage-resistant blood vessels in mice transgenically overexpressing angiopoietin-1. Science, 286(5449), 2511-2514.

Treuting, P., \& Dintzis, S. (Eds.). (2012). Comparative anatomy and histology: a mouse and human atlas. Oxford, UK: Academic Press.

Unemori, E. N., Ferrara, N., Bauer, E. A., \& Amento, E. P. (1992). Vascular endothelial growth factor induces interstitial collagenase expression in human endothelial cells. Journal of Cellular Physiology, 153(3), 557-562.

Van Eyck, A. S., Bouzin, C., Feron, O., Romeu, L., Van Langendonckt, A., Donnez, J., \& Dolmans, M. M. (2010). Both host and graft vessels contribute to revascularization of xenografted human ovarian tissue in a murine model. Fertility and Sterility, 93(5), 1676-1685.

Vandesande F. (1987). Double and multiple immunoenzymatic labeling of tissue sections for light microscopy. Acta Histochemica, 35(3), 107-115.

Vane, J. R. (1971). Inhibition of prostaglandin synthesis as a mechanism of action for aspirin-like drugs. Nature, 231(25), 232-235.

Vaughan, E. E., \& O'Brien, T. (2012). Isolation of circulating angiogenic cells. Methods in Molecular Biology, 9(16), 351-356.

Vaughan, C. W., Ingram, S. L., Connor, M. A., \& Christie, M. J. (1997). How opioids inhibit GABA-mediated neurotransmission. Nature, 390(6660), 611-614.

Vermeulen, P. B., Gasparini, G., Fox, S. B., Toi, M., Martin, L., McCulloch, P., ... \& Dirix, L. Y. (1996). Quantification of angiogenesis in solid human tumors: an international consensus on the methodology and criteria of evaluation. European Journal of Cancer, 32(14), 2474-2484. 
Vermeulen, P. B., Gasparini, G., Fox, S. B., Colpaert, C., Marson, L. P., Gion, M., ... \& Dirix, L. Y. (2002). Second international consensus on the methodology and criteria of evaluation of angiogenesis quantification in solid human tumors. European Journal of Cancer, 38(12), 1564-1579.

Vickerman, M. B., Keith, P. A., McKay, T. L., Gedeon, D. J., Watanabe, M., Montano, M., ... \& Parsons-Wingerter, P. (2009). VESGEN 2D: Automated, userinteractive software for quantification and mapping of angiogenic and lymphangiogenic trees and networks. The Anatomical Record, 292(3), 320-332.

von Frey, M. M., \& Gruber, M. (1885). Studies on metabolism of isolated organs: A respiration-apparatus for isolated organs. Archives of Physiology, 519-532.

Wang, D., Stockard, C. R., Harkins, L., Lott, P., Salih, C., Yuan, K., ... \& Siegal, G. P. (2008). Immunohistochemistry in the evaluation of neovascularization in tumor xenografts. Biotechnic and Histochemistry, 83(3), 179-189.

Whitten, W. K. (1956). Modification of the oestrous cycle of the mouse by external stimuli associated with the male. Journal of Endocrinology, 13(4), 399-404.

Wilt, F. H. (1965). Erythropoiesis in the chick embryo: the role of endoderm. Science, 147(3665), 1588-1590.

Witzenbichler, B., Maisonpierre, P. C., Jones, P., Yancopoulos, G. D., \& Isner, J. M. (1998). Chemotactic properties of angiopoietin-1 and-2, ligands for the endothelial-specific receptor tyrosine kinase Tie2. Journal of Biological Chemistry, 273(29), 18514-18521.

Xin, B., Yokoyama, Y., Shigeto, T., Futagami, M., \& Mizunuma, H. (2007). Inhibitory effects of meloxicam, a selective cyclooxygenase-2 inhibitor, and ciglitazone, a peroxisome proliferator-activated receptor gamma ligand, o the growth of human ovarian cancers. Cancer, 110(4), 791-800.

Yamagishi, S. I., Yonekura, H., Yamamoto, Y., Fujimori, H., Sakurai, S., Tanaka, N., \& Yamamoto, H. (1999). Vascular endothelial growth factor acts as a pericyte mitogen under hypoxic conditions. Laboratory Investigation, 79(4), 501-509.

Yamane, A., Seetharam, L., Yamaguchi, S., Gotoh, N., Takahashi, T., Neufeld, G., \& Shibuya, M. (1994). A new communication system between hepatocytes and sinusoidal endothelial cells in liver through vascular endothelial growth factor and Flt tyrosine kinase receptor family (Flt-1 and KDR/Flk-1). Oncogene, 9(9), 26832690 . 
Yassen, A., Kan, J., Olofsen, E., Suidgeest, E., Dahan, A., \& Danhof, M. (2007). Pharmacokinetic-pharmacodynamic modeling of the respiratory depressant effect of norbuprenorphine in rats. Journal of Pharmacology and Experimental Therapeutics, 321(2), 598-607.

Zagon, I. S., \& McLaughlin, P. J. (1981). Heroin prolongs survival time and retards tumor growth in mice with neuroblastoma. Brain Research Bulletin, 7(1), 25-32.

Zhang, J., Ferguson, S. S., Barak, L. S., Bodduluri, S. R., Laporte, S. A., Law, P. Y., \& Caron, M. G. (1998). Role for G protein-coupled receptor kinase in agonistspecific regulation of $\mu$-opioid receptor responsiveness. Proceedings of the National Academy of Sciences, 95(12), 7157-7162.

Zhang, W., Ramamoorthy, Y., Tyndale, R. F., \& Sellers, E. M. (2003). Interaction of buprenorphine and its metabolite norbuprenorphine with cytochromes p450 in vitro. Drug Metabolism and Disposition, 31(6), 768-772.

Zheng, J., Fricke, P. M., Reynolds, L. P., \& Redmer, D. A. (1994). Evaluation of growth, cell proliferation, and cell death in bovine corpora lutea throughout the estrous cycle. Biology of Reproduction, 51(4), 623-632.

Zocchi, M. R., Ferrero, E., Leone, B. E., Rovere, P., Bianchi, E., Toninelli, E., \& Pardi, R. (1996). CD31/PECAM-1-driven chemokine-independent transmigration of human T lymphocytes. European Journal of Immunology, 26(4), 759-767. 